UNIVERSIDADE DE SÃO PAULO

ESCOLA DE ENFERMAGEM

CAROLLINY ROSSI DE FARIA ICHIKAWA

\title{
ADAPTAÇÃO CULTURAL DO FAMILY MANAGEMENT MEASURE PARA FAMÍLIAS DE CRIANÇAS PORTADORAS DE DOENÇAS CRÔNICAS
}




\section{CAROLLINY ROSSI DE FARIA ICHIKAWA}

\section{ADAPTAÇÃO CULTURAL DO FAMILY MANAGEMENT MEASURE PARA FAMÍLIAS DE CRIANÇAS PORTADORAS DE DOENÇAS CRÔNICAS}

Dissertação apresentada ao Programa de Pós Graduação em Enfermagem da Escola de Enfermagem da Universidade de São Paulo, para obtenção do título de Mestre em Cuidado em Saúde.

Área de Concentração: Cuidado em Saúde

Orientadora: Profa. Dra. Regina Szylit Bousso 
Autorizo a reprodução e divulgação total ou parcial deste trabalho, por qualquer meio convencional ou eletrônico, para fins de estudo e pesquisa, desde que citada a fonte.

Assinatura:

Data:

Catalogação na Publicação (CIP)

Biblioteca "Wanda de Aguiar Horta"

Escola de Enfermagem da Universidade de São Paulo

Ichikawa, Carolliny Rossi de Faria

Adaptação cultural do Family Management Measure para famílias de crianças portadoras de doenças crônicas / Carolliny Rossi de Faria Ichikawa. -- São Paulo, 2011. 138 p.

Dissertação (Mestrado) - Escola de Enfermagem da Universidade de São Paulo.

Orientadora: Profa. Dra. Regina Szylit Bousso

1. Família 2. Pediatria 3. Doença crônica 4. FaMM I. Título. 
Nome: Ichikawa, Carolliny Rossi de Faria

Título: Adaptação cultural do Family Management Measure para famílias de crianças portadoras de doenças crônicas

Dissertação apresentada ao Programa de Pós Graduação em Enfermagem da Escola de Enfermagem da Universidade de São Paulo, para obtenção do título de Mestre em Cuidado em Saúde.

Aprovado em:

Banca Examinadora

Prof. Dr. Instituição:

Julgamento:

Assinatura:

Prof. Dr. Instituição:

Julgamento: Assinatura:

Prof. Dr. Instituição:

Julgamento: Assinatura: 
Dedico este estudo à minha família, Jorge e Marina. 


\section{AGRADECIMENTOS}

Agradeço primeiramente a Deus pelo dom da vida e me iluminar em minhas buscas.

Aos meus pais Ana Maria e Sebastião que apesar das dificuldades sempre me mostraram o valor do estudo.

Ao meu marido Jorge pelo amor, compreensão, dedicação e companheirismo durante todo este período.

Às minhas irmãs Célia e Magda que sempre permaneceram presentes em todas as horas.

À professora Doutora Regina Szylit Bousso pela valiosa orientação e pelos momentos agradáveis.

À professora Doutora Estela Bianchi pela grande colaboração desde o exame de qualificação até a conclusão deste trabalho.

Às professoras Lisabelle e Elaine pelo tempo de convívio e auxílio durante o curso.

Aos amigos Mário Augusto Vedove e Ana Márcia C. Mendes-Castillo pelo auxílio nas traduções.

À amiga Patrícia Fiori pelo seu acolhimento e companheirismo neste período em São Paulo.

À querida Maira Deguer Misko pelo incentivo e exemplo de dedicação e competência.

Às amigas Patrícia, Cláudia, Andréia e Cris Pauli pelos bons momentos que passamos na escola.

Às enfermeiras Adriana e Iria e demais funcionários do AHC de Londrina pela gentileza e colaboração na coleta de dados.

Às minhas colegas do Departamento de Enfermagem da UEL pelo apoio e compreensão na finalização deste estudo.

Às alunas Ligyana e Duanne pelo auxílio na coleta de dados e pelas muitas conversas sobre famílias e crianças.

À Nisléia por transmitir-nos sua experiência de mãe e cuidadora para colaborar e enriquecer esta pesquisa.

Aos funcionários da EEUSP pela colaboração, boa vontade e acolhimento.

Às famílias que participaram da pesquisa. 


\section{RESUMO}

Ichikawa CRF. Adaptação cultural do Family Management Measure para famílias de crianças portadoras de doenças crônicas [dissertação]. São Paulo: Universidade de São Paulo, Escola de Enfermagem, 2011. 138 f.

Este estudo teve como objetivos realizar a adaptação cultural do Family Management Measure (FaMM) para a língua portuguesa do Brasil; avaliar a confiabilidade da versão adaptada do Family Management Measure (FaMM) verificando a consistência interna de seus itens em amostra de família de crianças e adolescentes com doença crônica. Na realidade brasileira, não se localizou qualquer outro instrumento que tivesse objetivos iguais, nem semelhantes aos propostos pelo FaMM, além de haver uma lacuna no que diz respeito à maneira como a família maneja a situação de doença crônica da criança. Consiste de um estudo metodológico com abordagem quantitativa a fim de alcançar os objetivos propostos, seguindo as seguintes etapas: tradução, adaptação transcultural do Family Management Measure para o português e validação das propriedades de medida do instrumento adaptado. Para tanto, utilizou-se a metodologia proposta por Guillemin para tradução e adaptação transcultural de instrumentos (Guillemin 1993, 2002), composta pelo seguinte processo: permissão dos autores para a adaptação transcultural e validação do Family Management Measure (FaMM); tradução para língua portuguesa do Family Management Measure; obtenção do primeiro consenso das versões traduzidas; avaliação pelo Comitê de Especialistas; retrotradução (Back translation); pré-teste; tratamentos dos dados. A população da pesquisa foi composta por 72 famílias de crianças e adolescentes com doenças crônicas em atendimento em um ambulatório de especialidades de hospital-escola público no município de Londrina. A confiabilidade interna medida através do Alfa de Cronbach foi de 0,8660 para o instrumento todo e variou de 0,4430 a 0,7908 entre as dimensões do instrumento. Houve a eliminação do item 35 da dimensão "Esforço de manejo". Concluiu-se que o Family Management Measure (FaMM) apresenta-se adaptado para a língua portuguesa do Brasil e recomenda-se a realização de outros estudos junto a outros familiares de crianças.

Palavras-chave: Família. Pediatria. Doença crônica. FaMM. 


\begin{abstract}
Ichikawa CRF. Cultural Adaptation of Family Management Measure for families of children with chronic illness [dissertation]. São Paulo: Universidade de São Paulo, Escola de Enfermagem, 2011. $138 \mathrm{f}$.

This study aimed to realize the cultural adaptation of the Family Management Measure (FaMM) for the Portuguese language of Brazil, to evaluate the reliability of the adapted version of the Family Management Measure (FaMM) by verifying the internal consistency of the items from a family sample of children and adolescents with a chronic disease. In Brazil, no other instrument having the same goals was located, nor were any similar to those proposed by FaMM, moreover there is a gap regarding how the family handles the child's chronic illness. This was a methodological study with a quantitative approach attempting to achieve the proposed objectives, following these steps: translation and cultural adaptation of the Family Management Measure to Portuguese; validation of the measurement properties of the adapted instrument. For this purpose, the methodology proposed by Guillemin was used for the translation and the cultural adaptation of instruments (Guillemin 1993, 2002) consisting of the following process: Permission of the authors for the cultural adaptation and validation of the Family Management Measure (FaMM) Translation into Portuguese the Family Management Measure; Obtaining the consent of the first translated versions; Evaluation Committee of Experts; Retro-translation (Back translation); Pre-test; Treatment of the data. The study population consisted of 72 families with children and adolescents who have chronic diseases being attended in specialty outpatient clinic in a public teaching hospital in Londrina. The internal reliability measured with Cronbach's alpha was 0.8660 for the entire instrument and varied from 0.4430 to 0.7908 between the dimensions of the instrument. There was an elimination of item 35 in the dimension "Stress management". It can be concluded that the Family Management Measure (FaMM) appears to adapt well to the Portuguese language in Brazil and it is recommended that further studies be performed with other families with children.
\end{abstract}

Keywords: Family. Pediatrics. Chronic disease. FaMM. 


\section{LISTA DE DIAGRAMAS}

Diagrama 1 - Etapas do processo de adaptação cultural do FaMM. 


\section{LISTA DE QUADROS}

Quadro 1 - Concordância entre juízes, São Paulo - 2011 43

Quadro 2 - Comparação da versão original do FaMM com a Versão Português 1 e Versão Final do instrumento... 51

Quadro 3 - Comparação da versão original com as retrotraduções. 53 


\section{LISTA DE TABELAS}

Tabela 1 - Distribuição da caracterização demográfica da amostra 54

Tabela 2 - Coeficiente de correlação do item com o total, o valor alfa total dos 53 itens do FaMM - Londrina, 2011

Tabela 3 - Estatística descritiva dos escores totais por dimensões e da composição do FaMM, Londrina - 2011

Tabela 4 - Coeficiente de correlação do item com o total da dimensão Identidade da criança, valor alfa total da dimensão - Londrina, 2011 ......60

Tabela 5 - Coeficiente de correlação do item com o total da dimensão Habilidade de manejo, valor alfa total da dimensão - Londrina, 2011 ....60

Tabela 6 - Coeficiente de correlação do item com o total da dimensão Esforço de manejo, valor alfa total da dimensão - Londrina, 2011

Tabela 7 - Coeficiente de correlação do item com o total da dimensão Dificuldade da família, valor alfa total da dimensão - Londrina, 2011 ......62

Tabela 8 - Coeficiente de correlação do item com o total da dimensão Mutualidade dos pais, valor alfa total da dimensão - Londrina, 2011 ......63

Tabela 9 - Coeficiente de correlação do item com o total da dimensão Visão do impacto da doença, valor alfa total da dimensão - Londrina, 2011 .....63 


\section{SUMÁRIO}

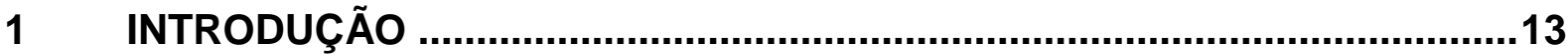

1.1 APRESENTAÇÃO E JUSTIFICATIVA DO ESTUDO ...............................13

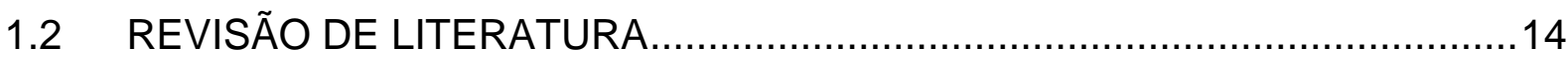

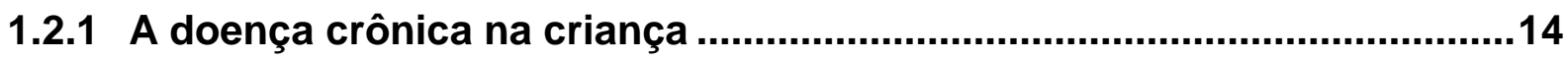

1.2.2 O impacto da doença crônica sobre a família ...........................................16

1.2.3 O Family Management Style Framework (FMSF) ….................................19

1.2.4 O Family Management Measure (FaMM) ................................................24

2 OBJETIVO

3 REFERENCIAL TEÓRICO-METODOLÓGICO ...........................................28

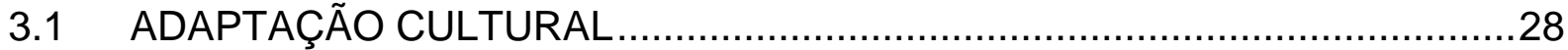

3.2 VALIDAÇÃO DAS PROPRIEDADES PSICOMÉTRICAS DO

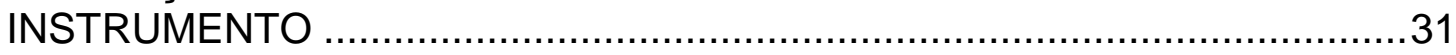

$4 \quad$ MÉTODO

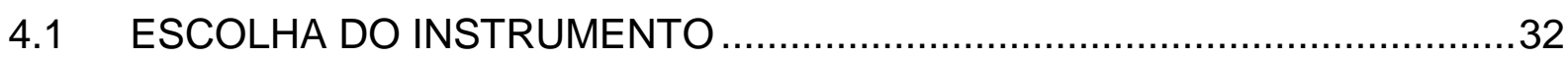

4.1.1 Permissão dos autores para a tradução, adaptação transcultural e validação do Family Management Measure (FaMM) ..................................32

4.2 PROCEDIMENTO METODOLÓGICO PARA A ADAPTAÇÃO CULTURAL DO FAMILY MANAGEMENT MEASURE ..................................................

4.2.1 Tradução para língua portuguesa do Family Management

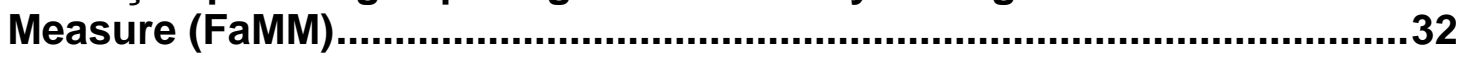

4.2.2 Obtenção do primeiro consenso das versões traduzidas ........................33

4.2.3 Avaliação pelo Comitê de Especialistas...................................................33

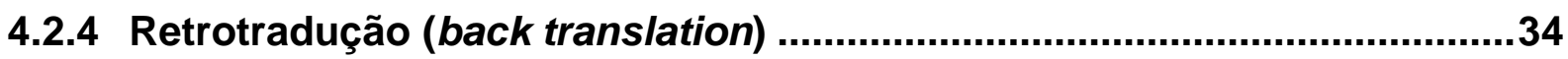

4.3 VALIDAÇÃO DAS PROPRIEDADES PSICOMÉTRICAS DO

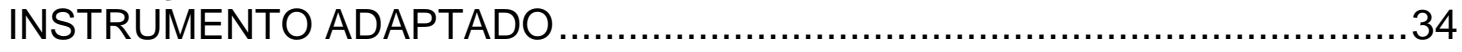

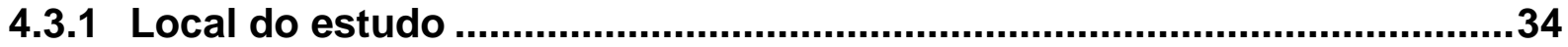

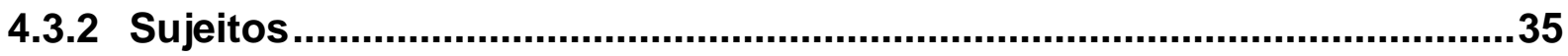

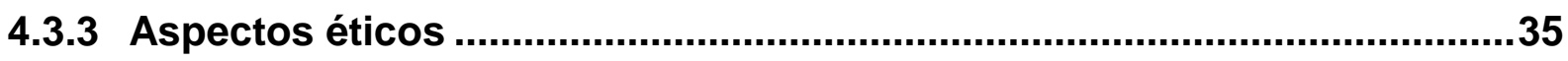

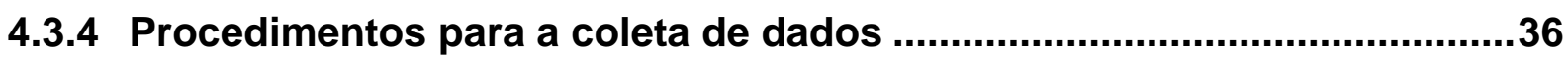

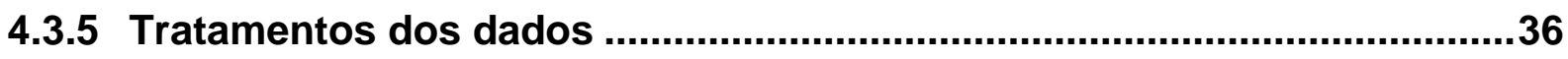




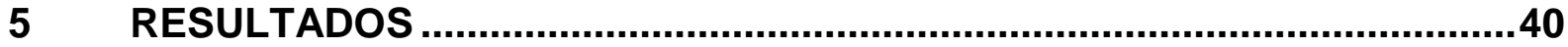

5.1 ADAPTAÇÃO DO FAMILY MANAGEMENT MEASURE (FaMM) .................40

5.1.1 Avaliação do Comitê de especialistas .....................................................40

5.2 ANÁLISE DAS PROPRIEDADES PSICOMÉTRICAS DO FaMM ...................54

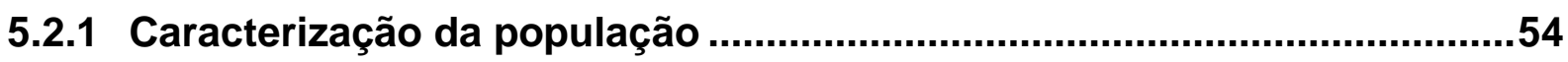

5.2.2 Estatística descritiva do FaMM adaptado.................................................56

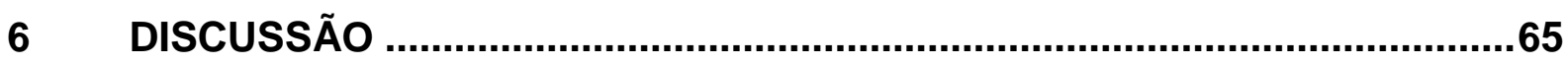

7 CONCLUSÃO

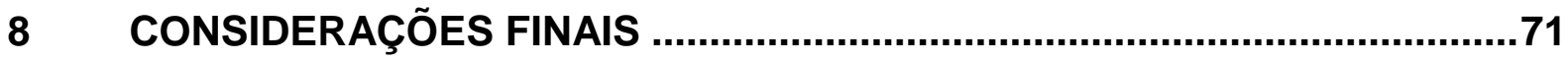

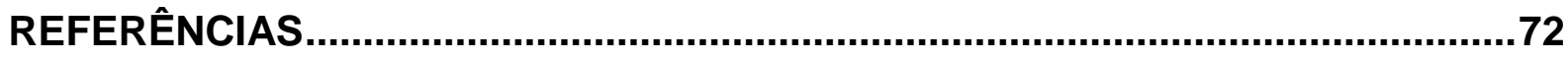

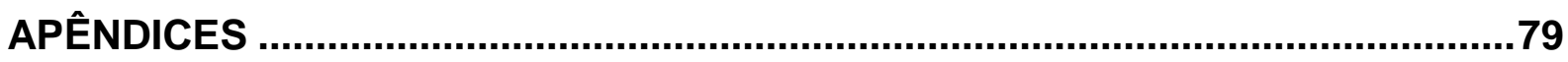

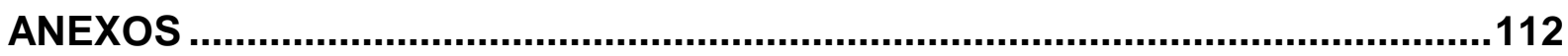




\section{INTRODUÇÃO}

\subsection{APRESENTAÇÃO E JUSTIFICATIVA DO ESTUDO}

Desde a época de graduanda do Curso de Enfermagem, a área de pediatria causava em mim certo fascínio, principalmente quando se tratava das relações familiares de crianças hospitalizadas.

Enquanto enfermeira assistencial, minha atuação no serviço de internação domiciliar me fez vivenciar as relações familiares de crianças tratadas no próprio domicílio. O que mais me intrigava era observar o modo como as famílias realizavam os cuidados com a criança em casa, desde os mais simples até os mais complexos, conforme o grau de dependência da criança.

Durante minha atuação como enfermeira foi muito significativo o meu envolvimento com as famílias, aumentando cada vez mais meu grau de preocupação com relação ao bem-estar da criança doente, e meu respeito pela dedicação e luta da família para salvar a saúde do filho enfermo. Desenvolvi, nesse tempo, laços de amizade, principalmente com as mães, que na maioria das vezes era quem acompanhava mais de perto e desenvolvia os cuidados com o filho doente.

Observei que, para muitas famílias, ter um filho doente causava considerável desequilíbrio no sistema familiar, advindo daí as dificuldades de relacionamento entre os pais, que até mesmo se afastavam do convívio social.

$\mathrm{Na}$ convivência com essas famílias, fui sentindo a necessidade de aprimorar o cuidado familiar, não de maneira empírica como até então eu fazia, mas de forma sistemática e fundamentada em estudos teóricos. Essa vontade de me capacitar para desenvolver um trabalho eficaz centrado na família me levou a buscar o curso de pós-graduação.

Ingressando no curso, pude ter contato com trabalhos desenvolvidos por autoras como Kathleen Knafl e Janet Deatrick, o que fez com que eu me interessasse não só em aprofundar o conhecimento das teorias dessas estudiosas, mas também que essa curiosidade me ensinasse a lidar cada vez melhor com essas famílias de crianças doentes. 
As autoras, após anos a fio estudando a família e o manejo da doença crônica da criança, criaram um instrumento para medir esse comportamento: o Family Management Measure.

A partir do conhecimento desse instrumento, verificamos que em nosso país, além do termo "manejo" ser pouco abordado e conhecido, não encontramos qualquer outro instrumento que tivesse objetivos iguais, nem semelhantes ao criado pelas autoras. Percebemos haver então uma lacuna no que diz respeito à maneira como a família maneja a situação de doença crônica da criança.

Acredito, pois, que a adaptação transcultural e a validação deste instrumento contribuirão significativamente para a melhoria da área da enfermagem pediátrica, podendo posteriormente ser adaptada também a outras áreas da enfermagem, possibilitando o desenvolvimento de estudos comparativos entre a realidade brasileira e os estudos internacionais.

\subsection{REVISÃO DE LITERATURA}

\subsubsection{A doença crônica na criança}

A doença crônica na criança vem sendo importante foco de estudo por pesquisadores nacionais e internacionais.

As doenças crônicas segundo a OMS (2009) são doenças de longa duração e de progressão geralmente lenta. As doenças crônicas, como as cardíacas, acidente vascular cerebral, câncer, doenças respiratórias crônicas e diabetes são, de longe, a principal causa de mortalidade no mundo, representando $60 \%$ de todas as mortes no ano de $2005 .^{1}$

Doenças crônicas ou condição crônica em crianças são definidas por Muscari (1998) como condições que afetam diariamente o funcionamento do organismo por mais de três meses por ano, causa de internação durante um mês por ano, ou que necessitam de dispositivos adaptativos. A autora cita que doenças como fibrose cística, asma, diabetes mellitus, defeitos do tubo neural, anemia falciforme,

\footnotetext{
${ }^{1}$ Ver: www.who.int/topics/chronic_diseases/en/
} 
HIV, artrite juvenil, defeitos cognitivos, paralisia cerebral, por exemplo, afetam mais de $10 \%$ de todas as crianças nos Estados Unidos.

Atualmente, estima-se que 20 a 30\% das crianças e adolescentes dos EUA sofram de alguma doença crônica ou de condição crônica de saúde. Essas condições podem afetar as crianças ao longo de suas vidas e também afetam a unidade familiar (Willians et al., 2003; Brown et al., 2008). O aumento dos cuidados necessários no dia a dia, as atividades complexas para o manejo da doença, o estilo de vida e a dinâmica familiar, individual ou coletiva, podem influenciar os resultados de saúde, a longo prazo (Brown et al., 2008). A maioria dessas crianças vivem em casa e isso causa um grande impacto sobre o sistema familiar, não obstante a necessidade do serviço de saúde (Balling, McCubbin, 2001; Williams et al., 2003).

A criança e o adolescente com doenças crônicas têm seu cotidiano modificado. Essas modificações estão muitas vezes relacionadas com as limitações, principalmente as de ordem física, devido a sinais e a sintomas da doença, o que pode submetê-los frequentemente a hospitalizações, à medida que a doença progride (Vieira, Lima, 2002).

Um estudo de revisão sobre o adolescente convivendo com a doença crônica revela que essa situação pode modificar e alterar seu desenvolvimento e retardar seu planejamento em relação ao futuro, o que pode ter entre outras causas, as frequentes internações hospitalares (Taylor et al., 2008).

Apesar dos avanços científicos e tecnológicos, algumas doenças, especialmente as crônicas, promovem ainda alterações orgânicas, emocionais e sociais, que exigem constantes cuidados e adaptação do enfermo à nova realidade (Vieira, Lima, 2002).

A doença crônica na infância afeta a dimensão existencial do doente, envolvendo várias facetas; ela pode afetar a participação social, a escolaridade, a prática esportiva, o lazer, o relacionamento com os membros da família, as relações grupais e interpessoais e também o status financeiro (Nascimento, 2003; Brown et al., 2008; Lopes, Stuhler, 2008).

Frente às situações que advêm da doença crônica, é fundamental uma abordagem multiprofissional, que envolva não só seus aspectos clínicos, mas também a repercussão psicológica e social, tanto para a criança como para a família. Reforça-se hoje com frequência a importância que os profissionais de saúde devem dar a esses dados, estando sempre atentos aos aspectos que transcendem o 
tratamento médico da doença da criança, pois sem a visão abrangente da evolução da enfermidade e sem conhecer e considerar as relações da criança com as figuras significativas que a cercam, o êxito do tratamento pode ficar comprometido (Castro, Piccininni, 2002).

As enfermeiras têm, nesse caso, papel fundamental na adaptação das famílias à doença, para auxiliá-las a encontrar a melhor forma de enfrentamento dessa difícil tarefa. Damião (2002) afirma que os profissionais de saúde devem conhecer bem as estratégias desenvolvidas pela família que convive com a doença crônica.

\subsubsection{O impacto da doença crônica sobre a família}

A família constitui parte importante do cuidado em saúde de crianças com doenças crônicas, sendo considerada membro da equipe, por ser a responsável pelo cuidado direto da criança/adolescente.

Rolland (2007) conceitua as grandes distinções do curso da vida com a doença crônica, descrevendo a importância de esclarecer o relacionamento entre a doença e o ciclo de vida familiar, considerando a interface da doença e sua relação com o indivíduo e a família. $O$ autor descreve que a doença exige mobilização da família, e com o aparecimento da doença, algumas famílias se mostram mais capacitadas a tolerar as mudanças, e com isso assumem funções, resolvem problemas eficazmente, e são capazes de utilizar recursos externos.

Como consequência da doença da criança, os familiares têm assumido os cuidados diários necessários à terapêutica dessa clientela em seus próprios domicílios, durante episódios de hospitalização e, ainda, quando necessário, participam do processo terapêutico (Misko, Bousso, 2007).

No Brasil, há vários estudos sobre a criança com doença crônica e sua família (Vieira, 2001; Damião, 1997, 2002; Castro, Piccinini, 2002; Furtado, Lima, 2003; Guimarães et al., 2009). Todos esses pesquisadores vêm demonstrando a importância de se estudar a família e suas estratégias de enfrentamento e de convívio com o filho doente. 
O impacto da doença crônica ocorre na família como um todo incluindo a criança. A doença produz na família impacto marcante, pois gera muitas incertezas, muitas angústias, devido às crises recorrentes e à sobrecarga física, emocional e financeira (Radovanovic et al., 2004). Também atinge as relações sociais, ocupacionais, escolares e profissionais e, pode ainda envolver perigo ou risco de vida a seus membros (Lopes, Stuhler, 2008).

Além das alterações naturais no ciclo de vida familiar, a família com criança portadora de doença crônica sofre alterações muito maiores, uma vez que a estrutura familiar é modificada como um todo, muitas adaptações devem ser feitas e os papéis, redefinidos.

A família da criança portadora de doença crônica terá que interagir com mudanças irreversíveis, as quais requerem administração contínua da situação vivenciada. Para isso, as famílias precisam buscar o significado apresentado pela doença em suas vidas, além de demarcar a percepção e os comportamentos relacionados à experiência, tendo como objetivo a manutenção da vida (Guimarães et al., 2009).

Tanto a família como a criança/adolescente doente passam por processos de adaptação, tendo de elaborar estratégias de enfrentamento para administrar e lidar com as mudanças ocorridas. Assim, cada um deles vivencia esse processo de forma diferente. Essas alterações acabam impondo mudanças na vida da família, propiciando readaptações e criação de estratégias para o enfrentamento da nova situação (Vieira, 2001).

Cuidar da criança com doença crônica é muito difícil, ainda mais quando a doença tem prognóstico fechado e com reduzida expectativa de vida (Damião, 1997).

A família e a criança enfrentam problemas como longos períodos de hospitalização, enfrentam reinternações frequentes, terapêutica agressiva, com sérios efeitos indesejáveis advindos do próprio tratamento, dificuldades pela separação dos membros da família durante as internações, interrupção das atividades diárias, limitações na compreensão do diagnóstico, desajuste financeiro, angústia, dor, sofrimento e o medo constante da possibilidade de morte (Nascimento et al., 2005).

Nessa fase, a família está buscando adaptar-se à nova realidade e reorganizar-se para enfrentar a experiência de viver e conviver com a doença 
crônica, por isso a necessidade de adaptações e redefinições de papéis, a fim de reconstruir a sua identidade como grupo familiar (Rolland, 2007). Ter um filho com doença crônica faz com que a família experiencie períodos de ansiedade, o que pode ser minimizado quando esta é preparada para realizar os cuidados com a criança (Furtado, Lima, 2003).

Por isso, a família deve ser auxiliada e estimulada a adquirir o controle da situação de doença da sua criança, por meio da busca de suas próprias demandas e desafios em cada etapa do processo. Assim, a família pode se tornar mais bem adaptada e competente para cuidar da criança e conseguir administrar a situação que todos vivenciam, com sofrimento menos intenso (Damião, Angelo, 2001).

A literatura tem delineado uma gama de fatores estressantes que os pais podem experimentar na situação da doença crônica da criança, incluindo estresse financeiro, tensões, separações, adaptação aos vários componentes do sistema médico, interrupções nas rotinas diárias e nos planos para o futuro, e incerteza geral no que diz respeito ao prognóstico da criança. Todas essas experiências podem levar direta ou indiretamente à ansiedade, à depressão, ao estresse, à desesperança e a sentimentos de perda de controle (Brown et al., 2008).

Sentimentos como medos, anseios, culpa, frustração, revolta são comuns entre os membros da família ao se tratar da doença da criança. Manifestações como essas afetam a habilidade da família em participar do tratamento e da tomada de decisões (Vieira, 2001).

Damião e Angelo (2001) revelam que o processo de adaptação das famílias não é estanque, pois que a família pode passar por períodos de controle da situação para outro de falta de controle e vice-versa. As autoras acreditam que o importante é que a família não permaneça estagnada no meio do processo, sem conseguir cuidar ou crescer.

O controle e o manejo da doença crônica estão relacionados ao preparo e à confiança que a família possui em relação à doença, porém, esse controle pode ser influenciado pelo estágio em que a doença se encontra (Rolland, 2007).

A doença faz parte do contexto familiar e, assim, modifica as relações de todos os seus membros (Furtado, Lima, 2003). Algumas famílias fortalecem suas relações com a doença da criança, tornando mais sólidas as relações entre os pais, entre os filhos e entre outros membros da família. Constroem-se relações de cumplicidade, de auxílio e de respeito como enfrentamento dos períodos de crise. 
A doença da criança, de outro modo, pode, então, propiciar aproximação, consolidação da relação do casal e maior contato com outros elementos da família. Porém, com seu aparecimento, o modo de ser da família também pode ser transformado. Além disso, as relações entre seus membros podem tornar-se difíceis em relação a seu manejo no dia a dia do cuidado do filho doente (Gallo, Knafl, 1998).

Deatrick et al. (2006), em seu estudo sobre a família de crianças com tumores cerebrais, revela que pouco se sabe sobre a forma como elas o manejam em seu dia a dia e como a equipe interdisciplinar pode proporcionar melhor apoio aos cuidados por ela realizados para otimizar o funcionamento dessa família.

Diante da doença crônica, a enfermagem deve buscar maior conhecimento da dinâmica da família afetada, a fim de encorajá-la neste enfrentamento e para minimizar entre seus membros a carga provocada pela doença. A capacitação dessas famílias deve ser realizada como intervenção de enfermagem (Wrigth, Leahey, 2009).

Knafl e Zoeller (2000) relatam que para a equipe de enfermagem dar suporte e promover a saúde da família, ela precisa conhecer a situação familiar: o que a doença da criança significa para a família, como esta lida com as situações estressantes que ocorrem e como enfrenta a carga extra causada pela doença e a que tipo de recursos essa família tem acesso.

Para o desenvolvimento dos cuidados voltados à família é necessário como ponto de partida, a avaliação de cada situação familiar (Hopia et al., 2004).

\subsubsection{O Family Management Style Framework (FMSF)}

O Family Management Style Framework (FMSF) foi desenvolvido por Kathleen Knafl e Janet Deatrick em 1990, como modelo inicial de estrutura para o entendimento de como a unidade familiar incorporava às demandas da doença da criança na vida familiar.

Baseado numa revisão de literatura, o modelo original do FMSF teve por objetivo identificar aspectos relevantes de como a unidade familiar respondia à doença da criança (Knafl, Deatrick, 1990). No entanto, as autoras afirmam que esse 
modelo era altamente abstrato em função da limitada literatura da época, tampouco permitia a elaboração do conteúdo das três principais dimensões: a definição da situação, manejo de comportamentos e contexto sociocultural, não identificando explicitamente o estilo do manejo utilizado pela família.

Inúmeras pesquisas foram realizadas desde a publicação da sua estrutura inicial, pesquisas estas que forneceram evidências da utilidade do FMSF na elaboração de modelos que apresentassem as respostas ou as reações da família à experiência de doença (Scharer, Dixon, 1989; Gallo, 1990; Mccarthy, Gallo, 1992; Clarke-Steffen, 1997).

Knafl e Deatrick (1990) realizaram uma análise de conceito, focalizando esse conceito mais amplamente, sempre à procura de melhor compreensão dos estilos de manejo da família. Posteriormente, buscando uma melhor elaboração das dimensões do modelo FMSF, as autoras realizaram um novo estudo de revisão da literatura, com o objetivo de conhecer os avanços das pesquisas sobre as respostas da família frente à doença crônica da criança. A revisão permitiu refinar a estrutura do FMSF e propor uma definição para o manejo da doença crônica infantil pela família (Knafl et al., 1996). Definiram então o manejo familiar como "o papel da família enquanto responde ativamente à doença e diferentes situações de cuidado à saúde".

Mendes-Castillo (2011) revela que a descrição inicial do FMSF enfatizava a interface entre as definições da situação feitas pelos membros da família e seus comportamentos de manejo, e precedeu a identificação de padrões mais específicos de resposta familiar diante da criança em situação de doença crônica. Sendo seus principais componentes do modelo: definição da situação, comportamentos de manejo e contexto sociocultural:

- Definição da situação: representa o sentido subjetivo que os membros da família atribuem a importantes elementos da sua situação.

- Comportamentos de manejo: representa os esforços direcionados ao cuidado com a doença e adaptação da vida familiar às demandas relacionadas à doença.

- Contexto sociocultural: representa os fatores que moldam a maneira pela qual a família define e maneja a situação. 
O modelo do FMSF serviu como referencial conceitual para estudo desenvolvido com 63 famílias de crianças com doença crônica, cujo objetivo era conhecer como elas definiam e manejavam a doença (Knafl et al., 1996). Neste estudo definiu-se cinco estilos distintos de manejo: próspero; em adaptação; tolerante; em conflito e caótico.

As mesmas autoras ampliaram o modelo, a fim de promover uma estrutura teórica, criando padrões de comportamento que possam ser avaliados com maior eficácia, gerando assim intervenções nos mais variados contextos que atendessem as demandas da família (Knafl, Deatrick, 2003).

Mendes-Castillo (2011) descreve que nesta reformulação foi incluindo o item consequências percebidas: como uma dimensão distinta no FMSF, definida como os resultados atuais ou esperados da família, da criança e da doença, que moldam os comportamentos de manejo e, consequentemente, afetam a definição da situação. A autora cita ainda, que o contexto sociocultural que anteriormente era considerado uma das dimensões do FMSF, foi descrito como uma das influências perceptíveis no manejo, ao invés de dimensão principal do estilo de manejo familiar.

A seguir apresentam-se os componentes conceituais do FMSF e seus temas conceituais (Knafl, Deatrick, 2003).

Definição da situação:

- Identidade da criança: visão dos pais sobre a criança e o quanto estas perspectivas focam a doença ou normalidade, habilidades ou vulnerabilidades.

- Visão da doença: crenças dos pais acerca da causa, gravidade, prognóstico e percurso da doença.

- Comportamento de manejo: visão dos pais acerca da facilidade ou dificuldade de obedecer ao regime de tratamento e suas habilidades de 0 manejarem com eficácia.

- Mutualidade entre os pais: crenças dos cuidadores a respeito do quanto eles têm de perspectivas compartilhadas ou divergentes acerca da criança, da doença, de suas filosofias sobre parentalidade, e suas abordagens no manejo da doença. 
Comportamentos de manejo:

- Filosofia sobre parentalidade: alvos, prioridades e valores dos pais que direcionam a abordagem e estratégias específicas para o manejo da doença.

- Abordagem de manejo: avaliação dos pais acerca do quanto eles têm desenvolvido uma rotina, estratégias relacionadas para o manejo da doença e incorporado tais estratégias ao cotidiano familiar.

Consequências percebidas:

- Foco familiar. avaliação dos pais a respeito do equilíbrio entre o manejo da doença e outros aspectos da vida familiar.

- Expectativas futuras: avaliação dos pais sobre as implicações da doença no futuro da criança e da família.

Por trazer a identificação do amplo espectro de estilos de manejo da família e especificar áreas únicas de forças e de dificuldades dela em manejar a doença crônica da criança, estes estudos foram importantes para reforçar a utilidade do uso do modelo FMSF como guia para expandir a compreensão dos fatores que contribuem para o funcionamento do indivíduo e da família no contexto da doença crônica (Knafl, Deatrick, 2002).

O modelo FMSF identifica aspectos cognitivos e de comportamento da experiência da família de crianças com doença crônica e serve para salientar suas áreas de forças e suas dificuldades. Além disso, permite conceituar seu estilo de manejo como configuração formada através das percepções e dos comportamentos individuais dos membros familiares. Investigações utilizando esse modelo são indicadas para maior expansão do conhecimento na área (Knafl, Deatrick, 2003).

$O$ interesse por conhecer os diferentes estilos de manejo familiar nas mais variadas situações de doença e com abordagens diferenciadas, tem crescido nos últimos anos. A expressão "estilo de manejo familiar", apesar de pouco conhecida em nossa realidade, vem sendo muito utilizada na literatura internacional para referir-se a um padrão relativamente consistente de resposta da unidade familiar a alguma condição de doença, e o termo "manejo" reforça o foco no ingrediente comportamental ativo da resposta familiar, diferenciando-a de outros componentes 
da dinâmica familiar, como comunicação e tomada de decisão (Knafl, Deatrick, 2006).

A importância de estabelecer padrões e perfis de manejo familiar, tem levado os pesquisadores a investirem em estudos tipológicos, como Fisher et al., (2000), para que o profissional de saúde possa aplicar intervenções personalizadas à estas famílias.

Kendall e Sheldon (2003) também reforçam que por meio da análise das tipologias é possível identificar as características comuns entre as famílias de uma determinada população. Segundo as autoras, o uso de tipologias permite que um sistema complexo e dinâmico, como a família, seja descrito com tal eficácia que permite a elaboração de perfis de acordo com cada tipo de família.

O uso de tipologia tem 0 intuito apenas de gerar classificações generalizadas para direcionar a avaliação e intervenção de Enfermagem, sem descartar o fato de que modificações e adaptações são necessárias para atender demandas específicas da família em situações especiais (Kendall, Sheldon, 2003).

Knafl e Deatrick (2003) descrevem a importância do estudo tipológico para se identificar padrões e perfis de manejo, para que assim o profissional possa realizar uma intervenção personalizada. Estudos como os de Sullivan-Bolyai et al, (2003), Deatrick et al., (2006), Nelson et al., (2006) e Ogle, (2006) reforçam esta importância do FMSF quando aplicado à diferentes contextos da doença crônica.

Wiegand et al. (2008) realizaram estudo qualitativo com o objetivo de definir os estilos de manejo familiar na população adulta e as características de cada estilo utilizado por famílias participantes do processo de tomada de decisão, quanto à retirada de suporte de vida a um membro da família que tenha sido acometido por condição grave e terminal. Os dados agrupados segundo as dimensões do FMSF, validaram os cinco estilos de manejo familiar propostos por Knafl et al. (1996), indicando que o Modelo também é aplicável a adultos.

Os avanços decorrentes do desenvolvimento do Modelo, bem como de estudos a ele relacionados, levantaram nova demanda: a instrumentalização, tanto dos pesquisadores, como dos profissionais assistenciais. Apesar da existência de grande número de instrumentos já consagrados para mensurar processos familiares em geral (comunicação, tomada de decisão, coping, resiliência), não existem instrumentos direcionados a acessar o manejo familiar na situação de doença, e a incorporação da doença e do regime de tratamento na vida familiar. 
Diante disso, a partir do modelo apresentado acima, foi desenvolvido recentemente um instrumento de medida de manejo familiar, o Family Management Measure (FaMM). Este instrumento mostrou-se confiável e aplicável no contexto da cultura norte-americana, e passa por fase de aplicação em diferentes contextos de doença (Knafl et al., 2008).

\subsubsection{O Family Management Measure (FaMM)}

Diante desse cenário, em que vemos crescer internacionalmente a importância da identificação de estilos de manejo familiar dentro de variados contextos de doença, as oito dimensões conceituais do FMSF foram usadas para gerar um conjunto inicial de itens para o instrumento. Reconhecendo esses distintos estilos de manejo de família e como tal instrumento contribuiria à avaliação clínica mais eficiente do manejo da família e a uma pesquisa que testa o relacionamento entre 0 FMS e as várias respostas da criança e da família, as autoras desenvolveram o Family Management Measure (FaMM) (Anexo A).

O FaMM foi desenvolvido pela equipe: Kathleen Knafl, Janet Deatrick, Agatha Gallo, Margaret Grey e Jane Dixon, pesquisadoras com experiência em pesquisa de família com doença crônica na infância, prática avançada de enfermagem, estatística e elaboração de instrumentos de pesquisa (Knafl, Deatrick, 2006).

O objetivo é o de compreender como as famílias manejam a doença crônica da criança e como eles incorporam essa condição na vida cotidiana da família . As autoras acreditam que os dados do FaMM contribuirão para os pesquisadores mais bem entenderem o funcionamento da família no contexto de condições crônicas na infância, e que levarão a uma compreensão mais precisa dos fatores que apoiam ou impedem o funcionamento ideal familiar para a criança.

O teste das propriedades psicométricas do FaMM foi baseado em dados de 579 pais de crianças com condição crônica, e havia forte apoio para a confiabilidade e a validade de todas as seis dimensões do FaMM (Knafl et al., 2008).

O FaMM é composto de 53 itens e dividido em 6 dimensões, 5 para serem respondidas pelo pai ou pela mãe da criança, medindo as dimensões: Identidade da 
Criança, Habilidade de Manejo, Esforço de Manejo, Dificuldade Familiar, e Visão do impacto da condição da criança, e ainda uma sexta escala que deve ser aplicada apenas quando ambos os pais participarem da entrevista, medindo a dimensão de Mutualidade entre os pais. Os itens são pontuados de 1 a 5 , significando desde 0 discordo totalmente até concordo muito (Anexo A).

A parte que aborda a Identidade da criança possui 5 itens sobre a percepção dos pais acerca de seus filhos e de sua vida cotidiana. Valores mais altos revelam vida mais normal para a criança, apesar da condição de enferma.

$\mathrm{Na}$ dimensão da Habilidade de manejo, a escala aborda 12 itens sobre a percepção dos pais acerca do manejo global do estado da criança, incluindo o saber a respeito do que precisa ser feito para cuidar da doença e de sua habilidade e competência para proceder ao manejo da condição de seus filhos. Os valores mais altos significam que o estado é visto como mais facilmente manejado.

O Esforço de manejo é avaliado por 4 itens que enfatizam o tempo e o trabalho necessários para manejar a situação. Os valores mais altos significam maior esforço para manejar a doença.

Na dimensão da Dificuldade da família são 14 itens que tratam da percepção dos pais sobre em que medida ter uma criança com doença crônica torna a vida familiar mais difícil. Os itens dessa escala vêm principalmente do foco da família e da gestão do manejo. Os valores mais elevados indicam maior dificuldade em manejar a situação.

Para medir a dimensão da Visão do impacto da doença, a escala possui 10 itens que abordam a percepção dos pais sobre a gravidade da doença e suas implicações para seus filhos e para o futuro da família. Valores mais altos demonstram maior preocupação em manejar a condição.

A dimensão de Mutualidade dos pais é composta por 8 itens e utilizado somente para pais que moram juntos para abordar as percepções de apoio, partilha de opinião e satisfação com a forma como os parceiros trabalham juntos para manejar a condição da criança. Valores mais altos indicam resposta mais comum e maior satisfação com a forma como o casal trabalha em conjunto para manejar essa condição.

Tal instrumento mostrou-se confiável e aplicável no contexto da cultura norte-americana, e passa por fase de aplicação em diferentes contextos de doença (Knafl et al., 2008). 
Em nossa cultura, no entanto, existe uma lacuna no que diz respeito a instrumentos de medida de manejo familiar no contexto da doença crônica da criança. Acredita-se que o FaMM pode ser útil na realidade brasileira, por gerar informações precisas acerca da maneira com que a família tem conseguido manejar o tratamento e a experiência de crianças com doenças crônicas, justificando o presente estudo. 


\section{OBJETIVO}

Este estudo teve por objetivos:

1. Realizar a adaptação cultural do Family Management Measure (FaMM) para a língua portuguesa do Brasil.

2. Avaliar a confiabilidade da versão adaptada do Family Management Measure (FaMM) verificando a consistência interna de seus itens em amostra de família de crianças/adolescentes com doença crônica. 


\section{REFERENCIAL TEÓRICO-METODOLÓGICO}

\subsection{ADAPTAÇÃO CULTURAL}

A prática da construção de instrumentos não é recomendada quando já existam instrumentos em outra cultura ou língua já validadas. Nesse caso é aconselhável a adaptação do instrumento para a cultura e a língua em que se deseja estudar o fenômeno (Beaton et al., 2000; Sperber, 2004; Ferreira, 2006).

Ao se tratar de um instrumento desenvolvido em outra língua, em outra cultura ou outro país, faz-se necessária suas tradução e adaptação para o novo idioma e a nova realidade cultural. Esse processo garante que fenômenos similares possam ser avaliados em diferentes culturas (Guillemin et al., 1993; Gallagher et al., 1995).

A adaptação transcultural de instrumento ou escala, para ser utilizado em nova cultura, país ou idioma, requer metodologia única a fim de obter equivalência entre o instrumento original e o que se destina (Gallagher et al., 1995).

Mesmo sendo processo de menor custo, a adaptação cultural deve seguir rigoroso percurso metodológico, cujo objetivo é manter o significado e a intenção do instrumento original, sendo compreensível e culturalmente relevante (Chwalow, 1995; Beaton et al., 2000; Sperber, 2004; Ferreira, 2006).

Esse rigoroso processo se faz necessário, visto que somente a adaptação semântica não cobre as diferenças culturais entre os dois universos explorados, além de prejudicar a análise dos resultados de validade e confiabilidade dos instrumentos (Pesce et al, 2005).

A adaptação cultural pressupõe a combinação de duas etapas associadas à tradução do instrumento e sua adaptação propriamente dita. É feita a tradução literal de palavras e de sentenças de um idioma para outro. Após essa etapa ocorre uma avaliação da qualidade da medida adaptada em relação à sua compreensibilidade, à validade aparente e de conteúdo, bem como a replicabilidade e à adequação da nova versão do instrumento (Guillemin et al., 1993). 
Nesse estudo a opção foi por seguir a metodologia proposta por Guillemin para tradução e adaptação transcultural de instrumentos (Guillemin et al., 1993, 2002) composta pelo processo descrito abaixo:

\section{Tradução}

Aconselha-se duas traduções independentes, com o objetivo de permitir a detecção de erros e interpretações divergentes.

\section{Comitê de especialistas}

O instrumento traduzido deve ser avaliado por um comitê de especialistas. Este comitê irá avaliar a equivalência do instrumento traduzido em comparação ao instrumento original. O comitê deverá ser composto por indivíduos que tenham conhecimento da metodologia do estudo ou que tenham experiência na área de interesse do estudo, ou ambos.

\section{Retrotradução}

É a tradução de volta ao idioma de origem, com o intuito de aumentar a qualidade da versão final, pois permite avaliar possíveis distorções na tradução e adaptação ao contexto da cultura alvo. As retrotraduções devem ser feitas por tradutores que tenham a língua original do instrumento como língua-mãe. Os tradutores não devem ter o conhecimento prévio dos objetivos do trabalho. A partir das retrotraduções chega-se a uma versão a ser comparada com a versão original.

\section{Pré-teste}

É a primeira aplicação do instrumento e a última etapa do processo de adaptação. Tem como objetivo verificar erros e desvios na tradução, avaliando as respostas obtidas e explorando os significados dos itens.

\section{Ponderação dos escores}

A ponderação dos escores no contexto cultural deve ser considerada, esta consideração é realizada por qualquer juiz (membro do comitê de especialista) ou usando uma abordagem estatística, através dos dados obtidos a partir da população alvo. 
Com o objetivo de proporcionar a equivalência entre o instrumento original e o instrumento traduzido dentro da cultura alvo, as seguintes equivalências foram analisadas, segundo as literaturas consultadas neste estudo:

\section{Equivalência conceitual:}

Verifica a equivalência de conceito explorado na cultura original em comparação com a cultura alvo, ou seja, se o conceito é relevante para ambas as culturas (Guillemin et al., 1993; Herdman et al.,1998; Beaton et al., 2000; Pesce et al., 2005).

\section{Equivalência de itens:}

Refere-se à equivalência dos itens que compõem o instrumento, se estimam os mesmos domínios e têm a mesma relevância nas duas culturas. Isto pode resultar na modificação de um item ou em seu descarte, caso não se encontre experiências, atividades ou sentimentos equivalentes na cultura alvo (Guillemin et al., 1993; Pesce et al., 2005). A análise crítica dos itens que compõem o instrumento verifica sua relevância dentro dos domínios e/ou conceito, pois, podem variar de acordo com cultura estudada (Herdman et al.,1998).

\section{Equivalência semântica:}

Consiste na tradução do instrumento original não só conservando o significado das palavras entre os dois idiomas diferentes, como também buscando atingir o mesmo efeito em culturas distintas (Herdman et al.,1998; Beaton et al., 2000).

Há duas categorias de equivalência semântica: significado referencial que corresponde à concordância em termos de tradução literal entre um item original e o mesmo traduzido, e o significado geral, que corresponde à concordância mais ampla, em termos de articulação de idéias e impacto entre um item original e sua tradução (Guillemin et al., 1993).

\section{Equivalência operacional:}

O objetivo é manter as características do instrumento original, propiciando maior confiabilidade e validade do instrumento. Assegurar que os métodos de administração são apropriados na cultura alvo, podendo ser utilizado um formato 
similar do instrumento original, com as mesmas instruções, formas de administração e métodos de avaliação, um vez que esses aspectos não alterem os resultados do instrumento (Herdman et al.,1998; Pesce et al., 2005).

\section{Equivalência de medida:}

Verifica o comportamento do instrumento ao apresentar níveis aceitáveis das suas propriedades psicométricas, em termos de validade e confiabilidade (Herdman et al.,1998).

\section{Equivalência funcional:}

É entendido como auge da adaptação, pois verifica se todos os tipos de equivalência foram alcançados, o instrumento medirá igualmente o conceito nas duas culturas, proporcionando resultados comparáveis e estabelecendo que a nova versão esteja adaptada (Herdman et al.,1998).

\subsection{VALIDAÇÃO DAS PROPRIEDADES PSICOMÉTRICAS DO INSTRUMENTO}

Apenas a adaptação cultural não é suficiente para a validação das propriedades psicométricas do instrumento. A validação do instrumento se faz por completo após a análise dos dados coletados, para se certificar da validação e confiabilidade do instrumento.

A aplicação do teste na população alvo é o primeiro passo para a validação do instrumento adaptado. A determinação da amostra pode ser realizada através do método estatístico que se baseia nos valores apresentados pelo instrumento original. 


\section{MÉTODO}

\subsection{ESCOLHA DO INSTRUMENTO}

O Family Management Measure foi escolhido por se tratar de um instrumento de medida de manejo familiar, por ser uma escala que avalia como a família lida com sua criança doente, servindo como principal motivação para essa escolha o fato de não haver no Brasil nenhum outro instrumento parecido. Em sua versão original é aplicada a famílias de crianças com doenças crônicas, mas futuramente poderá ser adaptada e utilizada em diversos tipos de doenças.

\subsubsection{Permissão dos autores para a tradução, adaptação transcultural e validação do Family Management Measure (FaMM)}

A autorização para validação do instrumento - Family Management Measure está disponível no site http://nursing.unc.edu/research/famm/ (Anexo B). Vale ressaltar que a autora principal, Dra Kathleen Knafl, foi contatada e auxiliou na compreensão da escala, bem como na análise estatística para sua validação.

\subsection{PROCEDIMENTO METODOLÓGICO PARA A ADAPTAÇÃO CULTURAL DO FAMILY MANAGEMENT MEASURE}

\subsubsection{Tradução para língua portuguesa do Family Management Measure (FaMM)}

Foram realizadas duas traduções por tradutores fluentes no idioma inglês, idioma da versão original. Uma tradução foi feita por um profissional da área de saúde que conhecia os objetivos do estudo (Anexo C) e outra, por professor de inglês que não tinha conhecimento dos objetivos do estudo (tradução cega) (Anexo D), gerando assim duas versões. 


\subsubsection{Obtenção do primeiro consenso das versões traduzidas}

A partir das duas traduções feitas anteriormente, foi realizado pela pesquisadora e pela orientadora o consenso da tradução na língua portuguesa, consenso este apresentado como Versão Português 1 (Apêndice A) que foi enviada ao comitê de especialistas.

\subsubsection{Avaliação pelo Comitê de Especialistas}

Os componentes do Comitê de Especialistas foram eleitos e convidados pela pesquisadora e pela orientadora. Composto por: 3 (três) especialistas no construto da doença crônica da criança; 3 (três) especialistas em adaptação cultural de instrumentos; 3 (três) familiares de crianças com doenças crônicas.

Todos os componentes apresentaram proficiência em língua inglesa, exceto os participantes familiares.

A função do comitê de especialistas foi o de avaliar o instrumento traduzido, quanto às equivalências: conceitual, de itens, semântica/idiomática e operacional, bem como sua validade de conteúdo. Foram fornecidos aos membros do comitê de especialistas, os instrumentos, na forma original e traduzida: um instrumento de avaliação e um roteiro de orientações (Apêndices B). O envio e devoluções dos documentos foram realizados através de correio eletrônico.

Os especialistas avaliaram todos os itens do instrumento separadamente, de acordo com as cinco propriedades citadas anteriormente. Socilitou-se que cada item fosse avaliado segundo os critérios:

$$
\begin{aligned}
& -1=\text { não equivalente } \\
& 0=\text { indeciso } \\
& +1=\text { equivalente }
\end{aligned}
$$

Nos casos que foram atribuídos os conceitos $\underline{-1}$ ou $\underline{0}$, solicitou-se ao especialista que fizesse seu comentário e suas sugestões para a melhor forma de tradução. 
Após a entrega de todas as avaliações dos especialistas, foi feita uma análise de respostas tendo um nível de concordância menor que $80 \%$ entre os especialistas, o que não foi aceitável para a validação do instrumento.

Sendo assim, optou-se por realizar uma reunião com o comitê de especialistas, exceto os componentes familiares, para se chegar num consenso sobre o instrumento. Esta reunião foi realizada na EEUSP e teve $100 \%$ de participação dos especialistas, que após revisarem todas os itens do instrumento chegaram a uma concordância de 100\%.

Após a avaliação do comitê de especialistas foi construída a versão Português 2.

\subsubsection{Retrotradução (back translation)}

A versão Português 2 foi enviada para dois tradutores para a realização da tradução para o idioma de origem (Anexos E e F). Os tradutores eram de mesma origem do país onde o instrumento foi criado (EUA) e não tinham o conhecimento prévio da temática em estudo. Cada tradutor fez uma versão e as mesmas foram comparadas com a versão original do instrumento.

\subsection{VALIDAÇÃO DAS PROPRIEDADES PSICOMÉTRICAS DO INSTRUMENTO ADAPTADO}

\subsubsection{Local do estudo}

O estudo foi realizado em ambulatório de especialidades de um hospitalescola público do município de Londrina, com famílias de crianças e adolescentes portadores de doença crônica. 


\subsubsection{Sujeitos}

A população estudada foi 72 famílias de crianças e adolescentes portadores de doença crônica, atendidas em ambulatório de especialidades de um hospitalescola público do município de Londrina. As consultas são realizadas conforme a necessidade da criança e da família.

Critério de inclusão:

- Famílias de crianças e adolescentes com até 18 anos, portadores de doenças crônicas que concordem em participar da pesquisa mediante assinatura do consentimento livre e esclarecido.

- O respondente deveria ser um familiar, morar na mesma residência da criança e participar dos cuidados com a doença da criança.

A amostra foi determinada por conveniência.

\subsubsection{Aspectos éticos}

O projeto foi submetido e aprovado pelo Comitê de Ética em Pesquisa da Escola de Enfermagem da Universidade de São Paulo sob a aprovação n. 887/2010 (Anexo G), e a aprovação do Comitê de Ética em Pesquisa da Universidade Estadual de Londrina aprovação n. 031/2011(Anexo H), conforme Resolução 196/96 do Conselho Nacional de Saúde.

O contato com o serviço de saúde, onde se realizou o estudo, foi feito pelo pesquisador através de solicitação por escrito para autorização do estudo e também pela submissão do projeto ao Comitê de Ética e Pesquisa da instituição em questão.

Os participantes foram convidados a participar do estudo, sendo assegurados a eles direito de privacidade e não identificação dos sujeitos. Os objetivos do estudo foram esclarecidos aos participantes através do termo de consentimento livre e esclarecido (Apêndice $\mathrm{C}$ ). Esse termo foi assinado pelo participante e pelo pesquisador, em duas cópias, contendo nome e telefone do 
pesquisador. Uma das cópias deveria permanecer com o participante, conforme Resolução 196/96 do Conselho Nacional de Saúde (CNS, 1996).

\subsubsection{Procedimentos para a coleta de dados}

As entrevistas foram realizadas durante os meses de junho a agosto de 2011, no ambulatório em questão. A pesquisadora e duas alunas do terceiro ano de Enfermagem da Universidade Estadual de Londrina foram responsáveis pela realização das entrevistas. As alunas foram treinadas anteriormente pela pesquisadora, foram orientadas quanto aos objetivos do estudo e o instrumento foi apresentado detalhadamente. A seguir as alunas acompanharam a pesquisadora até o local da pesquisa e observaram as primeiras entrevistas, a fim de se familiarizarem com o instrumento e com a forma da coleta dos dados. Após, a pesquisadora observou as primeiras entrevistas das alunas para realizar possíveis correções.

A coleta de dados foi realizada de forma aleatória, sendo selecionadas as crianças/adolescentes através da agenda médica do dia. Os familiares foram abordados e esclarecidos quanto aos objetivos do estudo e as entrevistas realizadas nas salas de espera do ambulatório em questão mediante aceitação e assinatura do termo de consentimento. As entrevistas eram realizadas em uma média de 20 minutos para cada respondente, primeiramente aplicavam-se o questionário sóciodemográfico (Apêndice D) e após a versão adaptada do FaMM (Apêndice E).

\subsubsection{Tratamentos dos dados}

Os dados foram digitados e processados eletronicamente. O nível de significância adotada nos testes foi de $5 \%$. As análises foram realizadas com o pacote estatístico Stata 10.0. Utilizou-se a estatística descritiva tanto para caracterização da amostra quanto para o cálculo dos valores frequência, proporções, médias, desvio-padrão e valores mínimos e máximos. Na comparação dos escores 
médios da escala foi utilizado o teste Kruskal Wallis para mais de duas categorias e Mann Whitney até duas categorias. O teste de distribuição das variáveis contínuas foi Shapiro Wilk e o nível de significância adotado foi de 5\%.

Analisou-se a confiabilidade da versão adaptada do instrumento através do Alfa de Cronbach, um coeficiente utilizado para avaliar a consistência interna dos itens. Ele avalia até que ponto todas as subpartes do instrumento medem a mesma característica, se seus índices variam de 0,00 a 1,00 e quanto mais alto o coeficiente de confiabilidade, mais exata (internamente consistente) é a medida (Polit, Beck, Hungler, 2004). Para esse estudo foi calculado o Alpha de Cronbach do instrumento total adota-se um coeficiente de 0,7 como satisfatório e por dimensões do instrumento utilizando o coeficiente mínimo de 0,4, conforme referencial de Nunnaly, (1978). Descreveu-se também todos os alfas das dimensões quando excluídos os itens.

O tratamento dos dados foi realizado de forma semelhante à que as autoras do instrumento original realizaram como os dados coletados em sua validação, obtidos através do site da Universidade da Carolina do Norte (http://nursing.unc.edu/research/rsc/resources/famm/index.htm). Foram calculadas as frequências das respostas dos itens da escala, organizado por dimensões.

A seguir apresenta-se as dimensões do FaMM, os itens que compõem cada dimensão e a interpretação do instrumento:

\section{Identidade da criança}

Exemplo: itens 1, 5, 10, 16, 20.

O maior escore demonstra melhor uma vida mais normal para a criança.

\section{Habilidade de manejo}

Exemplo: itens 4, 13, 14, 15, 17, 18, 19, 25, 27, 28, 34, 41.

O escore mais alto determina que o estado da criança é mais facilmente manejável. Os itens 17, 27, 28 e 34 são itens reversos.

\section{Esforço de manejo}

Exemplo: itens 3, 7, 12, 35.

O maior escore identifica um maior esforço no manejo da doença. O item 12 é o único item reverso desta dimensão. 


\section{Dificuldade da família}

Exemplo: itens 2, 6, 9, 22, 31, 33, 36, 39, 42, 43, 45, 23, 38, 44.

O maior valor do escore identifica maior dificuldade em manejar a doença da criança. Os itens 23, 38 e 44 são os itens considerados negativos.

\section{Mutualidade dos pais}

Exemplo: itens: 46, 47, 48, 49, 50, 51, 52, 53.

Quanto maior o escore, maior a mutualidade entre os pais. Os itens 47, 49 e 52 são os itens negativos desta dimensão.

\section{Visão do impacto da doença}

Exemplo itens: 8, 11, 21, 24, 26, 29, 30, 32, 37, 40.

Quanto maior o escore, maior a preocupação da família em manejar a doença da criança. Os itens 21, 26, 32 e 40 são itens reversos desta dimensão.

Devido à grande diversidade de doenças das crianças das famílias abordadas durante a coleta dos dados, optou-se por classificá-las de acordo com Rolland (2009), que classifica as doenças crônicas em três grupos: como as doenças de curso progressivo, de curso constante e as reincidentes. Optamos por esta classificação por ser validada e facilitar a análise dos dados. Nesta classificação Rolland considera como progressiva as doenças continuamente ou geralmente sintomáticas e que geralmente progridem com severidade. $O$ indivíduo com uma doença progressiva defronta com efeitos perpetuamente sintomáticos e cuja incapacidade vai aumentando de modo gradual ou progressivo. São consideradas doenças de curso progressivo: diabetes juvenil, hipotireoidismo, síndromes convulsivas, entre outras. As doenças constantes são aquelas em que, após o evento inicial da doença, o curso da doença se estabiliza. Foram classificadas como doenças de curso constante as paralisias cerebrais, talassemia minor, comunicação intraventricular e intolerância à lactose. $\mathrm{E}$ as doenças de curso reincidentes ou episódicos que alternam períodos estáveis de duração variada, caracterizada por poucos ou nenhum sintomas, com períodos de exacerbação. Foram consideradas reincidentes: asma, bronquites e rinites. 


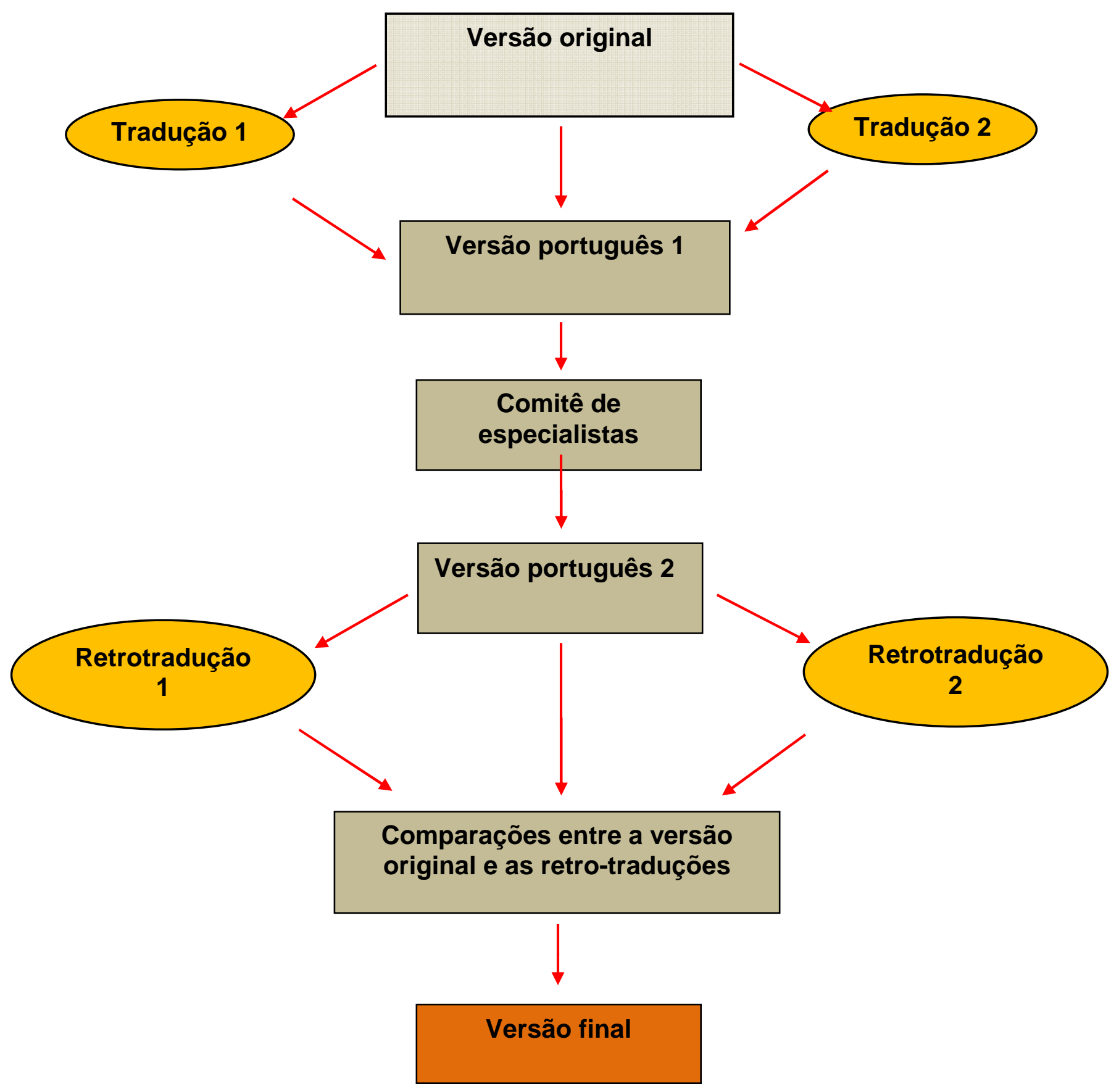

Diagrama 1 - Etapas do processo de adaptação cultural do FaMM. 


\section{RESULTADOS}

\subsection{ADAPTAÇÃO DO FAMILY MANAGEMENT MEASURE (FaMM)}

\subsubsection{Avaliação do Comitê de especialistas}

As duas traduções realizadas foram avaliadas gerando a Versão Português 1 (Apêndice A) do FaMM.

Com esta primeira versão foi construído um instrumento para avaliação que foi encaminhado ao comitê de especialistas para a análise do instrumento. O título e as orientações do preenchimento alcançaram a equivalência semântica e conceitual. Porém, a avaliação semântica do instrumento teve grande discordância entre os especialistas.

O quadro abaixo apresenta a concordância entre os especialistas, quanto às equivalências conceituais, de item, semântica e idiomática e quanto à validade de conteúdo. A equivalência operacional não foi destacada no quadro, pois entende-se que deve ser avaliada no instrumento com um todo e não em itens separadamente, obteve-se na avaliação desta equivalência $100 \%$ de concordância.

\begin{tabular}{c|c|c|c|c|c|c|c|c|c|}
\cline { 3 - 11 } \multicolumn{2}{c|}{} & \multicolumn{2}{c|}{ Eq. conceitual } & \multicolumn{2}{l|}{ Eq. de item } & \multicolumn{2}{l|}{ Eq. semântica } & \multicolumn{2}{l|}{ Eq. de conteúdo } \\
\hline Domínio & Item & $\mathbf{N}$ & $\%$ & $\mathbf{N}$ & $\%$ & $\mathbf{N}$ & $\%$ & $\mathbf{N}$ & $\%$ \\
\hline Identidade da criança & 1 & 9 & 100,0 & 9 & 100,0 & 6 & 66,7 & 9 & 100,0 \\
\hline Dificuldade da família & 2 & 9 & 100,0 & 9 & 100,0 & 6 & 66,7 & 9 & 100,0 \\
\hline Esforço de manejo & 3 & 9 & 100,0 & 9 & 100,0 & 7 & 77,8 & 9 & 100,0 \\
\hline Habilidade de manejo & 4 & 9 & 100,0 & 9 & 100,0 & 6 & 66,7 & 9 & 100,0 \\
\hline Identidade da criança & 5 & 9 & 100,0 & 9 & 100,0 & 8 & 88,9 & 9 & 100,0
\end{tabular}




\begin{tabular}{|c|c|c|c|c|c|c|c|c|c|}
\hline \multirow[b]{2}{*}{ Domínio } & \multirow[b]{2}{*}{ Item } & \multicolumn{2}{|c|}{ Eq. conceitual } & \multicolumn{2}{|c|}{ Eq. de item } & \multicolumn{2}{|c|}{ Eq. semântica } & \multicolumn{2}{|c|}{ Eq. de conteúdo } \\
\hline & & $\mathbf{N}$ & $\%$ & $\mathbf{N}$ & $\%$ & $\mathbf{N}$ & $\%$ & $\mathbf{N}$ & $\%$ \\
\hline Dificuldade da família & 6 & 9 & 100,0 & 9 & 100,0 & 5 & 55,6 & 9 & 100,0 \\
\hline Esforço de de manejo & 7 & 8 & 88,9 & 9 & 100,0 & 6 & 66,7 & 9 & 100,0 \\
\hline $\begin{array}{l}\text { Visão do impacto da } \\
\text { doença }\end{array}$ & 8 & 9 & 100,0 & 9 & 100,0 & 5 & 55,6 & 9 & 100,0 \\
\hline Dificuldade da família & 9 & 9 & 100,0 & 9 & 100,0 & 5 & 55,6 & 9 & 100,0 \\
\hline Identidade da criança & 10 & 9 & 100,0 & 9 & 100,0 & 6 & 66,7 & 9 & 100,0 \\
\hline $\begin{array}{l}\text { Visão do impacto da } \\
\text { doença }\end{array}$ & 11 & 9 & 100,0 & 9 & 100,0 & 5 & 55,6 & 9 & 100,0 \\
\hline Esforço de de manejo & 12 & 9 & 100,0 & 9 & 100,0 & 4 & 44,4 & 9 & 100,0 \\
\hline Habilidade de manejo & 13 & 9 & 100,0 & 9 & 100,0 & 4 & 44,4 & 9 & 100,0 \\
\hline Habilidade de manejo & 14 & 9 & 100,0 & 9 & 100,0 & 4 & 44,4 & 9 & 100,0 \\
\hline Habilidade de manejo & 15 & 9 & 100,0 & 9 & 100,0 & 5 & 55,6 & 9 & 100,0 \\
\hline Identidade da criança & 16 & 9 & 100,0 & 9 & 100,0 & 5 & 55,6 & 9 & 100,0 \\
\hline Habilidade de manejo & 17 & 9 & 100,0 & 9 & 100,0 & 6 & 66,7 & 9 & 100,0 \\
\hline Habilidade de manejo & 18 & 9 & 100,0 & 9 & 100,0 & 7 & 77,8 & 9 & 100,0 \\
\hline Habilidade de manejo & 19 & 9 & 100,0 & 9 & 100,0 & 5 & 55,6 & 9 & 100,0 \\
\hline Identidade da criança & 20 & 9 & 100,0 & 9 & 100,0 & 5 & 55,6 & 9 & 100,0 \\
\hline $\begin{array}{l}\text { Visão do impacto da } \\
\text { doença }\end{array}$ & 21 & 9 & 100,0 & 9 & 100,0 & 4 & 44,4 & 9 & 100,0 \\
\hline Dificuldade da família & 22 & 9 & 100,0 & 9 & 100,0 & 5 & 55,6 & 9 & 100,0 \\
\hline
\end{tabular}




\begin{tabular}{|c|c|c|c|c|c|c|c|c|c|}
\hline \multirow[b]{2}{*}{ Domínio } & \multirow[b]{2}{*}{ Item } & \multicolumn{2}{|c|}{ Eq. conceitual } & \multicolumn{2}{|c|}{ Eq. de item } & \multicolumn{2}{|c|}{ Eq. semântica } & \multicolumn{2}{|c|}{ Eq. de conteúdo } \\
\hline & & $\mathbf{N}$ & $\%$ & $\mathbf{N}$ & $\%$ & $\mathbf{N}$ & $\%$ & $\mathbf{N}$ & $\%$ \\
\hline Dificuldade da família & 23 & 9 & 100,0 & 9 & 100,0 & 5 & 55,6 & 9 & 100,0 \\
\hline $\begin{array}{l}\text { Visão do impacto da } \\
\text { doença }\end{array}$ & 24 & 9 & 100,0 & 9 & 100,0 & 4 & 44,4 & 9 & 100,0 \\
\hline Habilidade de manejo & 25 & 9 & 100,0 & 9 & 100,0 & 5 & 55,6 & 9 & 100,0 \\
\hline $\begin{array}{l}\text { Visão do impacto da } \\
\text { doença }\end{array}$ & 26 & 9 & 100,0 & 9 & 100,0 & 4 & 44,4 & 9 & 100,0 \\
\hline Habilidade de manejo & 27 & 9 & 100,0 & 9 & 100,0 & 6 & 66,7 & 9 & 100,0 \\
\hline Habilidade de manejo & 28 & 9 & 100,0 & 9 & 100,0 & 4 & 44,4 & 9 & 100,0 \\
\hline $\begin{array}{l}\text { Visão do impacto da } \\
\text { doença }\end{array}$ & 29 & 9 & 100,0 & 9 & 100,0 & 4 & 44,4 & 9 & 100,0 \\
\hline $\begin{array}{l}\text { Visão do impacto da } \\
\text { doença }\end{array}$ & 30 & 9 & 100,0 & 9 & 100,0 & 4 & 44,4 & 9 & 100,0 \\
\hline Dificuldade da família & 31 & 9 & 100,0 & 9 & 100,0 & 4 & 44,4 & 9 & 100,0 \\
\hline $\begin{array}{l}\text { Visão do impacto da } \\
\text { doença }\end{array}$ & 32 & 9 & 100,0 & 9 & 100,0 & 3 & 33,3 & 9 & 100,0 \\
\hline Dificuldade da família & 33 & 9 & 100,0 & 9 & 100,0 & 3 & 33,3 & 9 & 100,0 \\
\hline Habilidade de manejo & 34 & 9 & 100,0 & 9 & 100,0 & 4 & 44,4 & 9 & 100,0 \\
\hline Esforço de de manejo & 35 & 8 & 88,9 & 8 & 88,9 & 4 & 44,4 & 8 & 88,9 \\
\hline Dificuldade da família & 36 & 8 & 88,9 & 8 & 88,9 & 2 & 22,2 & 8 & 88,9 \\
\hline $\begin{array}{l}\text { Visão do impacto da } \\
\text { doença }\end{array}$ & 37 & 9 & 100,0 & 9 & 100,0 & 5 & 55,6 & 9 & 100,0 \\
\hline Dificuldade da família & 38 & 9 & 100,0 & 9 & 100,0 & 5 & 55,6 & 9 & 100,0 \\
\hline Dificuldade da família & 39 & 9 & 100,0 & 9 & 100,0 & 4 & 44,4 & 9 & 100,0 \\
\hline
\end{tabular}




\begin{tabular}{|c|c|c|c|c|c|c|c|c|c|}
\hline \multirow[b]{2}{*}{ Domínio } & \multirow[b]{2}{*}{ Item } & \multicolumn{2}{|c|}{ Eq. conceitual } & \multicolumn{2}{|c|}{ Eq. de item } & \multicolumn{2}{|c|}{ Eq. semântica } & \multicolumn{2}{|c|}{ Eq. de conteúdo } \\
\hline & & $\mathbf{N}$ & $\%$ & $\mathbf{N}$ & $\%$ & $\mathbf{N}$ & $\%$ & $\mathbf{N}$ & $\%$ \\
\hline $\begin{array}{l}\text { Visão do impacto da } \\
\text { doença }\end{array}$ & 40 & 9 & 100,0 & 9 & 100,0 & 4 & 44,4 & 9 & 100,0 \\
\hline Habilidade de manejo & 41 & 9 & 100,0 & 9 & 100,0 & 4 & 44,4 & 9 & 100,0 \\
\hline Dificuldade da família & 42 & 9 & 100,0 & 9 & 100,0 & 4 & 44,4 & 9 & 100,0 \\
\hline Dificuldade da família & 43 & 9 & 100,0 & 9 & 100,0 & 5 & 55,6 & 9 & 100,0 \\
\hline Dificuldade da família & 44 & 9 & 100,0 & 9 & 100,0 & 6 & 66,7 & 9 & 100,0 \\
\hline Dificuldade da família & 45 & 9 & 100,0 & 9 & 100,0 & 4 & 44,4 & 9 & 100,0 \\
\hline Mutualidade dos pais & 46 & 9 & 100,0 & 9 & 100,0 & 4 & 44,4 & 9 & 100,0 \\
\hline Mutualidade dos pais & 47 & 9 & 100,0 & 9 & 100,0 & 4 & 44,4 & 9 & 100,0 \\
\hline Mutualidade dos pais & 48 & 9 & 100,0 & 9 & 100,0 & 3 & 33,3 & 9 & 100,0 \\
\hline Mutualidade dos pais & 49 & 9 & 100,0 & 9 & 100,0 & 4 & 44,4 & 9 & 100,0 \\
\hline Mutualidade dos pais & 50 & 9 & 100,0 & 9 & 100,0 & 7 & 77,8 & 9 & 100,0 \\
\hline Mutualidade dos pais & 51 & 9 & 100,0 & 9 & 100,0 & 6 & 66,7 & 9 & 100,0 \\
\hline Mutualidade dos pais & 52 & 9 & 100,0 & 9 & 100,0 & 4 & 44,4 & 9 & 100,0 \\
\hline Mutualidade dos pais & 53 & 9 & 100,0 & 9 & 100,0 & 3 & 33,3 & 9 & 100,0 \\
\hline
\end{tabular}

Quadro 1 - Concordância entre juízes, São Paulo - 2011

$\mathrm{Na}$ concordância conceitual, equivalência de item e validade de conteúdo, todos os itens apresentaram concordância acima de $80 \%$. Porém, na equivalência 
semântica/idiomática apenas o item 5 obteve concordância acima de $80 \%$, os demais item foram avaliados pelos especialistas com uma concordância abaixo do esperado.

Com as sugestões dos especialistas para os itens com concordância abaixo do esperado, notou-se que a maioria dos itens que não contemplaram o percentual esperado era de fácil alteração, porém, havia divergências entre os especialistas. Quatro especialistas acreditavam que o termo doença crônica deveria ser utilizada em todos os itens e o termo condição crônica deveria ser substituído. Uma especialista e um familiar convidado para compor o comitê de especialistas sugeriram que termo condição crônica seria mais abrangente e mais fiel à versão original. Outra divergência encontrada nas avaliações foi em relação ao termo "our child's", que traduzimos como nosso filho(a), uma especialista sugeriu que fosse alterado para nossa criança, visto que a criança pode ter outro cuidador.

Foi realizada uma reunião entre todas as especialistas para se chegar a um consenso para reformulação dos itens com baixa concordância.

A autora do instrumento original Kathleen Knafl foi consultada via internet para opinar quanto às divergências apontadas pelos especialistas. Com a orientação da autora chegou-se ao consenso que o termo doença crônica deveria ser empregado em todos os itens do instrumento a fim de facilitar a compreensão por parte do entrevistado. E o termo nosso filho ou nossa criança deveria ser substituído pelo nome da criança, pois em nossa cultura nem sempre a mãe é a principal responsável pelo cuidado da criança. Com a reunião obteve-se um consenso de 100\% de concordância entre os especialistas.

O quadro abaixo demonstra as alterações realizadas no instrumento encaminhado para a avaliação dos especialistas, versão adaptada após a reunião com os especialistas em comparação com o instrumento original.

\begin{tabular}{l|l|l}
\hline Instrumento original & $\begin{array}{l}\text { Versão encaminhada ao } \\
\text { comitê de especialistas }\end{array}$ & Versão adaptada \\
\hline $\begin{array}{l}\text { 1. Our child's everyday } \\
\text { life is similar to that of } \\
\text { other children his/her } \\
\text { age. }\end{array}$ & $\begin{array}{l}\text { 1. O dia a dia de nosso } \\
\text { filho é parecido com o de } \\
\text { outras crianças na mesma } \\
\text { idade dele. }\end{array}$ & $\begin{array}{l}\text { 1. O dia a dia de (nome } \\
\text { da criança) é parecido } \\
\text { com o de outras } \\
\text { crianças na mesma } \\
\text { idade dele. }\end{array}$
\end{tabular}




\begin{tabular}{|c|c|c|}
\hline Instrumento original & $\begin{array}{l}\text { Versão encaminhada ao } \\
\text { comitê de especialistas }\end{array}$ & Versão adaptada \\
\hline $\begin{array}{l}\text { 2. Our child's condition } \\
\text { gets in the way of family } \\
\text { relationships. }\end{array}$ & $\begin{array}{l}\text { 2. A condição de nosso } \\
\text { filho interfere no } \\
\text { relacionamento da família. }\end{array}$ & $\begin{array}{l}\text { 2. A doença do (nome } \\
\text { da criança) interfere no } \\
\text { relacionamento da } \\
\text { família. }\end{array}$ \\
\hline $\begin{array}{l}\text { 3. Our child's condition } \\
\text { requires frequent visits } \\
\text { to the clinic. }\end{array}$ & $\begin{array}{l}\text { 3. A condição do nosso } \\
\text { filho requer visitas } \\
\text { frequentes ao médico. }\end{array}$ & $\begin{array}{l}\text { 3. A doença do (nome } \\
\text { da criança) requer } \\
\text { visitas frequentes ao } \\
\text { médico. }\end{array}$ \\
\hline $\begin{array}{l}\text { 4. In the future we } \\
\text { expect our child to take } \\
\text { care of the condition. }\end{array}$ & $\begin{array}{l}\text { 4. Esperamos que nosso } \\
\text { filho no futuro seja capaz } \\
\text { de cuidar de sua doença. }\end{array}$ & $\begin{array}{l}\text { 4. Esperamos que } \\
\text { (nome da criança) no } \\
\text { futuro seja capaz de } \\
\text { cuidar de sua doença. }\end{array}$ \\
\hline $\begin{array}{l}\text { 5. Our child enjoys life } \\
\text { less because of the } \\
\text { condition. }\end{array}$ & $\begin{array}{l}\text { 5. Nosso filho aproveita } \\
\text { menos a vida por causa da } \\
\text { sua condição. }\end{array}$ & $\begin{array}{l}\text { 5. (nome da criança) } \\
\text { aproveita menos a vida } \\
\text { por causa da sua } \\
\text { doença. }\end{array}$ \\
\hline $\begin{array}{l}\text { 6. Taking care of our } \\
\text { child's condition is } \\
\text { often overwhelming. }\end{array}$ & $\begin{array}{l}\text { 6. Cuidar da doença de } \\
\text { nosso filho é } \\
\text { frequentemente muito } \\
\text { pesado. }\end{array}$ & $\begin{array}{l}\text { 6. Cuidar da doença de } \\
\text { (nome da criança) é } \\
\text { frequentemente muito } \\
\text { difícil. }\end{array}$ \\
\hline $\begin{array}{l}\text { 7. Our child's condition } \\
\text { is like a roller coaster } \\
\text { with lots of ups and } \\
\text { downs. }\end{array}$ & $\begin{array}{l}\text { 7. A doença de nosso filho } \\
\text { é como uma montanha- } \\
\text { russa, cheia de altos e } \\
\text { baixos. }\end{array}$ & $\begin{array}{l}\text { 7. A doença de (nome } \\
\text { da criança) é como uma } \\
\text { montanha-russa, cheia } \\
\text { de altos e baixos. }\end{array}$ \\
\hline $\begin{array}{l}\text { 8. Our child's condition } \\
\text { is the most important } \\
\text { thing in our family. }\end{array}$ & $\begin{array}{l}\text { 8. A doença de nosso filho } \\
\text { é a coisa mais importante } \\
\text { em nossa família. }\end{array}$ & $\begin{array}{l}\text { 8. A doença de (nome } \\
\text { da criança) é a coisa } \\
\text { mais importante em } \\
\text { nossa família. }\end{array}$ \\
\hline $\begin{array}{l}\text { 9. It is very hard for us } \\
\text { to take care of our } \\
\text { child's condition. }\end{array}$ & $\begin{array}{l}\text { 9. Para nós é muito difícil } \\
\text { cuidar da doença de nosso } \\
\text { filho. }\end{array}$ & $\begin{array}{l}\text { 9. É muito difícil para } \\
\text { nós cuidar da doença } \\
\text { de (nome da criança). }\end{array}$ \\
\hline $\begin{array}{l}\text { 10. Our child takes part } \\
\text { in activities he/she } \\
\text { wishes to despite the } \\
\text { condition. }\end{array}$ & $\begin{array}{l}\text { 10. Nosso filho participa de } \\
\text { atividades que deseja } \\
\text { apesar da sua condição. }\end{array}$ & $\begin{array}{l}\text { 10. (nome da criança) } \\
\text { participa de atividades } \\
\text { que deseja apesar da } \\
\text { sua doença. }\end{array}$ \\
\hline
\end{tabular}




\begin{tabular}{|c|c|c|}
\hline Instrumento original & $\begin{array}{l}\text { Versão encaminhada ao } \\
\text { comitê de especialistas }\end{array}$ & Versão adaptada \\
\hline $\begin{array}{l}\text { 11. Because of the } \\
\text { condition, we worry } \\
\text { about our child's future. }\end{array}$ & $\begin{array}{l}\text { 11. Nos preocupamos com } \\
\text { o futuro do nosso filho por } \\
\text { causa da sua condição. }\end{array}$ & $\begin{array}{l}\text { 11. Nos preocupamos } \\
\text { com o futuro do (nome } \\
\text { da criança) por causa } \\
\text { da sua doença. }\end{array}$ \\
\hline $\begin{array}{l}\text { 12. Our child's } \\
\text { condition doesn't take a } \\
\text { great deal of time to } \\
\text { manage. }\end{array}$ & $\begin{array}{l}\text { 12. Os cuidados com a } \\
\text { condição do nosso filho } \\
\text { não requer muito tempo. }\end{array}$ & $\begin{array}{l}\text { 12. Lidar com a doença } \\
\text { do (nome da criança) } \\
\text { não exige muito tempo. }\end{array}$ \\
\hline $\begin{array}{l}\text { 13. We have some } \\
\text { definite ideas about } \\
\text { how to help our child } \\
\text { live with the condition. }\end{array}$ & $\begin{array}{l}\text { 13. Temos algumas idéias } \\
\text { bem definidas acerca de } \\
\text { como ajudar nosso filho a } \\
\text { conviver com a doença. }\end{array}$ & $\begin{array}{l}\text { 13. Temos algumas } \\
\text { idéiasdefinidas acerca } \\
\text { de como ajudar (nome } \\
\text { da criança) a conviver } \\
\text { com a doença. }\end{array}$ \\
\hline $\begin{array}{l}\text { 14. Despite the } \\
\text { condition, we expect } \\
\text { our child to live away } \\
\text { from home in the } \\
\text { future. }\end{array}$ & $\begin{array}{l}\text { 14. Apesar da sua } \\
\text { condição, esperamos que, } \\
\text { no futuro, nosso filho } \\
\text { possa viver em sua própria } \\
\text { casa. }\end{array}$ & $\begin{array}{l}\text { 14. Apesar da sua } \\
\text { doença, esperamos } \\
\text { que, no futuro, (nome } \\
\text { da criança) possa viver } \\
\text { em sua própria casa. }\end{array}$ \\
\hline $\begin{array}{l}\text { 15. We have enough } \\
\text { money to manage our } \\
\text { child's condition. }\end{array}$ & $\begin{array}{l}\text { 15. Nós temos condição } \\
\text { financeira suficiente para } \\
\text { pagar as despesas da } \\
\text { doença do nosso filho. }\end{array}$ & $\begin{array}{l}\text { 15. Nós temos condição } \\
\text { financeira suficiente } \\
\text { para pagar as despesas } \\
\text { da doença do (nome da } \\
\text { criança). }\end{array}$ \\
\hline $\begin{array}{l}\text { 16. Our child is } \\
\text { different from other } \\
\text { children his/her age } \\
\text { because of the } \\
\text { condition. }\end{array}$ & $\begin{array}{l}\text { 16. Nosso filho é diferente } \\
\text { de outras crianças da } \\
\text { mesma idade por causa de } \\
\text { sua condição. }\end{array}$ & $\begin{array}{l}\text { 16. (nome da criança) é } \\
\text { diferente de outras } \\
\text { crianças da mesma } \\
\text { idade por causa de sua } \\
\text { doença. }\end{array}$ \\
\hline $\begin{array}{l}\text { 17. It is difficult to know } \\
\text { when our child's } \\
\text { condition must come } \\
\text { first in the family. }\end{array}$ & $\begin{array}{l}\text { 17. É difícil saber quando a } \\
\text { condição do nosso filho } \\
\text { deve vir em primeiro lugar } \\
\text { na família. }\end{array}$ & $\begin{array}{l}\text { 17. É difícil saber } \\
\text { quando a doença de } \\
\text { (nome da criança) deve } \\
\text { vir em primeiro lugar na } \\
\text { família. }\end{array}$ \\
\hline $\begin{array}{l}\text { 18. We are looking } \\
\text { forward to a happy } \\
\text { future with our child. }\end{array}$ & $\begin{array}{l}\text { 18. Nós esperamos ter um } \\
\text { futuro feliz com nosso } \\
\text { filho. }\end{array}$ & $\begin{array}{l}\text { 18. Nós esperamos ter } \\
\text { um futuro feliz com } \\
\text { (nome da criança). }\end{array}$ \\
\hline
\end{tabular}




\begin{tabular}{|c|c|c|}
\hline Instrumento original & $\begin{array}{l}\text { Versão encaminhada ao } \\
\text { comitê de especialistas }\end{array}$ & Versão adaptada \\
\hline $\begin{array}{l}\text { 19. When something } \\
\text { unexpected happens } \\
\text { with our child's } \\
\text { condition, we usually } \\
\text { know how to handle it. }\end{array}$ & $\begin{array}{l}\text { 19. Quando algo } \\
\text { inesperado acontece na } \\
\text { condição de nosso filho, } \\
\text { nós geralmente sabemos } \\
\text { como lidar. }\end{array}$ & $\begin{array}{l}\text { 19. Quando alguma } \\
\text { coisa inesperada } \\
\text { acontece em relação à } \\
\text { doença de (nome da } \\
\text { criança), nós } \\
\text { geralmente sabemos } \\
\text { como lidar. }\end{array}$ \\
\hline $\begin{array}{l}\text { 20. Our child's } \\
\text { friendships are different } \\
\text { because of the } \\
\text { condition. }\end{array}$ & $\begin{array}{l}\text { 20. As amizades de } \\
\text { nosso filho são diferentes } \\
\text { por causa da sua } \\
\text { condição. }\end{array}$ & $\begin{array}{l}\text { 20. As amizades do } \\
\text { (nome da criança) são } \\
\text { diferentes por causa da } \\
\text { sua doença. }\end{array}$ \\
\hline $\begin{array}{l}\text { 21. We expect to be } \\
\text { devoting less time to } \\
\text { our child's condition in } \\
\text { the future. }\end{array}$ & $\begin{array}{l}\text { 21. No futuro, esperamos } \\
\text { dedicar menos tempo nos } \\
\text { cuidados com a condição } \\
\text { de nosso filho. }\end{array}$ & $\begin{array}{l}\text { 21. No futuro, nós } \\
\text { esperamos dedicar } \\
\text { menos tempo aos } \\
\text { cuidados com a doença } \\
\text { de (nome da criança). }\end{array}$ \\
\hline $\begin{array}{l}\text { 22. A condition like the } \\
\text { one our child has } \\
\text { makes family life very } \\
\text { difficult. }\end{array}$ & $\begin{array}{l}\text { 22. Uma condição como a } \\
\text { de nosso filho torna a vida } \\
\text { familiar muito difícil. }\end{array}$ & $\begin{array}{l}\text { 22. Uma doença como a } \\
\text { que (nome da criança) } \\
\text { tem torna a vida familiar } \\
\text { muito difícil. }\end{array}$ \\
\hline $\begin{array}{l}\text { 23. Our child's } \\
\text { condition rarely } \\
\text { interferes with other } \\
\text { family activities. }\end{array}$ & $\begin{array}{l}\text { 23. As atividades de nosso } \\
\text { filho raramente interferem } \\
\text { nas outras atividades da } \\
\text { família. }\end{array}$ & $\begin{array}{l}\text { 23. As atividades de } \\
\text { (nome da criança) } \\
\text { raramente interferem } \\
\text { nas outras atividades da } \\
\text { família. }\end{array}$ \\
\hline $\begin{array}{l}\text { 24. Our child's } \\
\text { condition requires } \\
\text { frequent hospital stays. }\end{array}$ & $\begin{array}{l}\text { 24. A condição de nosso } \\
\text { filho requer constantes } \\
\text { internações hospitalares. }\end{array}$ & $\begin{array}{l}\text { 24. A doença de (nome } \\
\text { da criança) requer } \\
\text { frequentes internações } \\
\text { hospitalares. }\end{array}$ \\
\hline $\begin{array}{l}\text { 25. We feel we are } \\
\text { doing a good job taking } \\
\text { care of our child's } \\
\text { condition. }\end{array}$ & $\begin{array}{l}\text { 25. Sentimos que } \\
\text { estamos fazendo um bom } \\
\text { trabalho no cuidado com o } \\
\text { nosso filho. }\end{array}$ & $\begin{array}{l}\text { 25. Sentimos que } \\
\text { estamos fazendo um } \\
\text { bom trabalho no } \\
\text { cuidado com o (nome } \\
\text { da criança). }\end{array}$ \\
\hline $\begin{array}{l}\text { 26. People with our } \\
\text { child's condition have a } \\
\text { normal length of live. }\end{array}$ & $\begin{array}{l}\text { 26. Pessoas com a } \\
\text { condição como a de nosso } \\
\text { filho tem uma expectativa } \\
\text { de vida normal. }\end{array}$ & $\begin{array}{l}\text { 26. Pessoas com a } \\
\text { doença como a de } \\
\text { (nome da criança) tem } \\
\text { uma expectativa de vida } \\
\text { normal. }\end{array}$ \\
\hline
\end{tabular}




\begin{tabular}{|c|c|c|}
\hline Instrumento original & $\begin{array}{l}\text { Versão encaminhada ao } \\
\text { comitê de especialistas }\end{array}$ & Versão adaptada \\
\hline $\begin{array}{l}\text { 27. It's often difficult to } \\
\text { know if we need to be } \\
\text { more protective of our } \\
\text { child. }\end{array}$ & $\begin{array}{l}\text { 27. Geralmente é difícil } \\
\text { saber se precisamos ser } \\
\text { mais protetores com } \\
\text { nosso filho. }\end{array}$ & $\begin{array}{l}\text { 27. Geralmente é difícil } \\
\text { saber se precisamos ser } \\
\text { mais protetores com } \\
\text { (nome da criança). }\end{array}$ \\
\hline $\begin{array}{l}\text { 28. We often feel } \\
\text { unsure about what to } \\
\text { do to take care of our } \\
\text { child's condition. }\end{array}$ & $\begin{array}{l}\text { 28. Geralmente nos } \\
\text { sentimos inseguros em } \\
\text { relação ao que fazer para } \\
\text { cuidar da condição de } \\
\text { nosso filho. }\end{array}$ & $\begin{array}{l}\text { 28. Geralmente nos } \\
\text { sentimos inseguros em } \\
\text { relação ao que fazer } \\
\text { para cuidar da doença } \\
\text { de (nome da criança). }\end{array}$ \\
\hline $\begin{array}{l}\text { 29. Our child's } \\
\text { condition Will be harder } \\
\text { to take care of in the } \\
\text { future. }\end{array}$ & $\begin{array}{l}\text { 29. No futuro, será mais } \\
\text { difícil de cuidar da } \\
\text { condição do nosso filho. }\end{array}$ & $\begin{array}{l}\text { 29. No futuro, será mais } \\
\text { difícil de cuidar da } \\
\text { doença do (nome da } \\
\text { criança). }\end{array}$ \\
\hline $\begin{array}{l}\text { 30. We think about our } \\
\text { child's condition all the } \\
\text { time. }\end{array}$ & $\begin{array}{l}\text { 30. Nós pensamos sobre a } \\
\text { condição do nosso filho o } \\
\text { tempo todo. }\end{array}$ & $\begin{array}{l}\text { 30. Nós pensamos } \\
\text { sobre a doença do } \\
\text { (nome da criança) o } \\
\text { tempo todo. }\end{array}$ \\
\hline $\begin{array}{l}\text { 31. It seems as if our } \\
\text { child's condition } \\
\text { controls our family life. }\end{array}$ & $\begin{array}{l}\text { 31. Parece que a condição } \\
\text { de nosso filho controla a } \\
\text { vida da nossa família. }\end{array}$ & $\begin{array}{l}\text { 31. Parece que a } \\
\text { doença de (nome da } \\
\text { criança) controla a vida } \\
\text { da nossa família. }\end{array}$ \\
\hline $\begin{array}{l}\text { 32. Many conditions } \\
\text { are more serious than } \\
\text { our child's. }\end{array}$ & $\begin{array}{l}\text { 32. Outras crianças têm } \\
\text { condições piores que a do } \\
\text { nosso filho. }\end{array}$ & $\begin{array}{l}\text { 32. Muitas doenças são } \\
\text { mais sérias do que a do } \\
\text { (nome da criança). }\end{array}$ \\
\hline $\begin{array}{l}\text { 33. It is hard to get } \\
\text { anyone else to help us } \\
\text { with our child's } \\
\text { condition. }\end{array}$ & $\begin{array}{l}\text { 33. É difícil conseguir } \\
\text { ajuda de outras pessoas } \\
\text { para cuidar da condição do } \\
\text { nosso filho. }\end{array}$ & $\begin{array}{l}\text { 33. É difícil conseguir } \\
\text { outras pessoas para } \\
\text { nos ajudar com a } \\
\text { doença do (nome da } \\
\text { criança). }\end{array}$ \\
\hline $\begin{array}{l}\text { 34. We have not been } \\
\text { able to develop a } \\
\text { routine for taking care } \\
\text { of our child's condition. }\end{array}$ & $\begin{array}{l}\text { 34. Nós não estamos } \\
\text { conseguindo criar uma } \\
\text { rotina para cuidar da } \\
\text { condição do nosso filho. }\end{array}$ & $\begin{array}{l}\text { 34. Nós não } \\
\text { conseguimos criar uma } \\
\text { rotina para cuidar da } \\
\text { doença do (nome da } \\
\text { criança). }\end{array}$ \\
\hline
\end{tabular}




\begin{tabular}{|c|c|c|}
\hline Instrumento original & $\begin{array}{l}\text { Versão encaminhada ao } \\
\text { comitê de especialistas }\end{array}$ & Versão adaptada \\
\hline $\begin{array}{l}\text { 35. It takes a lot of } \\
\text { organization to manage } \\
\text { our child's condition. }\end{array}$ & $\begin{array}{l}\text { 35. E necessário muita } \\
\text { organização para lidar com } \\
\text { a condição de nosso filho. }\end{array}$ & $\begin{array}{l}\text { 35. E necessário muita } \\
\text { organização para lidar } \\
\text { com a doença de (nome } \\
\text { da criança). }\end{array}$ \\
\hline $\begin{array}{l}\text { 36. We are sometimes } \\
\text { undecided about how } \\
\text { to balance the } \\
\text { condition and family } \\
\text { life. }\end{array}$ & $\begin{array}{l}\text { 36. Às vezes somos } \\
\text { indecisos de como } \\
\text { equilibrar a vida da família } \\
\text { com a condição de nosso } \\
\text { filho. }\end{array}$ & $\begin{array}{l}\text { 36. Às vezes ficamos } \\
\text { indecisos sobre como } \\
\text { equilibrar a vida da } \\
\text { família com a doença do } \\
\text { (nome da criança). }\end{array}$ \\
\hline $\begin{array}{l}\text { 37. It is hard to know } \\
\text { what to expect of our } \\
\text { child's condition in the } \\
\text { future. }\end{array}$ & $\begin{array}{l}\text { 37. É difícil saber o que } \\
\text { esperar da condição de } \\
\text { nosso filho no futuro. }\end{array}$ & $\begin{array}{l}\text { 37. É difícil saber o que } \\
\text { esperar da doença de } \\
\text { (nome da criança) no } \\
\text { futuro. }\end{array}$ \\
\hline $\begin{array}{l}\text { 38. Even though our } \\
\text { child has the condition, } \\
\text { we have a normal } \\
\text { family life. }\end{array}$ & $\begin{array}{l}\text { 38. Mesmo com a } \\
\text { condição de nosso filho, } \\
\text { nós temos uma vida } \\
\text { familiar normal. }\end{array}$ & $\begin{array}{l}\text { 38. Mesmo com a } \\
\text { doença de (nome da } \\
\text { criança), nós temos } \\
\text { uma vida familiar } \\
\text { normal. }\end{array}$ \\
\hline $\begin{array}{l}\text { 39. Our child would do } \\
\text { better in school if } \\
\text { he/she didn't have the } \\
\text { condition. }\end{array}$ & $\begin{array}{l}\text { 39. Nosso filho teria um } \\
\text { melhor desempenho na } \\
\text { escola se não tivesse esta } \\
\text { condição. }\end{array}$ & $\begin{array}{l}\text { 39. (nome da criança) } \\
\text { poderia se sair melhor } \\
\text { na escola se não } \\
\text { tivesse esta doença. }\end{array}$ \\
\hline $\begin{array}{l}\text { 40. We are confident } \\
\text { that we can take care o } \\
\text { four child's condition. }\end{array}$ & $\begin{array}{l}\text { 40. Temos confiança de } \\
\text { que podemos cuidar da } \\
\text { condição de nosso filho. }\end{array}$ & $\begin{array}{l}\text { 40. Temos confiança de } \\
\text { que podemos cuidar da } \\
\text { doença de (nome da } \\
\text { criança). }\end{array}$ \\
\hline $\begin{array}{l}\text { 41. We have goals in } \\
\text { mind to help us } \\
\text { manage our child's } \\
\text { condition. }\end{array}$ & $\begin{array}{l}\text { 41. Nós temos objetivos } \\
\text { que nos ajudam a cuidar } \\
\text { da condição do nosso filho. }\end{array}$ & $\begin{array}{l}\text { 41. Nós temos objetivos } \\
\text { que nos ajudam a lidar } \\
\text { com a doença do (nome } \\
\text { da criança). }\end{array}$ \\
\hline $\begin{array}{l}\text { 42. It is difficult to fit } \\
\text { care of our child's } \\
\text { condition into our usual } \\
\text { family routine. }\end{array}$ & $\begin{array}{l}\text { 42. É difícil adequar a } \\
\text { atividade de cuidar da } \\
\text { condição de nosso filho na } \\
\text { nossa rotina familiar. }\end{array}$ & $\begin{array}{l}\text { 42. É difícil adequar as } \\
\text { atividades do cuidado } \\
\text { do (nome da criança) à } \\
\text { nossa rotina familiar. }\end{array}$ \\
\hline
\end{tabular}




\begin{tabular}{|c|c|c|}
\hline Instrumento original & $\begin{array}{l}\text { Versão encaminhada ao } \\
\text { comitê de especialistas }\end{array}$ & Versão adaptada \\
\hline $\begin{array}{l}\text { 43. Dealing with our } \\
\text { child's condition makes } \\
\text { family life more difficult. }\end{array}$ & $\begin{array}{l}\text { 43. Lidar com a condição } \\
\text { de nosso filho torna a vida } \\
\text { familiar mais difícil. }\end{array}$ & $\begin{array}{l}\text { 43. Lidar com a doença } \\
\text { de (nome da criança) } \\
\text { torna a vida familiar } \\
\text { mais difícil. }\end{array}$ \\
\hline $\begin{array}{l}\text { 44. We Know when our } \\
\text { child needs to be a } \\
\text { child. }\end{array}$ & $\begin{array}{l}\text { 44. Nós sabemos quando } \\
\text { nosso filho precisa ser } \\
\text { criança. }\end{array}$ & $\begin{array}{l}\text { 44. Nós sabemos } \\
\text { quando (nome da } \\
\text { criança) precisa agir } \\
\text { como criança. }\end{array}$ \\
\hline $\begin{array}{l}\text { 45. A condition like the } \\
\text { one our child has } \\
\text { makes it very difficult to } \\
\text { live a normal life. }\end{array}$ & $\begin{array}{l}\text { 45. É difícil manter uma } \\
\text { vida normal com a } \\
\text { condição que nosso filho } \\
\text { tem. }\end{array}$ & $\begin{array}{l}\text { 45. É muito difícil } \\
\text { manter uma vida normal } \\
\text { com a doença que } \\
\text { (nome da criança) tem. }\end{array}$ \\
\hline $\begin{array}{l}\text { 46. We are closer } \\
\text { family because of how } \\
\text { we deal with our child's } \\
\text { condition. }\end{array}$ & $\begin{array}{l}\text { 46. Nossa família é mais } \\
\text { unida pela maneira como } \\
\text { lidamos com a condição de } \\
\text { nosso filho. }\end{array}$ & $\begin{array}{l}\text { 46. Nossa família é } \\
\text { mais unida pela maneira } \\
\text { como lidamos com a } \\
\text { doença de (nome da } \\
\text { criança). }\end{array}$ \\
\hline $\begin{array}{l}\text { 47. My partner and I } \\
\text { have different ideas } \\
\text { about how serious our } \\
\text { child's condition is. }\end{array}$ & $\begin{array}{l}\text { 47. Meu companheiro(a) e } \\
\text { eu temos idéias diferentes } \\
\text { sobre a gravidade da } \\
\text { condição de nosso filho. }\end{array}$ & $\begin{array}{l}\text { 47. Meu companheiro(a) } \\
\text { e eu temos } \\
\text { idéiasdiferentes sobre a } \\
\text { gravidade da doença de } \\
\text { (nome da criança). }\end{array}$ \\
\hline $\begin{array}{l}\text { 48. I am pleased with } \\
\text { how my partner and I } \\
\text { work together to } \\
\text { manage our child's } \\
\text { condition. }\end{array}$ & $\begin{array}{l}\text { 48. Estou satisfeito com a } \\
\text { maneira como eu e meu } \\
\text { companheiro(a) cuidamos } \\
\text { juntos da condição de } \\
\text { nosso filho. }\end{array}$ & $\begin{array}{l}\text { 48. Estou satisfeito com } \\
\text { a maneira como eu e } \\
\text { meu companheiro(a) } \\
\text { cuidamos juntos da } \\
\text { doença de (nome da } \\
\text { criança). }\end{array}$ \\
\hline $\begin{array}{l}\text { 49. My partner and I } \\
\text { argue about how to } \\
\text { manage our child's } \\
\text { condition. }\end{array}$ & $\begin{array}{l}\text { 49. Eu e meu } \\
\text { companheiro(a) } \\
\text { discutimos sobre como } \\
\text { lidar com a condição nosso } \\
\text { filho. }\end{array}$ & $\begin{array}{l}\text { 49. Eu e meu } \\
\text { companheiro(a) } \\
\text { discutimos sobre como } \\
\text { lidar com a doença do } \\
\text { (nome da criança). }\end{array}$ \\
\hline $\begin{array}{l}\text { 50. My partner and I } \\
\text { consult with each other } \\
\text { before we make a } \\
\text { decision about our } \\
\text { child's care. }\end{array}$ & $\begin{array}{l}\text { 50. Eu e meu } \\
\text { companheiro(a) sempre } \\
\text { conversamos antes de } \\
\text { tomar qualquer decisão } \\
\text { sobre os cuidados com o } \\
\text { nosso filho. }\end{array}$ & $\begin{array}{l}\text { 50. Eu e meu } \\
\text { companheiro(a) sempre } \\
\text { conversamos antes de } \\
\text { tomar qualquer decisão } \\
\text { sobre os cuidados com } \\
\text { (nome da criança). }\end{array}$ \\
\hline
\end{tabular}




\begin{tabular}{|c|c|c|}
\hline Instrumento original & $\begin{array}{l}\text { Versão encaminhada ao } \\
\text { comitê de especialistas }\end{array}$ & Versão adaptada \\
\hline $\begin{array}{l}\text { 51. My partner and I } \\
\text { have similar ideas } \\
\text { about how we should } \\
\text { be raising our child. }\end{array}$ & $\begin{array}{l}\text { 51. Eu e meu } \\
\text { companheiro(a) temos } \\
\text { idéias semelhantes sobre } \\
\text { como devemos criar nosso } \\
\text { filho. }\end{array}$ & $\begin{array}{l}\text { 51. Eu e meu } \\
\text { companheiro(a) temos } \\
\text { idéias parecidas sobre } \\
\text { como deveríamos criar } \\
\text { o (nome da criança). }\end{array}$ \\
\hline $\begin{array}{l}\text { 52. I am unhappy about } \\
\text { the way my partner and } \\
\text { I share the } \\
\text { management of our } \\
\text { child's condition. }\end{array}$ & $\begin{array}{l}\text { 52. Estou insatisfeito(a) } \\
\text { com a forma como eu e } \\
\text { meu companheiro(a) } \\
\text { compartilhamos os } \\
\text { cuidados com a condição } \\
\text { de nosso filho. }\end{array}$ & $\begin{array}{l}\text { 52. Estou insatisfeito(a) } \\
\text { com a forma como eu e } \\
\text { meu companheiro(a) } \\
\text { compartilhamos os } \\
\text { cuidados com a doença } \\
\text { do (nome da criança). }\end{array}$ \\
\hline $\begin{array}{l}\text { 53. My partner and I } \\
\text { support each other in } \\
\text { taking care of our } \\
\text { child's condition. }\end{array}$ & $\begin{array}{l}\text { 53. Eu e meu } \\
\text { companheiro(a) ajudamos } \\
\text { um ao outro nos cuidados } \\
\text { com a condição do nosso } \\
\text { filho. }\end{array}$ & $\begin{array}{l}\text { 53. Eu e meu } \\
\text { companheiro(a) } \\
\text { apoiamos um ao outro } \\
\text { nos cuidados com a } \\
\text { doença do (nome da } \\
\text { criança). }\end{array}$ \\
\hline
\end{tabular}

Quadro 2 - Comparação da versão original do FaMM com a Versão Português 1 e Versão Final do instrumento

Todos os itens do instrumento que continham a o termo condição crônica foram alterados para doença crônica, assim como o termo "our child's" que traduzimos inicialmente como nosso(a) filho(a) foi alterado pelo "nome da criança".

No item 6 do instrumento foi alterada a frase: "Cuidar da doença do nosso filho é frequentemente muito pesado" para: "Cuidar da doença de (nome da criança) é frequentemente muito difícil", por se acreditar que a palavra pesado poderia não ser compreendida pelos respondentes.

A redação do item 9 foi alterada de: "Para nós é muito difícil cuidar da doença de nosso filho", para: "É muito difícil para nós cuidar da doença de (nome da criança)" afim de facilitar a compreensão.

A questão 12: "Os cuidados com a condição do nosso filho não requer muito tempo" alterou-se a redação para: "Lidar com a doença do (nome da criança) não exige muito tempo", também com o objetivo de facilitar a compreensão.

No item 32: "Outras crianças têm condições piores que a do nosso filho", foi alterada para: "Muitas doenças são mais sérias do que a do (nome da criança)". 
Já no item 33: "É difícil conseguir ajuda de outras pessoas para cuidar da condição do nosso filho", alterou-se a redação do item para: "É difícil conseguir outras pessoas para nos ajudar com a doença do (nome da criança)".

O item 36: "Às vezes somos indecisos de como equilibrar a vida da família com a condição de nosso filho (a)" alterou-se a palavra "somos" para "ficamos", pois se refere apenas a alguns momentos.

O item 39: "Nosso filho teria um melhor desempenho na escola se não tivesse esta condição", alterou-se para: "(nome da criança) poderia se sair melhor escola se não tivesse esta doença".

Na questão 41: "Nós temos objetivos que nos ajudam a cuidar da condição do nosso filho", a palavra "cuidar" foi alterada para a palavra "lidar".

No item 42: "É difícil adequar a atividade de cuidar da condição de nosso filho na nossa rotina familiar", optou-ser pela alteração: "É difícil adequar as atividades do cuidado do (nome da criança) à rotina familiar".

O item 44: "Nós sabemos quando nosso filho precisa ser criança como criança", o termo "ser criança" foi alterado por "precisa agir como criança".

No item 51: "Eu e meu companheiro(a) temos idéias semelhantes sobre como devemos criar nosso filho", a palavra "semelhantes" foi alterada para "parecidas".

$\mathrm{Na}$ questão 53: "Eu e meu companheiro(a) ajudamos um ao outro nos cuidados com a condição do nosso filho", a palavra "ajudamos" foi alterada para "apoiamos".

Após a análise das sugestões foram realizadas as alterações necessárias, sendo gerada assim a Versão II em português (Apêndice E). Esta versão foi encaminhada para retrotradução, foram realizadas duas retro traduções (Anexos $\mathrm{E} e$ F) e estas foram comparadas com a versão original do instrumento.

As retrotraduções apresentaram pouca divergência. Observa-se no quadro abaixo as principais divergências entre elas.

\begin{tabular}{l|l|l}
\hline Instrumento original & \multicolumn{1}{|c|}{ Retrotradução I } & \multicolumn{1}{c}{ Retrotradução II } \\
\hline $\begin{array}{l}\text { 10. Our child takes part } \\
\text { in activities he/she } \\
\text { wishes to despite the (Child's name) } \\
\text { condition. }\end{array}$ & $\begin{array}{l}\text { participates in activities } \\
\text { that he/she wishes in spite } \\
\text { of the disease. }\end{array}$ & $\begin{array}{l}\text { part in name) takes } \\
\text { activities he/she wishes } \\
\text { in spite of his/her illness. }\end{array}$
\end{tabular}




\begin{tabular}{|c|c|c|}
\hline Instrumento original & Retrotradução I & Retrotradução II \\
\hline $\begin{array}{l}\text { 14. Despite the } \\
\text { condition, we expect } \\
\text { our child to live away } \\
\text { from home in the } \\
\text { future. }\end{array}$ & $\begin{array}{l}\text { 14. Despite the disease, } \\
\text { we hope that in the future } \\
\text { (child's name) can live in } \\
\text { his/her own home. }\end{array}$ & $\begin{array}{l}\text { 14. Despite his/her } \\
\text { illness, we hope that in } \\
\text { the future (child's name) } \\
\text { will be able to live in } \\
\text { his/her own home. }\end{array}$ \\
\hline $\begin{array}{l}\text { 29. Our child's } \\
\text { condition Will be harder } \\
\text { to take care of in the } \\
\text { future. }\end{array}$ & $\begin{array}{l}\text { 29. In the future it will be } \\
\text { more difficult to care for the } \\
\text { disease of (child's name). }\end{array}$ & $\begin{array}{l}\text { 29. In the future, it will } \\
\text { be more difficult to } \\
\text { handle (child's name) } \\
\text { illness. }\end{array}$ \\
\hline $\begin{array}{l}\text { 34. We have not been } \\
\text { able to develop a } \\
\text { routine for taking care } \\
\text { of our child's condition. }\end{array}$ & $\begin{array}{l}\text { 34. We cannot create a } \\
\text { routine to care for the } \\
\text { disease of (child's name). }\end{array}$ & $\begin{array}{l}\text { 34. We can't manage to } \\
\text { create a routine to deal } \\
\text { with (child's name) } \\
\text { illness. }\end{array}$ \\
\hline $\begin{array}{l}\text { 36. We are sometimes } \\
\text { undecided about how } \\
\text { to balance the } \\
\text { condition and family } \\
\text { life. }\end{array}$ & $\begin{array}{l}\text { 36. Sometimes we are } \\
\text { unsure how to balance } \\
\text { family life with the disease } \\
\text { of (child's name). }\end{array}$ & $\begin{array}{l}\text { 36. We're sometimes } \\
\text { undecided about how to } \\
\text { balance family life with } \\
\text { (child's name) illness. }\end{array}$ \\
\hline $\begin{array}{l}\text { 44. We Know when our } \\
\text { child needs to be a } \\
\text { child. }\end{array}$ & $\begin{array}{l}\text { 44. We know when (child's } \\
\text { name) needs to act like a } \\
\text { child. }\end{array}$ & $\begin{array}{l}\text { 44. We don't know when } \\
\text { (child's name) needs to } \\
\text { act like a child. }\end{array}$ \\
\hline $\begin{array}{l}\text { 51. My partner and I } \\
\text { have similar ideas } \\
\text { about how we should } \\
\text { be raising our child. }\end{array}$ & $\begin{array}{l}\text { 51. Me and my partner } \\
\text { have similar ideas about } \\
\text { how to raise (child's } \\
\text { name). }\end{array}$ & $\begin{array}{l}\text { 51. My partner and I } \\
\text { have similar ideas about } \\
\text { how we should raise } \\
\text { (child's name). }\end{array}$ \\
\hline
\end{tabular}

Quadro 3 - Comparação da versão original com as retrotraduções

Após a avaliação das retrotraduções não houve alteração na Versão II português, encerrando-se assim as etapas qualitativas do processo de adaptação cultural, enquanto validade de face e equivalência semântica/idiomática.

A etapa a seguir trata-se da aplicação da versão final do instrumento (Apêndice E) na população de familiares de criança portadoras de doença crônica participantes deste estudo, para verificar as demais propriedades da versão adaptada. 


\subsection{ANÁLISE DAS PROPRIEDADES PSICOMÉTRICAS DO FaMM}

\subsubsection{Caracterização da população}

Dos 72 familiares de crianças portadoras de doenças crônicas participantes do estudo, será apresentado a caracterização sócio-demográfica destes respondentes e das crianças na tabela a seguir.

Tabela 1 - Distribuição da caracterização demográfica da amostra (Londrina-2011) (continua)

\begin{tabular}{|c|c|c|}
\hline Variáveis & $\mathrm{N}$ & $\%$ \\
\hline \multicolumn{3}{|l|}{ Parentes * } \\
\hline Mãe & 60 & 83,3 \\
\hline Avós & 3 & 4,2 \\
\hline Pai & 7 & 9,7 \\
\hline Madrasta e outros & 2 & 2,8 \\
\hline \multicolumn{3}{|l|}{ Anos de estudo * } \\
\hline 0 a 4 & 16 & 22,2 \\
\hline 5 a 8 & 21 & 29,2 \\
\hline 9 ou mais & 35 & 48,6 \\
\hline \multicolumn{3}{|l|}{ Tem irmãos * } \\
\hline Sim & 53 & 73,6 \\
\hline Não & 18 & 25,0 \\
\hline Não respondeu & 1 & 1,4 \\
\hline \multicolumn{3}{|l|}{ Número de irmão ** } \\
\hline 1 & 20 & 37,7 \\
\hline 2 & 21 & 39,6 \\
\hline 3 & 5 & 9,4 \\
\hline 4 & 4 & 7,6 \\
\hline 5 & 2 & 3,8 \\
\hline 8 & 1 & 1,9 \\
\hline
\end{tabular}


Tabela 1 - Distribuição da caracterização demográfica da amostra (Londrina-2011) (conclusão)

\begin{tabular}{|c|c|c|}
\hline Variáveis & $\mathrm{N}$ & $\%$ \\
\hline \multicolumn{3}{|l|}{ Renda * } \\
\hline Suficiente & 41 & 57,0 \\
\hline Insuficiente & 25 & 34,7 \\
\hline Sobra dinheiro no fim do mês & 6 & 8,3 \\
\hline \multicolumn{3}{|l|}{ Renda antes da doença* } \\
\hline Suficiente & 46 & 63,9 \\
\hline Insuficiente & 15 & 20,8 \\
\hline $\begin{array}{l}\text { Sobrava dinheiro no fim do } \\
\text { mês }\end{array}$ & 11 & 15,3 \\
\hline \multicolumn{3}{|l|}{ Sexo da criança* } \\
\hline Masculino & 41 & 56,9 \\
\hline Feminino & 31 & 43,1 \\
\hline \multicolumn{3}{|l|}{ Idade da criança * } \\
\hline Média & 6,39 & \\
\hline Desvio padrão & 3,99 & \\
\hline P25 & 3 & \\
\hline P50 & 6 & \\
\hline P75 & 10 & \\
\hline$(\min -\max )$ & $(0-14)$ & \\
\hline \multicolumn{3}{|l|}{ Tipo de doença da criança * } \\
\hline Progressiva & 29 & 40,3 \\
\hline Constante & 29 & 40,3 \\
\hline Reincidente & 14 & 19,4 \\
\hline
\end{tabular}

Nota: ${ }^{*} \mathrm{~N}=72{ }^{* *} \mathrm{~N}=53$

A amostra foi composta pela grande maioria de $83,3 \%$ (60) mães das crianças, enquanto 9,7\% (7) eram pais, 4,2\% (3) avós e 2,8\% (2) respondentes eram madrastas e outros.

Quanto aos anos de estudo, 48,6\% (35) dedicaram 9 ou mais anos aos estudos, 29,2\% (21) responderam de 5 a 8 anos e 22,2\% (16) até 4 anos de estudo. 
Das famílias abordadas, 3,6\% possuam outros filhos e $25 \%$ não tinham outros filhos.

Em relação à renda da família, 57\% responderam que sua renda familiar era suficiente, 34,7\% responderam ter renda insuficiente e 8,3\% relataram sobrar dinheiro no final do mês. Quando questionados em relação à renda antes da doença da criança, 63,9\% dos familiares responderam que a renda era suficiente, 20,8\% responderam que a renda já era insuficiente e 15,3\% referiram que sobrava dinheiro no final do mês.

A média de idade das crianças foi de 6,39 anos (desvio padrão $=3,99$ ). Quanto ao sexo da criança, 41 (56,9\%) eram do sexo masculino e $31(43,1 \%)$ do sexo feminino.

Quanto ao tipo de doença da criança, 29 crianças (40,3\%) apresentavam doenças progressivas, 29 (40,3\%) doenças constantes e 14 (19,4\%) tinham doenças reincidentes.

\subsubsection{Estatística descritiva do FaMM adaptado}

A análise dos dados referentes à aplicação da versão adaptada do FaMM aos 72 familiares de crianças com doenças crônicas está apresentada de acordo com as 6 dimensões do instrumento: 1 - Identidade da criança; 2 - Habilidade de manejo; 3 - Esforço de manejo; 4 - Dificuldade da família; 5 - Mutualidade dos pais; e 6 - Visão do impacto da doença.

Esta análise foi obtida através da soma dos escores do total de itens de cada dimensão, dividida pelas diferenças entre o intervalo possível (mínimomáximo). O valor total de seus 53 itens (intervalo possível) e a média que seus itens indicam.

Ao avaliar as dimensões do instrumento obteve-se resultado estatisticamente significativo nas dimensões: Identidade da criança, Habilidade de manejo, Esforço de manejo e Visão do impacto da doença. Apresentaram correlações negativas as dimensões: Dificuldade da família e Mutualidade dos pais.

Observa-se que o alfa de Cronbach, usado para medir a confiabilidade interna dos itens do instrumento, para o instrumento todo é igual a 0,8660, podendo 
afirmar que $86,6 \%$ da variabilidade do fenômeno pode ser explicada por este instrumento. As dimensões Habilidade de manejo; Esforço de manejo e Visão do impacto da doença não alcançaram a consistência interna esperada. As dimensões Identidade da criança, Dificuldade da família e Mutualidade dos pais demonstraram uma consistência interna satisfatória.

Tabela 2 - Coeficiente de correlação do item com o total, o valor alfa total dos 53 itens do FaMM - Londrina, 2011 (continua)

\begin{tabular}{lllll}
\hline Dimensões & Item & Sinal & $\begin{array}{l}\text { Correlação } \\
\text { item-total }\end{array}$ & Alpha \\
\hline Identidade da criança & 1 & - & 0,6060 & 0,8595 \\
Identidade da criança & 5 & - & 0,6485 & 0,8583 \\
Identidade da criança & 10 & - & 0,3693 & 0,8633 \\
Identidade da criança & 16 & - & 0,5620 & 0,8598 \\
Identidade da criança & 20 & - & 0,5834 & 0,8584 \\
Habilidade de manejo & 4 & - & 0,3585 & 0,8645 \\
Habilidade de manejo & 13 & - & 0,2723 & 0,8658 \\
Habilidade de manejo & 14 & - & 0,4987 & 0,8617 \\
Habilidade de manejo & 15 & - & 0,4114 & 0,8618 \\
Habilidade de manejo & 18 & - & 0,4465 & 0,8629 \\
Habilidade de manejo & 19 & - & 0,1811 & 0,8666 \\
Habilidade de manejo & 25 & - & 0,2219 & 0,8646 \\
Habilidade de manejo & 41 & - & 0,1643 & 0,8674 \\
Habilidade de manejo & 17 & - & 0,3173 & 0,8645 \\
Habilidade de manejo & 27 & + & 0,1734 & 0,8672 \\
Habilidade de manejo & 28 & - & 0,2393 & 0,8655 \\
Habilidade de manejo & $\mathbf{3 4}$ & - & $\mathbf{0 , 0 8 6 4}$ & $\mathbf{0 , 8 6 8 6}$ \\
Esforço de manejo & 3 & + & 0,2284 & 0,8656 \\
Esforço de manejo & 7 & + & 0,4641 & 0,8620
\end{tabular}


Tabela 2 - Coeficiente de correlação do item com o total, o valor alfa total dos 53 itens do FaMM - Londrina, 2011 (continuação)

\begin{tabular}{|c|c|c|c|c|}
\hline Dimensões & Item & Sinal & $\begin{array}{l}\text { Correlação } \\
\text { item-total }\end{array}$ & Alpha \\
\hline Esforço de manejo & 35 & + & 0,2808 & 0,8646 \\
\hline Esforço de manejo & 12 & + & 0,4197 & 0,8617 \\
\hline Dificuldade da família & 2 & + & 0,5231 & 0,8602 \\
\hline Dificuldade da família & 6 & + & 0,3703 & 0,8631 \\
\hline Dificuldade da família & 9 & + & 0,4568 & 0,8615 \\
\hline Dificuldade da família & 22 & + & 0,5608 & 0,8608 \\
\hline Dificuldade da família & 31 & + & 0,4762 & 0,8599 \\
\hline Dificuldade da família & 33 & + & 0,3763 & 0,8638 \\
\hline Dificuldade da família & 36 & + & 0,3379 & 0,8627 \\
\hline Dificuldade da família & 39 & + & 0,5201 & 0,8599 \\
\hline Dificuldade da família & 42 & + & 0,3108 & 0,8646 \\
\hline Dificuldade da família & 43 & + & 0,4348 & 0,8616 \\
\hline Dificuldade da família & 45 & + & 0,4243 & 0,8622 \\
\hline Dificuldade da família & 23 & + & 0,4088 & 0,8633 \\
\hline Dificuldade da família & 38 & + & 0,3651 & 0,8641 \\
\hline Dificuldade da família & 44 & + & 0,0042 & 0,8679 \\
\hline Mutualidade dos pais & 46 & - & 0,2477 & 0,8656 \\
\hline Mutualidade dos pais & 48 & - & 0,5620 & 0,8613 \\
\hline Mutualidade dos pais & 50 & - & 0,2583 & 0,8651 \\
\hline Mutualidade dos pais & 51 & - & 0,2353 & 0,8657 \\
\hline Mutualidade dos pais & 53 & - & 0,3192 & 0,8643 \\
\hline Mutualidade dos pais & 47 & - & 0,2681 & 0,8653 \\
\hline Mutualidade dos pais & 49 & - & 0,1429 & 0,8674 \\
\hline Mutualidade dos pais & 52 & - & 0,2661 & 0,8652 \\
\hline Visão do impacto da doença & 8 & + & 0,2530 & 0,8655 \\
\hline Visão do impacto da doença & 11 & + & 0,1869 & 0,8658 \\
\hline Visão do impacto da doença & 24 & + & 0,3088 & 0,8655 \\
\hline Visão do impacto da doença & 29 & + & 0,5288 & 0,8602 \\
\hline Visão do impacto da doença & 30 & + & 0,2665 & 0,8644 \\
\hline
\end{tabular}


Tabela 2 - Coeficiente de correlação do item com o total, o valor alfa total dos 53 itens do FaMM - Londrina, 2011 (conclusão)

\begin{tabular}{lllll}
\hline Dimensões & Item & Sinal & $\begin{array}{l}\text { Correlação } \\
\text { item-total }\end{array}$ & Alpha \\
\hline Visão do impacto da doença & 37 & + & 0,1782 & 0,8658 \\
Visão do impacto da doença & 21 & + & 0,0839 & 0,8669 \\
Visão do impacto da doença & 26 & + & 0,4941 & 0,8624 \\
Visão do impacto da doença & 32 & - & 0,0838 & 0,8670 \\
Visão do impacto da doença & 40 & + & 0,1851 & 0,8655 \\
Escala total & & & & 0,8660 \\
\hline
\end{tabular}

Observa-se que o instrumento total teve um alfa de 0,8660, o que demonstra a confiabilidade interna de seus itens, com isso pode-se afirmar que $86,6 \%$ da variabilidade do fenômeno pode ser explicado por este instrumento.

Os itens 10, 4, 13, 19, 25, 41, 17, 27, 28, 34, 3, 35, 6, 33, 36, 42, 38, 44, 46, $50,51,53,47,49,52,8,11,24,30,37,21,32$ e 40 apresentam correlações individuais negativas com o total do instrumento, no entanto, a retirada dos mesmos não se justifica, pois o alfa do instrumento total não seria alterado de maneira significativa.

Tabela 3 - Estatística descritiva dos escores totais por dimensões e da composição do FaMM, Londrina - 2011

\begin{tabular}{llllll}
\hline Dimensões & N & Média & $\begin{array}{l}\text { Desvio } \\
\text { Padrão }\end{array}$ & (min-max) & $\begin{array}{l}\text { Alpha de } \\
\text { Cronbach }\end{array}$ \\
\hline Identidade da criança & 72 & 17,36 & 7,44 & $(3-25)$ & 0,7974 \\
Habilidade de manejo & 72 & 44,09 & 8,81 & $(17-60)$ & 0,5497 \\
Esforço de manejo & 72 & 14,12 & 4,45 & $(4-20)$ & 0,3636 \\
Dificuldade da família & 72 & 29,97 & 12,95 & $(12-61)$ & 0,7815 \\
Mutualidade dos pais & 59 & 30,91 & 9,10 & $(8-40)$ & 0,7908 \\
$\begin{array}{l}\text { Visão do impacto da } \\
\text { doença }\end{array}$ & 72 & 24,32 & 6,08 & $(12-42)$ & 0,4275 \\
Escala Total & & & & & 0,8660 \\
\hline
\end{tabular}


A maior média obtida entre as dimensões do instrumento foi a Habilidade de Manejo (44,09), porém na consistência interna alcançou apenas $(0,549)$ com um intervalo de (17- 60); na dimensão Esforço de manejo obteve-se para uma média de $(14,12)$, um intervalo de (4-20) e um alfa não representativo de (0,363); o melhor alfa encontrado foi na dimensão Identidade da criança $(0,797)$, com uma média de $(17,36)$, com um intervalo foi de (3-25).

Tabela 4 - Coeficiente de correlação do item com o total da dimensão Identidade da criança, valor alfa total da dimensão - Londrina, 2011

\begin{tabular}{llll}
\hline Item & Sinal & Correlação item -total & Alpha \\
\hline 1 & + & 0,8117 & 0,7262 \\
5 & + & 0,7758 & 0,7425 \\
10 & + & 0,6440 & 0,8007 \\
16 & + & 0,7330 & 0,7648 \\
20 & + & 0,7511 & 0,7546 \\
Dimensão & & & 0,7974 \\
\hline
\end{tabular}

A tabela acima demonstra que o alfa da dimensão Identidade da criança foi de 0,7974 , o que explica $79,7 \%$ da variabilidade do fenômeno desta dimensão. Os componentes internos desta dimensão não apresentaram grandes diferenças de valores.

Tabela 5 - Coeficiente de correlação do item com o total da dimensão Habilidade de manejo, valor alfa total da dimensão - Londrina, 2011 (continua)

\begin{tabular}{llll}
\hline Item & Sinal & Correlação item-total & Alpha \\
\hline 4 & + & 0,4959 & 0,5032 \\
13 & + & 0,5012 & 0,5105 \\
14 & + & 0,5266 & 0,4951 \\
15 & + & 0,3470 & 0,5546 \\
18 & + & 0,5858 & 0,4963 \\
19 & + & 0,5154 & 0,5040
\end{tabular}


Tabela 5 - Coeficiente de correlação do item com o total da dimensão Habilidade de manejo, valor alfa total da dimensão - Londrina, 2011 (conclusão)

\begin{tabular}{llll}
\hline Item & Sinal & Correlação item-total & Alpha \\
25 & + & 0,3281 & 0,5339 \\
41 & + & 0,5073 & 0,5004 \\
17 & + & 0,3100 & $\mathbf{0 , 5 4 7 6}$ \\
27 & - & 0,2179 & 0,5894 \\
28 & + & 0,4429 & 0,5277 \\
34 & + & 0,3348 & 0,5608 \\
Dimensão & & & 0,5497 \\
\hline
\end{tabular}

Conforme a tabela apresentada anteriormente, 0 alfa da dimensão Habilidade de manejo foi de 0,5497, o que explica $54,9 \%$ da variabilidade do fenômeno da dimensão. O item 27 apresentou a menor correlação com o total da dimensão, no entanto, sua retirada não apresenta uma melhora significativa no alfa da dimensão.

Tabela 6 - Coeficiente de correlação do item com o total da dimensão Esforço de manejo, valor alfa total da dimensão - Londrina, 2011

\begin{tabular}{llll}
\hline Item & Sinal & Correlação item-total & Alpha \\
\hline 3 & + & 0,5090 & 0,3721 \\
7 & + & 0,6233 & 0,2129 \\
12 & + & 0,7089 & 0,1137 \\
35 & - & 0,5006 & 0,4430 \\
Dimensão & & & 0,3636 \\
\hline
\end{tabular}

Na dimensão Esforço de manejo, conforme demonstra tabela anterior, alfa foi de 0,3636, explicando apenas 36,3\% da variabilidade do fenômeno da dimensão, o que não é aceitável para o processo de validação de instrumento. 0 item 35 apresentou a menor correlação com o total da dimensão e sua exclusão do 
instrumento aumentaria o alfa da dimensão 0,4430, o que explicaria 44,3\% do fenômeno de variabilidade desta dimensão, sendo assim considerada aceitável para o processo de validação.

Tabela 7 - Coeficiente de correlação do item com o total da dimensão Dificuldade da família, valor alfa total da dimensão - Londrina, 2011.

\begin{tabular}{llcl}
\hline Item & Sinal & Correlação item-total & Alpha \\
\hline 2 & + & 0,6437 & 0,7553 \\
6 & + & 0,5428 & 0,7659 \\
9 & + & 0,6502 & 0,7539 \\
22 & + & 0,5992 & 0,7595 \\
31 & + & 0,6127 & 0,7579 \\
33 & + & 0,4625 & 0,7771 \\
36 & + & 0,4785 & 0,7729 \\
39 & + & 0,4732 & 0,7745 \\
42 & + & 0,4393 & 0,7779 \\
43 & + & 0,7141 & 0,7466 \\
34 & + & 0,5243 & 0,7667 \\
23 & + & 0,4763 & 0,7738 \\
38 & + & 0,4136 & 0,7754 \\
44 & + & 0,1012 & 0,7950 \\
Dimensão & & & 0,7815 \\
\hline
\end{tabular}

Conforme a tabela apresentada anteriormente, na dimensão Dificuldade de vida da família, o alfa foi de 0,7815, o que explica $78,1 \%$ da variabilidade do fenômeno da dimensão. O item 44 apresentou a menor correlação com o total da dimensão, no entanto, apesar de baixo é um item positivo e sua retirada aumentaria pouco o valor de alfa, que passaria para 0,7950. 
Tabela 8 - Coeficiente de correlação do item com o total da dimensão Mutualidade dos pais, valor alfa total da dimensão - Londrina, 2011

\begin{tabular}{llll}
\hline Item & Sinal & Correlação item-total & Alpha \\
\hline 46 & + & 0,5271 & 0,7924 \\
48 & + & 0,7279 & 0,7500 \\
50 & + & 0,5796 & 0,7755 \\
51 & + & 0,7460 & 0,7450 \\
53 & + & 0,7727 & 0,7405 \\
47 & + & 0,5836 & 0,7807 \\
49 & + & 0,4951 & 0,8017 \\
52 & + & 0,7259 & 0,7494 \\
Dimensão & & & 0,7908 \\
\hline
\end{tabular}

$\mathrm{Na}$ dimensão Mutualidade dos pais, obteve-se um alfa de 0,7908, o que explica 79,0\% da variabilidade do fenômeno da dimensão. O item 46 apresentou a menor correlação com o total da dimensão, no entanto, seu valor é aceitável e foi considerado um item positivo.

Tabela 9 - Coeficiente de correlação do item com o total da dimensão Visão do impacto da doença, valor alfa total da dimensão - Londrina, 2011

\begin{tabular}{llll}
\hline Item & Sinal & Correlação item-total & Alpha \\
\hline 8 & + & 0,3749 & 0,4591 \\
11 & + & 0,3979 & 0,3918 \\
24 & + & 0,3401 & 0,4548 \\
29 & + & 0,4455 & 0,3947 \\
30 & + & 0,5698 & 0,3566 \\
37 & + & 0,4016 & 0,3912 \\
21 & + & 0,4501 & 0,3767 \\
26 & + & 0,4932 & 0,3590 \\
32 & - & 0,2939 & 0,4144 \\
40 & + & 0,3179 & 0,4084 \\
Dimensão & & & 0,4275 \\
\hline
\end{tabular}


Os itens da dimensão Visão do impacto da doença tiveram resultados bastante próximos, o que não justifica a retirada de nenhum item da dimensão, o alfa total foi de 0,4275 , o que explica $42,7 \%$ da variabilidade do fenômeno da dimensão. O item que apresentou a menor correlação com o total da dimensão foi o item 32 , porém, apesar de ser um valor inverso na dimensão, sua retirada não elevaria o alfa total da dimensão. 


\section{DISCUSSÃO}

Durante o processo de adaptação cultural foram realizadas duas traduções por pessoas com fluência no idioma inglês, uma conhecedora dos objetivos do trabalho e outro sem o conhecimento previo dos objetivos da pesquisa, considerado tradução cega. Após foi realizada a síntese destas duas traduções. Esta versão traduzida do instrumento foi encaminhada à um comitê de especialistas para avaliação, esta etapa da pesquisa seria realizada através de correio eletrônico, no entanto, as avaliações tiveram muitas divergências entre os especialistas quanto à equivalência semântica/idiomática do instrumento. Realizou-se então uma reunião na Escola de Enfermagem da Universidade de São Paulo, onde todas as especialistas participaram e chegaram à uma concordância de $100 \%$. A autora principal do instrumento original Kathleen Knafl colaborou significativamente com o processo de adaptação, participando desta reunião via correio eletrônico.

Segundo Beaton et al. (2000), o comitê de especialistas tem por objetivo consolidar as versões do instrumento e desenvolver o que seria a versão pré-final para ser aplicada no teste de campo.

O título do instrumento e as orientações para o seu preenchimento não foram alterados desde a primeira versão em português até a sua versão final após a avaliação dos especialistas.

Dos 53 itens do instrumento, todos os itens que continham o termo "condição crônica" sofreram alteração desse termo para "doença crônica", por sugestão da autora do instrumento original e com a concordância dos especialistas durante a reunião realizada para avaliação do instrumento traduzido. Esta alteração foi realizada por acreditar-se que em nossa cultura os respondentes do instrumento teriam mais facilidade para compreender o termo doença crônica.

Nenhum dos itens permaneceu igual ao da primeira versão em português, pois conforme as mudanças também sugeridas pela Dra Kathleen Knafl juntamente com o comitê de especialistas foram alterados em todos os itens do instrumento as palavras: de nosso (a) filho (a) para (nome da criança) por acreditar-se que em nossa cultura nem sempre a mãe é a cuidadora principal da criança.

Após a aplicação do instrumento traduzido percebeu-se que houve deficiência na parte que contém os dados sociodemográficos, com a ausência de 
questões abordando há quanto tempo a doença da criança foi diagnosticada, o que é considerado de grande importância relacionando ao manejo da família. Acredita-se que há uma relação entre o tempo de diagnóstico da doença com a adaptação da família em relação ao manejo da doença. Ao longo do tempo a maioria das famílias se veem com maior habilidade para reger o tratamento e para manejar a doença de forma que minimize a desorganização que a doença trás à família (Leonard et al, 1997; May, 1997; Grey et al. 2006).

Kovacs et al. (1985) revelam que somente após os primeiros seis meses de diagnóstico da doença que a família retorna ao seu funcionamento normal. Deatrick et al. (2006) reforçam que os estilos de manejo são alterados conforme o tempo e que no início da doença, a família se encontra "desestruturada".

$\mathrm{Na}$ caracterização da população deste estudo, a maioria dos respondentes eram mães, totalizando 60 (83,3\%) dos entrevistados e a maioria $(48,6 \%)$ relatou ter frequentado a escola durante 9 anos ou mais.

Mc Quaid et al. (2008), para avaliar as associações entre sintomas e morbidade na asma e a mediação por dimensões específicas do manejo familiar, aplicaram o Family Asthma Management System Scale em 110 crianças e seus cuidadores e obtiveram que $92 \%$ das respondentes eram mães. No Brasil esta realidade é parecida, pois Deon et al. (2011), na adaptação do instrumento DISABKIDS também obtiveram as 17 respostas das mães entre os 18 respondentes em sua pesquisa. Em Portugal, Ferreira et al. (2010) obtiveram que 84,2\% de mães dos 870 respondentes na pesquisa de validação do Needs of Parents Questionnaire.

Ao comparar o grau de instrução dos respondentes deste estudo com a validação do instrumento original, Knafl et al. (2009) encontraram dados parecidos, onde $53 \%$ das mães tinham grau universitário e $17 \%$ o segundo grau ou menos e dos pais entrevistados $57 \%$ cursaram o nível superior e $23 \%$ o nível secundário ou menos. Quanto à renda, as autoras relatam variar de U\$20,000 a U\$ 150,000 dólares anual, $30 \%$ com a renda inferior a U\$ 30,000 e $23 \%$ a renda maior que U\$ 100,000 dólares anuais. No estudo atual classificou-se a renda da família como suficiente, insuficiente e sobra dinheiro no final do mês, e conforme o encontrado na pesquisa original $34,7 \%$ das famílias obtinham a menor renda, considerada insuficiente para a família.

A idade das crianças com doenças crônicas participantes deste estudo variou de 0 a 14 anos, com uma média de 6 anos. Na validação do instrumento 
original, Knafl et al. (2009) realizaram o estudo junto às crianças das famílias participantes da pesquisa com a faixa etária de 2 a 19 anos, e com uma média de 11, 2 anos. Esses dados diferem dos obtidos na amostra do atual estudo, mas não compromete as etapas de adaptação do instrumento. Recomenda-se que outros estudos sejam realizados com diferentes proporções de crianças e adolescentes para comprovar a adaptação cultural realizada.

As autoras relataram uma variedade de 165 condições crônicas encontradas nas 417 crianças do estudo, sendo as mais prevalentes Diabetes mellitus $(15,4 \%)$, seguida de Doença de Crohn (14,4\%) e fibrose cística (12\%). Em nosso estudo, a diversidade de doenças encontradas foi similar ao do instrumento original, visto que na amostra abordamos 48 condições crônicas nas 72 crianças presentes na amostra.

Através da aplicação da versão adaptada do instrumento na população anteriormente descrita, realizou-se a análise descritiva do desempenho dos itens do instrumento.

O alfa de Cronbach foi usado para medir a confiabilidade interna dos itens do instrumento, para o instrumento completo foi igual a 0,8660, podendo-se afirmar que $86,6 \%$ da variabilidade do fenômeno pode ser explicada por este instrumento. $O$ alfa nas dimensões do instrumento Identidade da criança, Habilidade de manejo, Dificuldade da família, Mutualidade dos pais e Visão do impacto da doença foram consideradas aceitáveis para o processo de validação. Já na dimensão Esforço de manejo obteve-se uma alfa de 0,36 , o que não é aceitável para o processo de validação, optou-se então pela a retirada do item 35 do instrumento e com isso o alfa aumentou para 0,44. Nunnaly (1978) refere que a alfa de Cronbach se torna aceitável para o processo de validação a partir de 0,40 , com isso a retirada do item 35 torna satisfatório o alfa da dimensão Esforço de manejo para o processo de validação.

Cummings et al. (2003) referem que os valores baixos para a consistência interna de um instrumento indicam que algumas características individuais podem estar medindo características diferentes. Sendo assim, optou-se pela exclusão deste item do instrumento.

Os escores de alfa de Cronbach na versão adaptada se aproximam da versão original, com exceção da dimensão Esforço de manejo, considerada por Guillemin et al. $(1993,2000)$ como uma boa consistência interna do instrumento. No 
instrumento original, Knafl et al. (2009) alcançaram uma consistência interna com variação entre 0,72 a 0,91 para as seis dimensões do FaMM.

Serrano (2007), em sua adaptação cultural da Hardiness Scale obteve um alfa de Cronbach total para o instrumento de 0,73 e o alfa dos domínios da escala variou de 0,44 a 0,68 .

Já Queiroz (2008), na validação do instrumento Diabetes-39 obteve valores de 0,58 a 0,84 nas subescalas do instrumento e de 0,91 para o instrumento completo.

Durante a coleta dos dados observou-se que o item 23 da dimensão Dificuldade da família, "As atividades de (nome da criança) raramente interferem nas outras atividades da família", apresentou dificuldades de compreensão por parte dos respondentes e acredita-se que a palavra raramente tenha causado esta dificuldade. Porém, foi considerado um item positivo, e obteve um alfa de 0,44 e a sua exclusão não alteraria o alfa total do instrumento e da dimensão.

O item 42 da dimensão Dificuldade da família na primeira versão em português foi traduzido como: "É difícil adequar a atividade de cuidar da condição de nosso filho na nossa rotina familiar" e após a reunião com os especialistas foi alterado para: "É difícil adequar as atividades do cuidado do (nome da criança) à rotina familiar". No entanto, durante a coleta dos dados observou-se que a palavra condição fez diferença quanto à resposta dos entrevistados, pois a maioria dos respondentes verbalizou que o cuidado deve ser realizado com qualquer criança, e que as famílias se adaptam ao cuidado do filho, independentemente se ele possui ou não alguma doença. $\mathrm{Na}$ avaliação da consistência interna deste item separadamente, ele não obteve um alfa satisfatório para correlação item-instrumento $(0,31)$, porém não houve interferência no alfa de Cronbach do instrumento completo, não sendo justificada a sua retirada.

O menor alfa do instrumento $(0,0042)$ foi o item 44 da dimensão Dificuldade da família, "Nós sabemos quando nosso filho precisa agir como criança", acredita-se que isto não tenha ocorrido por dificuldade de compreensão da questão, mas sim pela dificuldade das famílias em saber quando devem ser menos protetores e deixarem a criança agir como criança.

O item 49 da dimensão Mutualidade dos pais "Eu e meu companheiro(a) discutimos sobre como lidar com a doença do (nome da criança)" é considerado um item inverso do instrumento e a melhor resposta para a questão seria "discordo 
totalmente", no entanto, observou-se que algumas famílias que respondiam para todos os item da dimensão como tendo uma boa mutualidade, nesta questão respondiam o inverso, o que indica dificuldade de compreensão do item em questão. Acredita-se que a palavra "discutimos" foi interpretada como "chegar a um consenso sobre", como um aspecto positivo da relação.

No que se refere à equivalência funcional do instrumento, constatou-se um grau satisfatório de equivalência. Os resultados da versão adaptada parecem apontar uma boa aplicação e entendimento do instrumento na amostra investigada.

Com os resultados alcançados, levando-se em conta os objetivos propostos neste estudo, infere-se que o FaMM apresenta equivalência conceitual, pois o instrumento apresentou-se relevante em todas as etapas do estudo. Infere-se a importância de se ter em nossa cultura instrumentos de medida para manejo familiar, pois somente conhecendo a dinâmica familiar é que se pode oferecer uma assistência integral capaz de suprir as necessidades da criança e sua família. Nelson et al. (2006) afirmam que medindo e avaliando as respostas das famílias à doença das crianças poderemos dar um suporte e desenvolvermos intervenções voltadas ao preparo da família para lidar com os desafios enfrentados no decorrer desta experiência. No entanto, em nossa cultura não encontramos instrumentos que realizem este tipo de medida, o que demonstra existir uma lacuna no que diz respeito à medida de manejo familiar.

Knafl e Gilliss (2002) afirmam que a família funciona de melhor maneira quando o cuidado está associado à rede de suporte social, adequação dos recursos, habilidade de encontrar sentido positivo nas experiências e menos stress. Acreditase que o grau de dificuldade encontrado pela família em relação ao manejo com a doença da criança está relacionado com a aceitação e qualidade da adaptação em relação à condição crônica da criança, adaptação esta que deve ser alcançada não somente pela família, mas também pela criança (Grey et al., 2006). Adaptação esta, onde profissionais de saúde têm papel fundamental, no preparo e estímulo da família, para que ela busque suas próprias demandas e assuma o controle da situação, tornando-se assim mais bem adaptada e competente para cuidar da criança (Damião, Angelo, 2001).

É necessário que se invista em outros estudos para que o conceito de manejo familiar seja mais amplamente explorado em nossa cultura e se expandindo para outras populações. 


\section{CONCLUSÃo}

A ausência de outros instrumentos de medida de manejo de crianças com doenças crônicas dificulta qualquer análise mais aprofundada do instrumento. Apenas com a disseminação do conhecimento sobre o tema poderemos avançar em pesquisas de medida de manejo familiar.

O valor do coeficiente alfa de Cronbach indica a fidedignidade do instrumento em sua aplicação a uma amostra de familiares de crianças/adolescentes portadores de doenças crônicas.

O processo de tradução e adaptação do Family Management Measure resultou em um instrumento adaptado à realidade brasileira e nos permite concluir que:

- O pré-teste mostrou que 0 instrumento tem aplicabilidade em nossa realidade, podendo fornecer dados para futuras pesquisas e podendo compará-las com pesquisas internacionais.

- O instrumento pode avaliar como a família maneja a criança/adolescente com doença crônica. 


\section{CONSIDERAÇÕES FINAIS}

O termo "manejo familiar" apesar de já ser utilizado há algumas décadas na cultura americana, em nossa cultura ainda é pouco usual.

O resultado deste estudo é a etapa fundamental para o processo da validação deste instrumento em uma amostra maior de famílias de crianças com doenças crônicas e, consequentemente, faz parte de um objetivo maior, o de conhecer como se dá o manejo familiar da criança com condições crônicas em nossa realidade.

A versão adaptada do FaMM para a cultura brasileira contribuirá como um instrumento válido e confiável para mensurar o manejo familiar da criança portadora de doença crônica. Esse instrumento trará conhecimento importante para os profissionais de saúde e, em especial, para o enfermeiro, para compreender 0 comportamento da família na adaptação e manejo da doença da criança.

A utilização do FaMM em uma amostra maior ou em diferentes populações trará resultados significativos, além de contribuir para uma melhor representação da realidade brasileira no que se refere ao manejo familiar. 


\section{REFERÊNCIAS}

Balling K, McCubbin M. Hospitalized children with chronic illness: parental caregiving needs and valuing parental expertise. J Pediatr Nurs. 2001 Apr; 16(2): 110-9.

Beaton DE, Bombardier C, Guillemin F, Ferraz MB. Guidelines for the process of cross-cultural adaptation of self-report measures. Spine. 2000; 25(24): 3186-91.

Bernaix LW, Jamerson PA, Smith J. The NICU experience of lactation and its relationship to family management style. MCN Am j matern child nurs. 2006; 31(2): 95-100.

Brown RT, Wiener L, Kupst MJ, Brennan T, Behrman R, Compas BE, et al. Single Parents of Children with Chronic Illness: An Understudied Phenomenon. J pediatr psychol. 2008; 33(4): 408-21.

Castro EK, Piccinini CA. Implicações da doença orgânica crônica na infância para as relações familiares: algumas questões teóricas. Psicol reflex crit. 2002; 15(3): 62535.

Chwalow AJ. Cross-cultural validation os existing quality of life scales. Patient Education and Counseling. 1995; (26):313-18.

Clarke-Steffen L. Reconstructing reality: Family strate-gies for managing childhood cancer. Journal of Pediatric Nursing. 1997; 12(5),278-87.

Conselho Nacional de Saúde (Brasil). Diretrizes e normas regulamentadoras de pesquisas envolvendo seres humanos. Resolução № 196, de 10 de outubro de 1996.

Cummings SR, Stwart A, Rulley SB. Elaboração de questionários e intrumentos de coleta de dados. In: Hulley S.B. et al. Delineando a pesquisa clínica. Uma abordagem epidemiológica. Porto Alegre: Artmed, 2003:265-81.

Damião EBC, Angelo M. A experiência da família ao conviver com a criança com doença crônica. Rev Esc Enferm USP. 2001 Mar; 35(1): 66-71. 
Damião EBC. Crenças da família da criança com fibrose cística [tese]. São Paulo (SP): Escola de Enfermagem da Universidade de São Paulo; 2002.

Damião EBC. Sendo difícil não ter controle: a família vivenciando a doença crônica da criança [dissertação]. São Paulo (SP): Escola de Enfermagem da Universidade de São Paulo; 1997.

Deatrick J, Thibodeaux A, Mooney K, Schmus C, Pollacki R, Davey B. Family management style framework: A new tool with potential to assess families who have children with brain tumors. J pediatr oncol nurs. 2006; 23(1): 19-27.

Deon K, Santos D, Reis R, Fegadolli C, Bullinger M, Santos C. Tradução e adaptação Cultural para o Brasil do Disabkids Attopic Dematitis Module (ADM). Rev Esc Enfermagem USP. 2011; 45:(2):450-7.

Ferreira E. Adaptação Cultural da "Burn specific Health Scale - Revised": versão para brasileiros que sofreram queimaduras [dissertação]. Ribeirão Preto (SP): Escola de Enfermagem de Ribeirão Preto - Universidade de São Paulo; 2006.

Ferreira L, Melo E, Reis G, Mello D. Validation and reliability analysis of the Portuguese language version of Needs of Parents Questionnaire. Jornal de Pediatria. 2010; 86(3): 221-26.

Fisher L, Chesla C, Skaff M, Gillis C, Kanter R, Lutz C et al. Disease management status: a typology of Latino and Euro-American patients with type 2 diabetes. Behav Med. 2000; 26(2): 53-66.

Furtado MCC, Lima RAG. O cotidiano da família com filhos portadores de fibrose cística: subsídios para a enfermagem pediátrica. Rev latinoam enferm. 2003 JanFev; 11(1): 66-73.

Gallagher EJ, Lombard G, Gennis P. Effectiveness of bystander cardiopulmonary resuscitation and survival following out-of-hospital cardiac arrest. JAMA. 1995 Dec; 274(24): 1922-5.

Gallo AM, Knafl KA. Parents reports of "tricks of the trade" for managing childhood chronic illness. J Soc Pediatr Nurs. 1998 Jul; 3(3): 93-100.

Grey M, Knafl K, McCorkle R. A framework for the study of self-and family management of chronic conditions. Nursing Outlook. 2006; 54(5): 278-86. 
Guillemin F, Bombardier C, Beaton DE. Cross-cultural adaptation of health-related quality of life measures: literature review and proposed guidelines. J clin epidemiol. 1993; 46(12): 1417-32.

Guillemin F, Bombardier C, Beaton DE. Cross-cultural adaptation of health-related quality of life measures: literature review and proposed guidelines. J clin epidemiol. 2002; 25(24): 3186-91.

Guimarães TMR, Miranda WL, Tavares MF. O cotidiano das famílias de crianças e adolescentes portadores de anemia falciforme. Rev bras hematol hemoter. 2009; 31(1): 9-14.

Herdman M, Fox-Rushby J, Badia X. A model of equivalence in the cultural adaptation of HRQol instruments: the universalist approach. Qual Life Res. 1998; 7: 323-35.

Hopia $\mathrm{H}$, Paavilainen E, Astedt-Kurki P. Promoting health for families of children with chronic conditions. J adv nurs. 2004 Dec; 48(6): 575-83.

Kendall J, Sheldon K. A typology of management styles in families with children with ADHD. J Fam Nurs. 2003; 9(3): 257-80.

Knafl K, Breitmayer B, Gallo A, Zoeller L. Family response to childhood chronic illness: description of management styles. J pediatr nurs. 1996 Oct; 11(5): 315-26.

Knafl K, Deatrick J, Gallo A, Dixon J, Grey M, Knafl G, O’Malley J. Description of the Family Management Measure (FaMM). [homepage on the internet. Disponível em: http://www.ohsu.edu/son/famm/index. Acesso em: 03 de mar. 2009.

Knafl K, Deatrick J, Gallo A, Dixon J, Grey M, Knafl G, O’Malley J. Assessment of the Psychometric Properties of the Family Management Measure. Journal of Pediatric Psychology. 2009 May; 18: 1-12.

Knafl K, Deatrick J, Gallo A. The interplay of concepts, data, and methods in the development of the family management style framework. J fam nurs. $2008 \mathrm{Nov}$; 14(4): 412-28.

Knafl K, Deatrick J. Family management style and the challenge of moving from conceptualization to measurement. J pediatr oncol nurs. 2006 Jan-Feb; 23(1): 12-8. 
Knafl K, Deatrick J. Family management style: concept analysis and development. J pediatr nurs. 1990; 5(1): 4-14.

Knafl K, Deatrick J. Further Refinement of the Family Management Style Framework. J fam nurs. 2003; 9(3): 232-56.

Knafl K, Gilliss C. Families and Chronic Ilness: A Synthesis of Current Research. J fam nurs. 2002. 8(3):178-98.

Knafl K, Zoeller L. Childhood Chronic Illness: A Comparison of Mothers' and Fathers' Experiences. J fam nurs. 2000 Feb; 6(3): 287-302.

Knafl KA, Deatrick JA. The challenge of normalization for families o children with chronic conditions. Pediatr Nurs. 2002; 28:49-53.

Kovacs M, Finkelstein R, Feinberg TL, Crouse-Novak M, Paulauskas S, Pollock M. Initial psychology responses of parents to the diagnosis of insulin-dependent diabetes mellitus in their children. Diabetes care. 1985; 8(6): 568-75.

Leonard B, Kratz B, Skay C, Rheinberg M. Comparsion of mother-father perceptions of their child's self-management of diabetes. Issue Compr Pediatr Nurs. 1997; 20:6987.

Lopes M, Stuhler GD. Atendimento psicológico a mães de crianças com doença crônica: relato de experiência. Psicol argum. 2008 Out/Dez; 26(55): 341-7.

May KM. Searching for normalcy: mothers'caregiving for low birth weight infants. Peditr Nurs 1997; 23:17-20.

Mc Quaid EL, Weiss-Laxer N, Kopel SJ, Mitchell DK, Nassau JH, Wamboldt MZ, Klein RB, Fritz GK. Pediatric asthma and problems in attention, concentration and impulsivity: disruption of the family management. Systems, families and health. 2008; 26(1): 16-29.

McCarthy S, Gallo A. A case illustration of family management style. Journal of Pediatric Nursing. 1992; 7(6):395-402.

Mendes-Castillo AMC. Manejo Familiar no transplante hepático da criança [tese]. São Paulo (SP): Escola de Enfermagem da Universidade de São Paulo; 2011. 
Misko MD, Bousso RS. Manejando o câncer e suas intercorrências: a família decidindo pela busca ao atendimento de emergência para o filho. Rev latinoam enferm. 2007 Jan/Fev; 15(1): 48-54.

Muscari ME. Coping with chronic illness. Nursing knowledge and compassion can empower ill or disabled teens. Am J Nurs. 1998 Sep; 98(9):20-2.

Nascimento LC, Rocha SMM, Hayes VH, Lima RAG. Crianças com câncer e suas famílias. Rev Esc Enferm USP. 2005 Dez; 39(4): 469-74.

Nascimento LC. Crianças com câncer: a vida das famílias em constante reconstrução [tese]. Ribeirão Preto (SP): Escola de enfermagem de Ribeirão Preto Universidade de São Paulo; 2003.

Nelson A, Deatrick J, Knafl K, Alderfer M, Ogle S. Consensus statements: The Family Management Style Framework and its use with families of children with cancer. J Pediatr Oncol Nurs. 2006 Jan-Feb;23(1): 36-7.

Nunnaly, JC. Psychometric Theory. New York, McGraw-Hill, 1978.

Ogle S. Clinical application of family management styles to families of children with cancer. J Pediatr Oncol Nurs. 2006 Jan-Fev; 23(1): 28-31.

Pesce RP, Assis SG, Avanci JQ, Santos NC, Malaquias JV, Carvalhaes R. Adaptação transcultural, confiabilidade e validade da escala de resiliência. Cad saúde pública. 2005; 21(2): 436-48.

Polit DF, Beck CT, Hungler BP. Fundamentos de Pesquisa em Enfermagem. $5^{\mathrm{a}}$ ed. Porto Alegre: Artmed; 2004.

Queiroz F. Adaptação Cultural e validação do instrumento de Diabetes - 39 (D-39): versão para brasileiros com diabetes mellitus tipo 2 - fase 1. [dissertação]. Ribeirão Preto (SP): Escola de Enfermagem de Ribeirão Preto - Universidade de São Paulo; 2008.

Radovanick CAT, Waidman MAP, Pereira MO, Felipes L, Ferrari I, Marcon SS. Caracterizando os problemas de saúde e o cuidado domiciliar oferecido às famílias do projeto "Promovendo a vida na Vila Esperança". Acta sci, Health sci. 2004; 26(1): 27-34. 
Rolland JS. Doença crônica e o ciclo de vida familiar. In: Carter B, McGoldrick M. As mudanças no ciclo de vida familiar: uma estrutura para a terapia familiar. $3^{\underline{a}}$ ed. Porto Alegre: Artes Médicas; 2007. 373-92.

Scharer K, Dixon D. Managing chronic illness: Parents with a ventilator-dependent child. Journal of Pediatric Nursing. 1998; 4(4): 236-47.

Serrano P. Adaptação Cultural da Hardiness Scale (HS) [dissertação]. São Paulo (SP): Escola de Enfermagem de Universidade de São Paulo; 2009.

Sperber AD. Translation and validation of study instruments for cross-cultural research. Gastroenterology. 2004 Jan;126(1 Suppl 1): S124-8.

Sullivan-Bolyai S, Knafl K, Deatrick J, Grey M. Maternal management behaviors for young children with type 1 diabetes. MCN Am J Matern Child Nurs. 2003 May-Jun; 28(3): 160-6.

Taylor RM, Faith G, Franck LS. The experience of living with a chronic illness during adolescence: a critical review of the literature. J Clin Nurs. 2008 Dec; 17(23): 308391.

Vieira MA, Lima RAG. Crianças e adolescentes com doença crônica: convivendo com mudanças. Rev latinoam enferm. 2002 Jul-Ago; 10(4): 552-60.

Vieira MA. Doença crônica: vivências de crianças e adolescentes [dissertação]. Ribeirão Preto (SP): Escola de Enfermagem de Ribeirão Preto - Universidade de São Paulo; 2001.

Wiegand DLM, Deatrick JA, Knafl K. Family Management Styles related to withdrawal of life-sustaining therapy from adults who are acutelly ill or injured. J Fam Nurs. 2008 Feb; 14(1): 16-32.

Williams PD, Williams AR, Graff C, Hanson S, Stanton A, Hafeman C, et al. A community-based intervention for siblings and parents of children with chronic illness or disability: The ISEE Study. J Pediatr. 2003 Sep; 143(3): 386-93.

World Health Organization (WHO/OMS) [homepage on the internet].Disponível em: http://www.who.int/topics/chronic_diseases/en/. Acesso em: 15 de dez. 2009. 
Wrigth LM, Leahey M. Enfermeiras e Famílias: um guia para avaliação e intervenção na família. $4^{a}$ ed. São Paulo: Roca; 2009. 


\section{APÊNDICE A: VERSÃO PORTUGUÊS 1}

\section{INSTRUMENTO DE MEDIDA DE MANEJO FAMILIAR}

Este questionário avalia como a sua família convive com uma criança com doença crônica.

Instruções

Para cada afirmação deste questionário, pedimos que você dê uma nota de 1 a 5 , sendo que 1 significa "discordo totalmente" e 5 indica "concordo totalmente". Por favor responda a estas questões com base no que você pensa, não em como você pensa que os outros poderiam responder. Se seu filho possui mais de uma doença crônica, a palavra "doença" se refere a todos os diagnósticos juntos. Além disso, várias questões utilizam a palavra "família". Ela se refere às pessoas que vivem na mesma casa que você, e que você considera como sendo da família.

\section{SEÇÃO 1 - a ser preenchida por todos na família}

Por favor marque um "x" no quadrado equivalente à sua resposta para cada questão.

\begin{tabular}{|c|c|c|c|c|c|}
\hline & $\begin{array}{l}\text { Discordo } \\
\text { totalmente }\end{array}$ & & & & $\begin{array}{l}\text { Concordo } \\
\text { totalmente }\end{array}$ \\
\hline & 1 & 2 & 3 & 4 & 5 \\
\hline $\begin{array}{l}\text { 1. O dia a dia de nosso filho é } \\
\text { parecido com o de outras } \\
\text { crianças na mesma idade dele. }\end{array}$ & & & & & \\
\hline $\begin{array}{l}\text { 2. A condição do nosso filho } \\
\text { interfere no relacionamento da } \\
\text { família. }\end{array}$ & & & & & \\
\hline $\begin{array}{l}\text { 3. A condição do nosso filho } \\
\text { requer visitas freqüentes ao } \\
\text { médico. }\end{array}$ & & & & & \\
\hline $\begin{array}{l}\text { 4. Esperamos que nosso filho no } \\
\text { futuro seja capaz de cuidar de } \\
\text { sua doença }\end{array}$ & & & & & \\
\hline $\begin{array}{l}\text { 5. Nosso filho aproveita menos a } \\
\text { vida por causa da sua condição. }\end{array}$ & & & & & \\
\hline $\begin{array}{l}\text { 6. Cuidar da doença de nosso } \\
\text { filho é freqüentemente muito } \\
\text { pesado. }\end{array}$ & & & & & \\
\hline $\begin{array}{l}\text { 7. A doença de nosso filho é } \\
\text { como uma montanha-russa, cheia } \\
\text { de altos e baixos. }\end{array}$ & & & & & \\
\hline
\end{tabular}




\begin{tabular}{|c|c|c|c|c|c|}
\hline & $\begin{array}{c}\text { Discordo } \\
\text { totalmente }\end{array}$ & 2 & 3 & 4 & $\begin{array}{c}\text { Concordo } \\
\text { totalmente } \\
5\end{array}$ \\
\hline $\begin{array}{l}\text { 8. A doença de nosso filho é a } \\
\text { coisa mais importante em nossa } \\
\text { família. }\end{array}$ & & & & & \\
\hline $\begin{array}{l}\text { 9. Para nós é muito difícil cuidar } \\
\text { da doença de nosso filho. }\end{array}$ & & & & & \\
\hline $\begin{array}{l}\text { 10. Nosso filho participa de } \\
\text { atividades que deseja apesar da } \\
\text { sua condição. }\end{array}$ & & & & & \\
\hline $\begin{array}{l}\text { 11. Nos preocupamos com o } \\
\text { futuro do nosso filho por causa da } \\
\text { sua condição. }\end{array}$ & & & & & \\
\hline $\begin{array}{l}\text { 12. Os cuidados com a condição } \\
\text { do nosso filho não exigem muito } \\
\text { tempo. }\end{array}$ & & & & & \\
\hline $\begin{array}{l}\text { 13. Temos algumas idéias bem } \\
\text { definidas acerca de como ajudar } \\
\text { nosso filho a conviver com a } \\
\text { doença. }\end{array}$ & & & & & \\
\hline $\begin{array}{l}\text { 14. Apesar da sua condição, } \\
\text { esperamos que, no futuro, nosso } \\
\text { filho possa viver em sua própria } \\
\text { casa. }\end{array}$ & & & & & \\
\hline $\begin{array}{l}\text { 15. Nós temos condição } \\
\text { financeira suficiente para pagar } \\
\text { as despesas da doença do nosso } \\
\text { filho. }\end{array}$ & & & & & \\
\hline $\begin{array}{l}\text { 16. Nosso filho é diferente de } \\
\text { outras crianças da mesma idade } \\
\text { por causa de sua condição. }\end{array}$ & & & & & \\
\hline $\begin{array}{l}\text { 17. } \vec{E} \text { difícil saber quando a } \\
\text { condição de nosso filho deve vir } \\
\text { em primeiro lugar na família. }\end{array}$ & & & & & \\
\hline $\begin{array}{l}\text { 18. Nós esperamos ter um futuro } \\
\text { feliz com nosso filho. }\end{array}$ & & & & & \\
\hline $\begin{array}{l}\text { 19. Quando algo inesperado } \\
\text { acontece na condição de nosso } \\
\text { filho, nós geralmente sabemos } \\
\text { como lidar. }\end{array}$ & & & & & \\
\hline $\begin{array}{l}\text { As amizades do nosso filho são } \\
\text { diferentes por causa da sua } \\
\text { condição. }\end{array}$ & & & & & \\
\hline $\begin{array}{l}\text { 21. No futuro, esperamos dedicar } \\
\text { menos tempo nos cuidados com } \\
\text { a condição de nosso filho. }\end{array}$ & & & & & \\
\hline
\end{tabular}




\begin{tabular}{|c|c|c|c|c|c|}
\hline & $\begin{array}{c}\text { Discordo } \\
\text { totalmente }\end{array}$ & ? & 3 & 1 & \begin{tabular}{|l|}
$\begin{array}{c}\text { Concordo } \\
\text { totalmente }\end{array}$ \\
5
\end{tabular} \\
\hline $\begin{array}{l}\text { 22. Uma condição como a de } \\
\text { nosso filho torna a vida familiar } \\
\text { muito difícil. }\end{array}$ & & & & & \\
\hline $\begin{array}{l}\text { 23. As atividades de nosso filho } \\
\text { raramente interferem nas outras } \\
\text { atividades da família. }\end{array}$ & & & & & \\
\hline $\begin{array}{l}\text { 24. A condição de nosso filho } \\
\text { requer frequentes internações } \\
\text { hospitalares. }\end{array}$ & & & & & \\
\hline $\begin{array}{l}25 . \quad \text { Sentimos que estamos } \\
\text { fazendo um bom trabalho no } \\
\text { cuidado com o nosso filho. }\end{array}$ & & & & & \\
\hline $\begin{array}{l}\text { 26. Pessoas com a condição } \\
\text { como a de nosso filho tem uma } \\
\text { expectativa de vida normal. }\end{array}$ & & & & & \\
\hline $\begin{array}{l}\text { 27. Geralmente é difícil saber se } \\
\text { precisamos ser mais protetores } \\
\text { com nosso filho. }\end{array}$ & & & & & \\
\hline $\begin{array}{l}\text { 28. Geralmente nos sentimos } \\
\text { inseguros em relação ao que } \\
\text { fazer para cuidar da condição de } \\
\text { nosso filho. }\end{array}$ & & & & & \\
\hline $\begin{array}{l}\text { 29. No futuro, será mais difícil de } \\
\text { cuidar da condição do nosso } \\
\text { filho. }\end{array}$ & & & & & \\
\hline $\begin{array}{l}\text { 30. Nós pensamos sobre a } \\
\text { condição do nosso filho o tempo } \\
\text { todo. }\end{array}$ & & & & & \\
\hline $\begin{array}{l}\text { 31. Parece que a condição de } \\
\text { nosso filho controla a vida da } \\
\text { nossa família. }\end{array}$ & & & & & \\
\hline $\begin{array}{l}32 \text { Outras crianças têm } \\
\text { condições piores do que a do } \\
\text { nosso filho. }\end{array}$ & & & & & \\
\hline $\begin{array}{l}\text { 33. É difícil conseguir ajuda de } \\
\text { outras pessoas para cuidar da } \\
\text { condição do nosso filho. }\end{array}$ & & & & & \\
\hline $\begin{array}{l}34 . \quad \text { Nós não estamos } \\
\text { conseguindo criar uma rotina } \\
\text { para cuidar da condição do nosso } \\
\text { filho. }\end{array}$ & & & & & \\
\hline $\begin{array}{l}35 . \quad \hat{E} \text { necessário muita } \\
\text { organização para lidar com a } \\
\text { condição de nosso filho. }\end{array}$ & & & & & \\
\hline $\begin{array}{l}\text { 36. Às vezes somos indecisos de } \\
\text { como equilibrar a vida da família } \\
\text { com a condição do nosso filho. }\end{array}$ & & & & & \\
\hline
\end{tabular}




\begin{tabular}{|c|c|c|c|c|c|}
\hline & $\begin{array}{c}\begin{array}{c}\text { Discordo } \\
\text { totalmente }\end{array} \\
1\end{array}$ & 2 & 3 & 4 & $\begin{array}{l}\text { Concordo } \\
\text { totalmente }\end{array}$ \\
\hline \multicolumn{6}{|l|}{$\begin{array}{l}\text { 37. É difícil saber o que esperar } \\
\text { da condição de nosso filho no } \\
\text { futuro. }\end{array}$} \\
\hline \multicolumn{6}{|l|}{$\begin{array}{l}\text { 38. Mesmo com a condição de } \\
\text { nosso filho, nós temos uma vida } \\
\text { familiar normal. }\end{array}$} \\
\hline \multicolumn{6}{|l|}{$\begin{array}{l}\text { 39. Nosso filho teria um melhor } \\
\text { desempenho na escola se não } \\
\text { tivesse esta condição. }\end{array}$} \\
\hline \multicolumn{6}{|l|}{$\begin{array}{l}\text { 40. Temos confiança de que } \\
\text { podemos cuidar da condição de } \\
\text { nosso filho. }\end{array}$} \\
\hline \multicolumn{6}{|l|}{$\begin{array}{l}\text { 41. Nós temos objetivos que nos } \\
\text { ajudam a cuidar da condição do } \\
\text { nosso filho. }\end{array}$} \\
\hline \multicolumn{6}{|l|}{$\begin{array}{l}\text { 42. É difícil adequar a atividade } \\
\text { de cuidar da condição de nosso } \\
\text { filho na nossa rotina familiar. }\end{array}$} \\
\hline \multicolumn{6}{|l|}{$\begin{array}{l}\text { 43. Lidar com a condição de } \\
\text { nosso filho torna a vida familiar } \\
\text { mais difícil. }\end{array}$} \\
\hline \multicolumn{6}{|l|}{$\begin{array}{l}\text { 44. Nós sabemos quando nosso } \\
\text { filho precisa ser criança. }\end{array}$} \\
\hline $\begin{array}{l}\text { 45. É difícil manter uma vida } \\
\text { normal com a condição que } \\
\text { nosso filho tem. }\end{array}$ & & & & & \\
\hline
\end{tabular}

Isto encerra a seção 1.

A Seção 2 aborda aspectos do manejo familiar quando existem parceiros adultos na mesma casa. O termo "parceiros" se refere ao cônjuge ou companheiro que vive na mesma casa.

Se você atualmente mora com um parceiro, por favor continue com o questionário na próxima página. Caso contrário, por favor pare por aqui. 


\section{SEÇÃO 2}

As questões nesta próxima seção referem-se a você e seu parceiro. Para cada afirmação deste questionário, pedimos que você dê uma nota de 1 a 5 , sendo que 1 significa "discordo totalmente" e 5 indica "concordo totalmente".

Novamente, por favor, responda a estas questões com base no que você pensa, não em como você pensa que seu parceiro ou os outros poderiam responder.

\begin{tabular}{|c|c|c|c|c|c|}
\hline \multirow{3}{*}{$\begin{array}{l}\text { 46. Nossa família é mais unida } \\
\text { pela maneira como lidamos com a } \\
\text { condição de nosso filho. }\end{array}$} & \multirow{2}{*}{$\begin{array}{c}\begin{array}{c}\text { Discordo } \\
\text { totalmente }\end{array} \\
1 \\
\end{array}$} & \multirow[b]{2}{*}{2} & \multirow[b]{2}{*}{3} & \multirow[b]{2}{*}{4} & \multirow{2}{*}{$\begin{array}{c}\begin{array}{c}\text { Concordo } \\
\text { totalmente }\end{array} \\
5\end{array}$} \\
\hline & & & & & \\
\hline & & & & & \\
\hline $\begin{array}{l}\text { 47. Meu companheiro(a) e eu } \\
\text { temos idéias diferentes sobre a } \\
\text { gravidade da condição de nosso } \\
\text { filho. }\end{array}$ & & & & & \\
\hline $\begin{array}{l}\text { 48. Estou satisfeito com a } \\
\text { maneira como eu e meu } \\
\text { companheiro(a) cuidamos juntos } \\
\text { da condição de nosso filho. }\end{array}$ & & & & & \\
\hline $\begin{array}{l}\text { 49. Eu e meu companheiro(a) } \\
\text { discutimos sobre como lidar com } \\
\text { a condição do nosso filho. }\end{array}$ & & & & & \\
\hline $\begin{array}{l}\text { 50. Eu e meu companheiro(a) } \\
\text { sempre conversamos antes de } \\
\text { tomar qualquer decisão sobre os } \\
\text { cuidados com nosso filho. }\end{array}$ & & & & & \\
\hline $\begin{array}{l}\text { 51. Eu e meu companheiro(a) } \\
\text { temos idéias semelhantes sobre } \\
\text { como devemos criar o nosso filho. }\end{array}$ & & & & & \\
\hline $\begin{array}{l}\text { 52. Estou insatisfeito(a) com a } \\
\text { forma como eu e meu } \\
\text { companheiro(a) compartilhamos } \\
\text { os cuidados com a condição do } \\
\text { nosso filho. }\end{array}$ & & & & & \\
\hline $\begin{array}{l}\text { 53. Eu e meu companheiro(a) } \\
\text { ajudamos um ao outro nos } \\
\text { cuidados com a condição do } \\
\text { nosso filho. }\end{array}$ & & & & & \\
\hline
\end{tabular}




\title{
APÊNDICE B - ORIENTAÇÕES ENVIADAS AO COMITÊ DE ESPECIALISTAS E INSTRUMENTO DE AVALIAÇÃO DOS ESPECIALISTAS
}

\author{
Instrumento para avaliação das equivalências entre as versões original e \\ traduzida do Family Management Measure (FaMM)
}

Prezada Dra.

Considerando o seu amplo conhecimento na área de validação de instrumentos, vimos convidá-la a participar no julgamento da tradução do instrumento Family Management Measure que esta sendo utilizado no projeto de pesquisa denominado:

\section{Adaptação Cultural do Family Management Measure para famílias de crianças portadoras de doenças crônicas.}

Este projeto está sendo desenvolvido junto ao Programa de Pós-Graduação em Enfermagem - Nível Mestrado, da Escola de Enfermagem da Universidade de São Paulo e tem por objetivo realizar a adaptação cultural do referido instrumento para a língua portuguesa do Brasil, avaliando suas propriedades psicométricas através da consistência interna dos itens e da validação.

O instrumento é original dos Estados Unidos, de autoria de Kathleen Knafl; Janet Deatrick; Agatha Gallo; Jane Dixon e Margaret Grey e possui em sua versão original 53 itens com a finalidade de avaliar o manejo de famílias de crianças portadoras de doenças crônicas.

Uma vez que não há nenhum instrumento, validado em nossa língua, justifica-se a relevância do estudo, e utiliza-se do percurso metodológico preconizado pela literatura contemporânea; para isso adotamos as etapas propostas por Guillemin $(1993,2002)$ que compreendem:

1. Tradução para língua portuguesa do Family Management Measure - já realizado

2. Primeiro consenso da versão traduzida - já realizado

3. Avaliação pelo Comitê de Especialistas - aguardando a sua participação

4. Retrotradução

5. Obtenção do consenso das versões em inglês

6. Avaliação semântica dos itens

7. Pré-teste

8. Análise das propriedades de medida 
Considerando seu conhecimento, experiência e atuação na temática deste estudo, habilidade no reconhecimento de expressões na língua inglesa e desenvoltura com a língua portuguesa, gostaríamos de contar com a sua inestimável colaboração neste estudo procedendo à análise da tradução do Family Management Measure para língua portuguesa do Brasil, avaliando as equivalências: conceitual, de itens, semântica/idiomática e operacional, bem como sua validade de conteúdo.

A seguir encontram-se as instruções para auxiliá-la nas etapas da avaliação.

Agradecemos antecipadamente pela atenção e colocamo-nos à disposição para quaisquer esclarecimentos que se façam necessários.

Atenciosamente,

Carolliny Rossi de Faria Ichikawa

Orientanda do PPGE -EEUSP
Regina Szylit Bousso

Orientadora do PPGE -EEUSP 


\section{Instruções para avaliação das equivalências entre as versões original e traduzida do Family Management Measure (FaMM)}

O instrumento original possui 53 itens distribuídos em 6 dimensões: 5 para serem respondidas pelo pai ou pela mãe da criança, medindo as dimensões: Identidade da criança, Habilidade de manejo, Esforço de manejo, Dificuldade familiar e Visão do impacto da condição da criança e uma sexta escala que deve ser aplicada apenas quando ambos os pais residem junto com a criança, medindo a mutualidade entre os pais.

Para realizar o processo de avaliação das equivalências entre as versões original e traduzida do Family Management Measure, solicitamos que considere as orientações que seguem:

Como juiz, sua opinião em concordância ou não com a afirmativa proposta deve ser imparcial, e a realização do seu procedimento de avaliação, deve considerar os seguintes critérios:

a) Equivalência conceitual: refere-se à equivalência do conceito na cultura original em comparação à cultura-alvo.

b) Equivalência de itens: indica se os itens que compõem a escala estimam os mesmos domínios e se são relevantes nas duas culturas.

c) Equivalência semântica/idiomática: consiste na tradução do instrumento original não só conservando o significado das palavras entre dois idiomas diferentes, como também buscando atingir o mesmo efeito em culturas distintas.

d) Equivalência operacional: visa manter as características operacionais do universo original, por intermédio de medidas empregadas antes e durante a aplicação da escala, tais como: mesmo número de questões; mesmas opções de respostas ordinais utilizadas no instrumento original; mesmo tempo de aplicação quando usado no país de origem; treinamento dos aplicadores, se necessário; elaboração de um instrumento para orientar o preenchimento do instrumento pelos sujeitos.

e) A validade de Conteúdo refere-se ao grau em que o conteúdo ou os domínios de um instrumento de mensuração são relevantes e representativos do construto-alvo.

Todos os itens do instrumento deverão ser avaliados separadamente, de acordo com as cinco propriedades, marque com um $\underline{X}$ no espaço correspondente, seguindo 0 seguinte critério:

-1 = não equivalente (não concorda com a tradução)

$0=$ indeciso

$+1=$ equivalente (concorda com a tradução) 
Quando forem atribuídos os conceitos $\underline{-1}$ ou $\underline{0}$, por favor, faça seu comentário e sugestões nas linhas disponíveis abaixo de cada item do instrumento.

Com o intuito de subsidiar o processo de avaliação, seguem em anexo:

- Instrumento original

- Instrumento traduzido

- Instrumento de avaliação da tradução

Todo o processo de avaliação será realizado via Internet pelos e-mails: caroll@usp.br e szylit@usp.br. Solicitamos a sua confirmação e disponibilidade em participar como juíza nesta fase do estudo, considerando que sua avaliação deve ser devolvida até dia 20/12/2010. Caso você queira participar, mas precise de um período maior por favor, entre em contato. 
Instrumento para Avaliação pelo Comitê de Juízes

\begin{tabular}{|c|c|c|c|c|c|c|c|c|c|c|c|c|c|c|c|c|}
\hline \multirow{2}{*}{$\begin{array}{l}\text { Frase original } \\
\text { Tradução }\end{array}$} & \multirow{2}{*}{$\begin{array}{l}\text { Family Management Measure } \\
\text { Instrumento de medida de manejo } \\
\text { familiar }\end{array}$} & \multicolumn{3}{|c|}{$\begin{array}{l}\text { Equivalência } \\
\text { Conceitual }\end{array}$} & \multicolumn{3}{|c|}{$\begin{array}{l}\text { Equivalência } \\
\text { De itens }\end{array}$} & \multicolumn{3}{|c|}{$\begin{array}{l}\text { Equivalência } \\
\text { Semântica/ } \\
\text { idiomática }\end{array}$} & \multicolumn{3}{|c|}{$\begin{array}{l}\text { Equivalência } \\
\text { Operacional }\end{array}$} & \multicolumn{3}{|c|}{$\begin{array}{l}\text { Validade de } \\
\text { Conteúdo }\end{array}$} \\
\hline & & -1 & 0 & +1 & -1 & 0 & +1 & -1 & 0 & +1 & -1 & 0 & +1 & -1 & $\mathbf{0}$ & +1 \\
\hline Sugestões & & & & & & & & & & & & & & & & \\
\hline
\end{tabular}

This questionnaire is about how your family manages caring for a child with a chronic condition.

For each statement in this questionnaire, you are asked to rate your response to the statement on a scale of 1 to 5 , with 1 indicating "Strongly disagree" and 5 indicating "Strongly agree". Please respond to each statement in this questionnaire based on what you think, not on how you think others might respond. If you child has more than one chronic condition the word "condition" refers to all of their diagnoses together. Also, many of these questions use the word "family". This refers to those people living in your household that you think of as family.

Section 1: to be completed by everyone.

Please check the boxes with your answers.

Este questionário avalia como a sua família convive com uma criança com doença crônica.

Para cada afirmação deste questionário, pedimos que você dê uma nota de 1 a 5 , sendo que 1 significa "discordo totalmente" e 5 indica "concordo totalmente". Por favor responda a estas questões com base no que você pensa, não em como você pensa que os outros poderiam responder. Se seu filho possui mais de uma doença crônica, a palavra "doença" se refere a todos os diagnósticos juntos. Além disso, várias questões utilizam a palavra "família". Ela se refere às pessoas que vivem na mesma casa que você, e que você considera como sendo da família.

SEÇÃO 1 - a ser preenchida por todos na família

Por favor marque um " $x$ " no quadrado equivalente à sua resposta para cada questão. 


\begin{tabular}{|c|c|c|c|c|c|c|c|c|c|c|c|c|c|c|c|c|}
\hline & & \multicolumn{3}{|c|}{$\begin{array}{l}\text { Equivalência } \\
\text { Conceitual }\end{array}$} & \multicolumn{3}{|c|}{$\begin{array}{l}\text { Equivalência } \\
\text { De itens }\end{array}$} & \multicolumn{3}{|c|}{$\begin{array}{l}\text { Equivalência } \\
\text { Semântica/ } \\
\text { idiomática }\end{array}$} & \multicolumn{3}{|c|}{$\begin{array}{l}\text { Equivalência } \\
\text { Operacional }\end{array}$} & \multicolumn{3}{|c|}{$\begin{array}{l}\text { Validade de } \\
\text { Conteúdo }\end{array}$} \\
\hline \multicolumn{2}{|c|}{$\begin{array}{l}\text { Orientações para o preenchimento } \\
\text { do instrumento }\end{array}$} & -1 & $\mathbf{0}$ & +1 & -1 & 0 & +1 & -1 & $\mathbf{0}$ & +1 & -1 & $\mathbf{0}$ & +1 & -1 & $\mathbf{0}$ & +1 \\
\hline \multicolumn{17}{|l|}{ Sugestões } \\
\hline Frase original & Strongly disagree & \multirow[b]{2}{*}{-1} & \multirow[b]{2}{*}{0} & \multirow[b]{2}{*}{+1} & \multirow[b]{2}{*}{-1} & \multirow[b]{2}{*}{$\mathbf{0}$} & \multirow[b]{2}{*}{+1} & \multirow[b]{2}{*}{-1} & \multirow[b]{2}{*}{0} & \multirow[b]{2}{*}{+1} & \multirow[b]{2}{*}{-1} & \multirow[b]{2}{*}{0} & \multirow[b]{2}{*}{+1} & \multirow[b]{2}{*}{-1} & \multirow[b]{2}{*}{0} & \multirow[b]{2}{*}{+1} \\
\hline Tradução & Discordo totalmente & & & & & & & & & & & & & & & \\
\hline \multicolumn{17}{|l|}{ Sugestões } \\
\hline Frase original & Strongly agree & \multirow[b]{2}{*}{-1} & \multirow[b]{2}{*}{0} & \multirow[b]{2}{*}{+1} & \multirow[b]{2}{*}{-1} & \multirow[b]{2}{*}{0} & \multirow[b]{2}{*}{+1} & \multirow[b]{2}{*}{-1} & \multirow[b]{2}{*}{0} & \multirow[b]{2}{*}{+1} & \multirow[b]{2}{*}{-1} & \multirow[b]{2}{*}{0} & \multirow[b]{2}{*}{+1} & \multirow[b]{2}{*}{-1} & & \\
\hline Tradução & Concordo totalmente & & & & & & & & & & & & & & 0 & +1 \\
\hline
\end{tabular}

\begin{tabular}{|c|c|c|c|c|c|c|c|c|c|c|c|c|c|c|c|c|}
\hline \multirow[b]{2}{*}{ Frase original } & \multirow[b]{2}{*}{$\begin{array}{l}\text { 1. Our child's everyday life is } \\
\text { similar to that of other children } \\
\text { his/her age. }\end{array}$} & \multicolumn{3}{|c|}{$\begin{array}{l}\text { Equivalência } \\
\text { Conceitual }\end{array}$} & \multicolumn{3}{|c|}{$\begin{array}{l}\text { Equivalência } \\
\text { De itens }\end{array}$} & \multicolumn{3}{|c|}{$\begin{array}{l}\text { Equivalência } \\
\text { Semântica/ } \\
\text { idiomática }\end{array}$} & \multicolumn{3}{|c|}{$\begin{array}{l}\text { Equivalência } \\
\text { Operacional }\end{array}$} & \multicolumn{3}{|c|}{$\begin{array}{l}\text { Validade de } \\
\text { Conteúdo }\end{array}$} \\
\hline & & \multirow[t]{2}{*}{-1} & \multirow[t]{2}{*}{0} & \multirow[t]{2}{*}{+1} & \multirow[t]{2}{*}{-1} & \multirow[t]{2}{*}{0} & \multirow[t]{2}{*}{+1} & \multirow[t]{2}{*}{$\mid-1$} & \multirow[t]{2}{*}{0} & \multirow[t]{2}{*}{+1} & \multirow[t]{2}{*}{-1} & \multirow[t]{2}{*}{0} & \multirow[t]{2}{*}{+1} & \multirow[t]{2}{*}{-1} & \multirow[t]{2}{*}{0} & \multirow[t]{2}{*}{+1} \\
\hline Tradução & $\begin{array}{l}\text { 1. O dia a dia de nosso filho é } \\
\text { parecido com o de outras crianças na } \\
\text { mesma idade dele. }\end{array}$ & & & & & & & & & & & & & & & \\
\hline \multicolumn{17}{|l|}{ Sugestões } \\
\hline Frase original & $\begin{array}{l}\text { 2. Our child's condition gets in } \\
\text { the way of family relationships. }\end{array}$ & \multirow[t]{2}{*}{-1} & \multirow[t]{2}{*}{0} & \multirow[t]{2}{*}{+1} & \multirow[t]{2}{*}{-1} & \multirow[t]{2}{*}{0} & \multirow[t]{2}{*}{+1} & \multirow[t]{2}{*}{-1} & \multirow[t]{2}{*}{0} & \multirow[t]{2}{*}{+1} & \multirow[t]{2}{*}{-1} & \multirow[t]{2}{*}{0} & \multirow[t]{2}{*}{+1} & \multirow[t]{2}{*}{-1} & \multirow[t]{2}{*}{0} & +1 \\
\hline Tradução & $\begin{array}{l}\text { 2. A condição de nosso filho interfere } \\
\text { no relacionamento da família. }\end{array}$ & & & & & & & & & & & & & & & \\
\hline Sugestões & & & & & & & & & & & & & & & & \\
\hline
\end{tabular}




\begin{tabular}{|c|c|c|c|c|c|c|c|c|c|c|c|c|c|c|c|c|}
\hline \multirow{2}{*}{$\begin{array}{l}\text { Frase original } \\
\text { Tradução }\end{array}$} & $\begin{array}{l}\text { 3. Our child's condition requires } \\
\text { frequent visits to the clinic. }\end{array}$ & \multirow[t]{2}{*}{-1} & \multirow[t]{2}{*}{0} & \multirow[t]{2}{*}{+1} & \multirow[t]{2}{*}{-1} & \multirow[t]{2}{*}{0} & \multirow[t]{2}{*}{+1} & \multirow[t]{2}{*}{-1} & \multirow[t]{2}{*}{0} & \multirow[t]{2}{*}{+1} & \multirow[t]{2}{*}{-1} & \multirow[t]{2}{*}{0} & \multirow[t]{2}{*}{+1} & \multirow[t]{2}{*}{-1} & \multirow[t]{2}{*}{0} & \multirow[t]{2}{*}{+1} \\
\hline & $\begin{array}{l}\text { 3. A condição do nosso filho requer } \\
\text { visitas freqüentes ao médico. }\end{array}$ & & & & & & & & & & & & & & & \\
\hline \multicolumn{17}{|l|}{ Sugestões } \\
\hline Frase original & $\begin{array}{l}\text { 4. In the future we expect our } \\
\text { child to take care of the } \\
\text { condition. }\end{array}$ & \multirow[t]{2}{*}{-1} & \multirow[t]{2}{*}{0} & \multirow[t]{2}{*}{+1} & \multirow[t]{2}{*}{-1} & \multirow[t]{2}{*}{0} & \multirow[t]{2}{*}{+1} & \multirow[t]{2}{*}{-1} & \multirow[t]{2}{*}{$\mathbf{0}$} & \multirow[t]{2}{*}{+1} & \multirow[t]{2}{*}{-1} & \multirow[t]{2}{*}{0} & \multirow[t]{2}{*}{+1} & \multirow[t]{2}{*}{-1} & \multirow[t]{2}{*}{0} & \multirow[t]{2}{*}{+1} \\
\hline Tradução & $\begin{array}{l}\text { 4. Esperamos que nosso filho no } \\
\text { futuro seja capaz de cuidar de sua } \\
\text { doença. }\end{array}$ & & & & & & & & & & & & & & & \\
\hline \multicolumn{17}{|l|}{ Sugestões } \\
\hline Frase original & $\begin{array}{l}\text { 5. Our child enjoys life less } \\
\text { because of the condition. }\end{array}$ & -1 & 0 & +1 & -1 & 0 & +1 & -1 & 0 & +1 & -1 & 0 & +1 & -1 & $\mathbf{0}$ & +1 \\
\hline Tradução & $\begin{array}{l}\text { 5. Nosso filho aproveita menos a vida } \\
\text { por causa da sua condição. }\end{array}$ & & & & & & & & & & & & & & & \\
\hline Sugestões & & & & & & & & & & & & & & & & \\
\hline Frase original & $\begin{array}{l}\text { 6. Taking care of our child's } \\
\text { condition is often overwhelming. }\end{array}$ & -1 & 0 & +1 & -1 & 0 & +1 & -1 & 0 & +1 & -1 & 0 & +1 & -1 & 0 & +1 \\
\hline Tradução & $\begin{array}{l}\text { 6. Cuidar da doença de nosso filho é } \\
\text { freqüentemente muito pesado. }\end{array}$ & & & & & & & & & & & & & & & \\
\hline Sugestões & & & & & & & & & & & & & & & & \\
\hline Frase original & $\begin{array}{l}\text { 7. Our child's condition is like a } \\
\text { roller coaster with lots of ups } \\
\text { and downs. }\end{array}$ & -1 & 0 & +1 & -1 & 0 & +1 & -1 & 0 & +1 & -1 & 0 & +1 & -1 & 0 & +1 \\
\hline Tradução & $\begin{array}{l}\text { 7. A doença de nosso filho é como } \\
\text { uma montanha-russa, cheia de altos } \\
\text { e baixos. }\end{array}$ & & & & & & & & & & & & & & & \\
\hline Sugestões & & & & & & & & & & & & & & & & \\
\hline
\end{tabular}




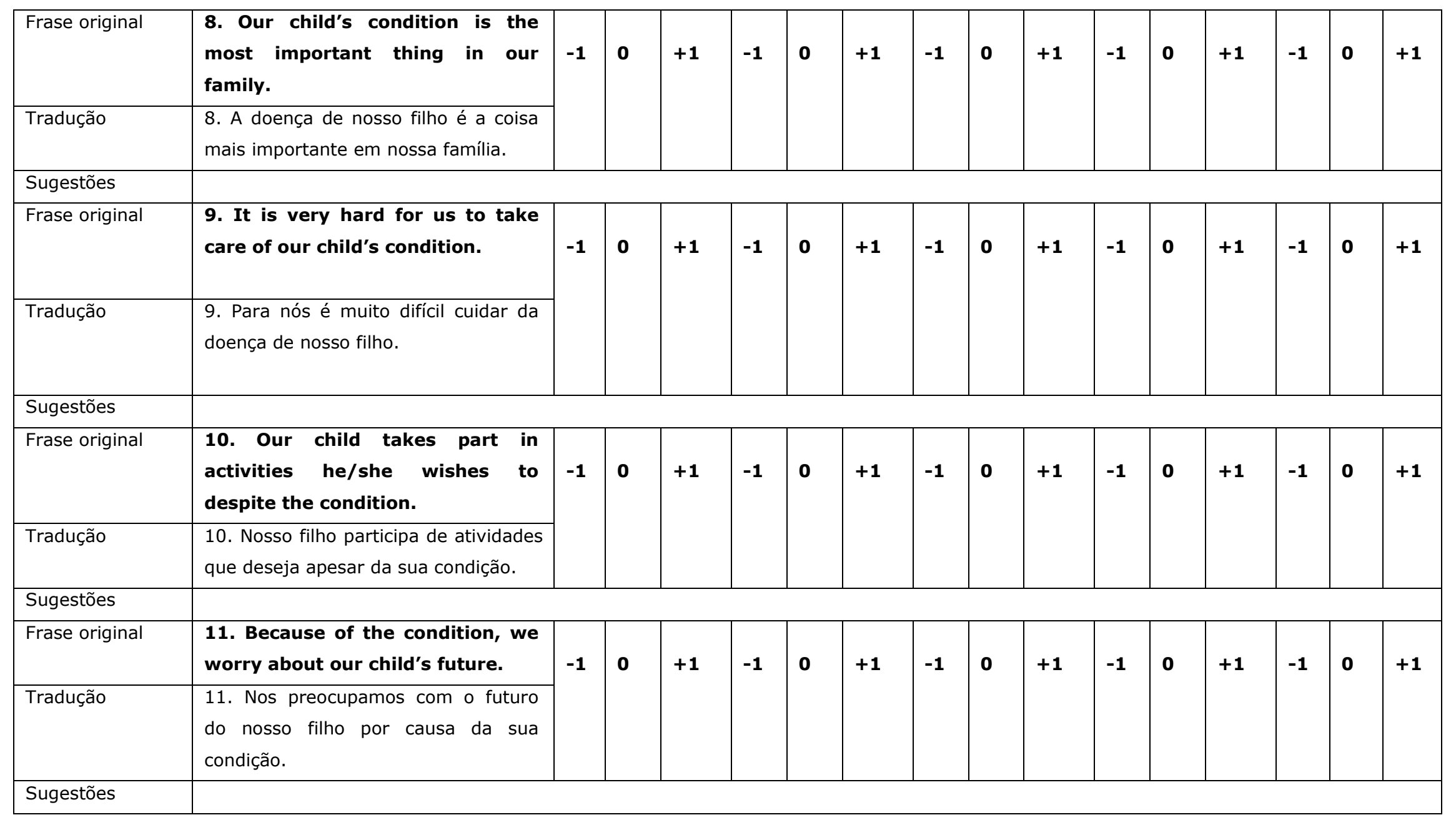




\begin{tabular}{|c|c|c|c|c|c|c|c|c|c|c|c|c|c|c|c|c|}
\hline Frase original & $\begin{array}{l}\text { 12. Our child's condition doesn't } \\
\text { take a great deal of time to } \\
\text { manage. }\end{array}$ & \multirow[t]{2}{*}{-1} & \multirow[t]{2}{*}{0} & \multirow[t]{2}{*}{+1} & \multirow[t]{2}{*}{-1} & \multirow[t]{2}{*}{0} & \multirow[t]{2}{*}{+1} & \multirow[t]{2}{*}{-1} & \multirow[t]{2}{*}{0} & \multirow[t]{2}{*}{+1} & \multirow[t]{2}{*}{-1} & \multirow[t]{2}{*}{0} & \multirow[t]{2}{*}{+1} & \multirow[t]{2}{*}{$|-1|$} & \multirow[t]{2}{*}{0} & \multirow[t]{2}{*}{+1} \\
\hline Tradução & $\begin{array}{l}\text { 12. Os cuidados com a condição do } \\
\text { nosso filho não requer muito tempo. }\end{array}$ & & & & & & & & & & & & & & & \\
\hline \multicolumn{17}{|l|}{ Sugestões } \\
\hline Frase original & $\begin{array}{l}\text { 13. We have some definite ideas } \\
\text { about how to help our child live } \\
\text { with the condition. }\end{array}$ & \multirow[t]{2}{*}{-1} & \multirow[t]{2}{*}{0} & \multirow[t]{2}{*}{+1} & \multirow[t]{2}{*}{-1} & \multirow[t]{2}{*}{0} & \multirow[t]{2}{*}{+1} & \multirow[t]{2}{*}{-1} & \multirow[t]{2}{*}{0} & \multirow[t]{2}{*}{+1} & \multirow[t]{2}{*}{$|-1|$} & \multirow[t]{2}{*}{0} & \multirow[t]{2}{*}{+1} & \multirow[t]{2}{*}{-1} & \multirow[t]{2}{*}{0} & \multirow[t]{2}{*}{+1} \\
\hline Tradução & $\begin{array}{l}\text { 13. Temos algumas idéias bem } \\
\text { definidas acerca de como ajudar } \\
\text { nosso filho a conviver com a doença. }\end{array}$ & & & & & & & & & & & & & & & \\
\hline \multicolumn{17}{|l|}{ Sugestões } \\
\hline Frase original & $\begin{array}{l}\text { 14. Despite the condition, we } \\
\text { expect our child to live away from } \\
\text { home in the future. }\end{array}$ & \multirow[t]{2}{*}{-1} & \multirow[t]{2}{*}{0} & \multirow[t]{2}{*}{+1} & $\mid-1$ & 0 & +1 & -1 & 0 & +1 & -1 & 0 & +1 & -1 & 0 & +1 \\
\hline Tradução & $\begin{array}{l}\text { 14. Apesar da sua condição, } \\
\text { esperamos que, no futuro, nosso filho } \\
\text { possa viver em sua própria casa. }\end{array}$ & & & & & & & & & & & & & & & \\
\hline Sugestões & & & & & & & & & & & & & & & & \\
\hline Frase original & $\begin{array}{l}\text { 15. We have enough money to } \\
\text { manage our child's condition. }\end{array}$ & -1 & 0 & +1 & -1 & 0 & +1 & -1 & 0 & +1 & $\mid-1$ & 0 & +1 & $\mid-1$ & 0 & +1 \\
\hline Tradução & $\begin{array}{l}\text { 15. Nós temos condição financeira } \\
\text { suficiente para pagar as despesas da } \\
\text { doença do nosso filho. }\end{array}$ & & & & & & & & & & & & & & & \\
\hline Sugestões & & & & & & & & & & & & & & & & \\
\hline
\end{tabular}




\begin{tabular}{|c|c|c|c|c|c|c|c|c|c|c|c|c|c|c|c|c|}
\hline Frase original & $\begin{array}{l}\text { 16. Our child is different from } \\
\text { other children his/her age } \\
\text { because of the condition. }\end{array}$ & \multirow[t]{2}{*}{-1} & \multirow[t]{2}{*}{0} & \multirow[t]{2}{*}{+1} & \multirow[t]{2}{*}{-1} & \multirow[t]{2}{*}{0} & \multirow[t]{2}{*}{+1} & \multirow[t]{2}{*}{-1} & \multirow[t]{2}{*}{0} & \multirow[t]{2}{*}{+1} & \multirow[t]{2}{*}{-1} & \multirow[t]{2}{*}{0} & \multirow[t]{2}{*}{+1} & \multirow[t]{2}{*}{-1} & \multirow[t]{2}{*}{$\mathbf{0}$} & \multirow[t]{2}{*}{+1} \\
\hline Tradução & $\begin{array}{l}\text { 16. Nosso filho é diferente de outras } \\
\text { crianças da mesma idade por causa } \\
\text { de sua condição. }\end{array}$ & & & & & & & & & & & & & & & \\
\hline \multicolumn{17}{|l|}{ Sugestões } \\
\hline Frase original & $\begin{array}{l}\text { 17. It is difficult to know when } \\
\text { our child's condition must come } \\
\text { first in the family. }\end{array}$ & \multirow[t]{2}{*}{-1} & \multirow[t]{2}{*}{0} & \multirow[t]{2}{*}{+1} & \multirow[t]{2}{*}{-1} & \multirow[t]{2}{*}{0} & \multirow[t]{2}{*}{+1} & \multirow[t]{2}{*}{-1} & \multirow[t]{2}{*}{0} & \multirow[t]{2}{*}{+1} & \multirow[t]{2}{*}{-1} & \multirow[t]{2}{*}{0} & \multirow[t]{2}{*}{+1} & \multirow[t]{2}{*}{-1} & \multirow[t]{2}{*}{0} & \multirow[t]{2}{*}{+1} \\
\hline Tradução & $\begin{array}{l}\text { 17. É difícil saber quando a condição } \\
\text { do nosso filho deve vir em primeiro } \\
\text { lugar na família. }\end{array}$ & & & & & & & & & & & & & & & \\
\hline \multicolumn{17}{|l|}{ Sugestões } \\
\hline Frase original & $\begin{array}{l}\text { 18. We are looking forward to a } \\
\text { happy future with our child. }\end{array}$ & \multirow[t]{2}{*}{-1} & \multirow[t]{2}{*}{0} & \multirow[t]{2}{*}{+1} & -1 & 0 & +1 & -1 & 0 & +1 & -1 & 0 & +1 & -1 & 0 & +1 \\
\hline Tradução & $\begin{array}{l}\text { 18. Nós esperamos ter um futuro feliz } \\
\text { com nosso filho. }\end{array}$ & & & & & & & & & & & & & & & \\
\hline Sugestões & & & & & & & & & & & & & & & & \\
\hline Frase original & $\begin{array}{l}\text { 19. When something unexpected } \\
\text { happens with our child's } \\
\text { condition, we usually know how } \\
\text { to handle it. }\end{array}$ & -1 & $\mathbf{0}$ & +1 & -1 & 0 & +1 & -1 & 0 & +1 & -1 & 0 & +1 & -1 & 0 & +1 \\
\hline Tradução & $\begin{array}{l}\text { 19. Quando algo inesperado acontece } \\
\text { na condição de nosso filho, nós } \\
\text { geralmente sabemos como lidar. }\end{array}$ & & & & & & & & & & & & & & & \\
\hline Sugestões & & & & & & & & & & & & & & & & \\
\hline
\end{tabular}




\begin{tabular}{|c|c|c|c|c|c|c|c|c|c|c|c|c|c|c|c|c|}
\hline Frase original & $\begin{array}{l}\text { 20. Our child's friendships are } \\
\text { different because of the } \\
\text { condition. }\end{array}$ & \multirow[t]{2}{*}{-1} & \multirow[t]{2}{*}{0} & \multirow[t]{2}{*}{+1} & \multirow[t]{2}{*}{-1} & \multirow[t]{2}{*}{0} & \multirow[t]{2}{*}{+1} & \multirow[t]{2}{*}{-1} & \multirow[t]{2}{*}{0} & \multirow[t]{2}{*}{+1} & \multirow[t]{2}{*}{-1} & \multirow[t]{2}{*}{0} & \multirow[t]{2}{*}{+1} & \multirow[t]{2}{*}{-1} & \multirow[t]{2}{*}{0} & \multirow[t]{2}{*}{+1} \\
\hline Tradução & $\begin{array}{l}\text { 20. As amizades de nosso filho são } \\
\text { diferentes por causa da sua condição. }\end{array}$ & & & & & & & & & & & & & & & \\
\hline \multicolumn{17}{|l|}{ Sugestões } \\
\hline Frase original & $\begin{array}{l}\text { 21. We expect to be devoting less } \\
\text { time to our child's condition in the } \\
\text { future. }\end{array}$ & $\mid-1$ & 0 & +1 & -1 & 0 & +1 & -1 & 0 & +1 & -1 & 0 & +1 & -1 & 0 & +1 \\
\hline Tradução & $\begin{array}{l}\text { 21. No futuro, esperamos dedicar } \\
\text { menos tempo nos cuidados com a } \\
\text { condição de nosso filho. }\end{array}$ & & & & & & & & & & & & & & & \\
\hline \multicolumn{17}{|l|}{ Sugestões } \\
\hline Frase original & $\begin{array}{l}\text { 22. A condition like the one our } \\
\text { child has makes family life very } \\
\text { difficult. }\end{array}$ & -1 & 0 & +1 & -1 & 0 & +1 & -1 & 0 & +1 & -1 & 0 & +1 & -1 & 0 & +1 \\
\hline Tradução & $\begin{array}{l}\text { 22. Uma condição como a de nosso } \\
\text { filho torna a vida familiar muito difícil. }\end{array}$ & & & & & & & & & & & & & & & \\
\hline \multicolumn{17}{|l|}{ Sugestões } \\
\hline Frase original & $\begin{array}{l}\text { 23. Our child's condition rarely } \\
\text { interferes with other family } \\
\text { activities. }\end{array}$ & -1 & 0 & +1 & -1 & 0 & +1 & -1 & 0 & +1 & -1 & 0 & +1 & $\mid-1$ & 0 & +1 \\
\hline Tradução & $\begin{array}{l}\text { 23. As atividades de nosso filho } \\
\text { raramente interferem nas outras } \\
\text { atividades da família. }\end{array}$ & & & & & & & & & & & & & & & \\
\hline Sugestões & & & & & & & & & & & & & & & & \\
\hline
\end{tabular}




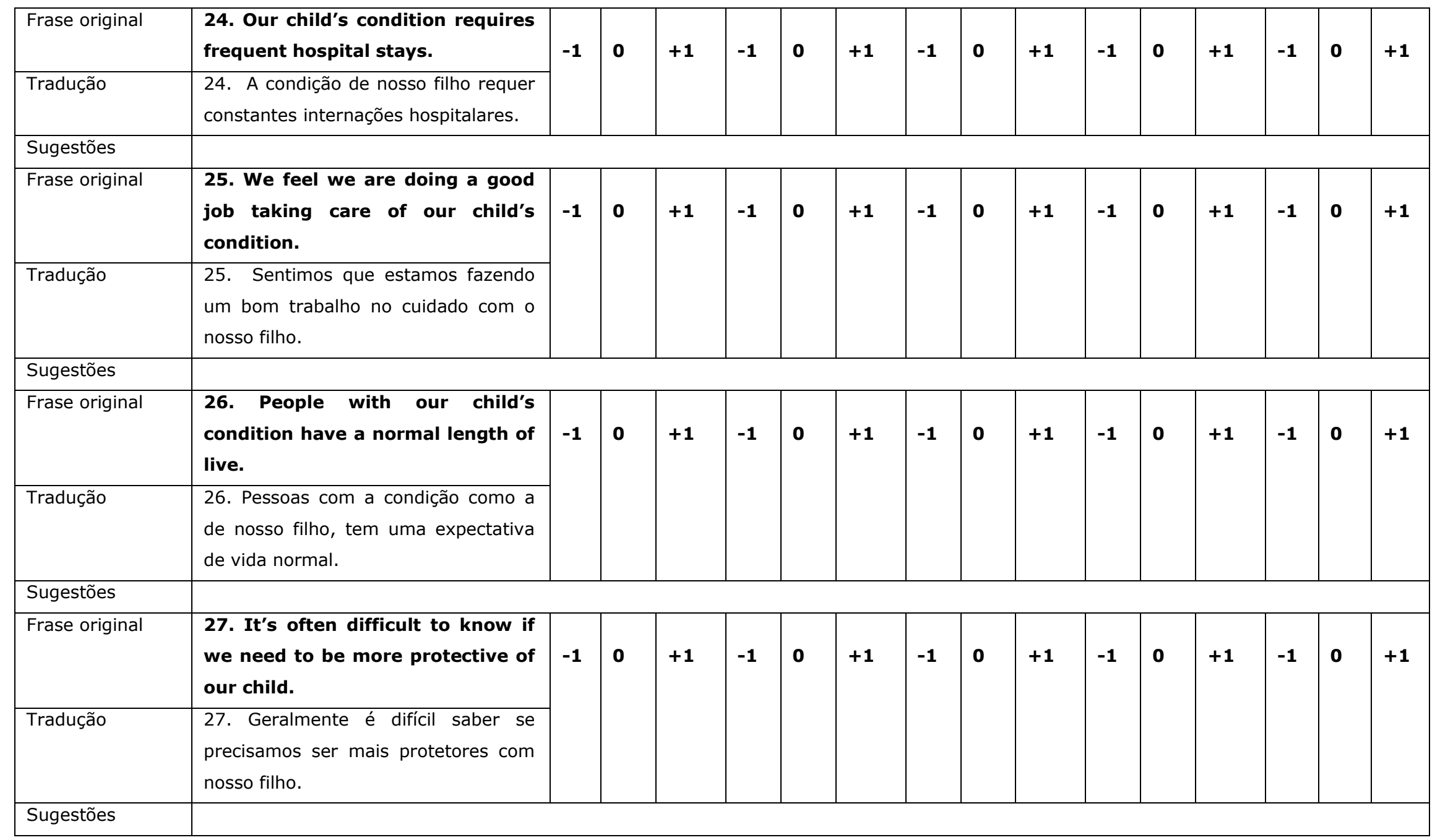




\begin{tabular}{|c|c|c|c|c|c|c|c|c|c|c|c|c|c|c|c|c|}
\hline Frase original & $\begin{array}{l}\text { 28. We often feel unsure about } \\
\text { what to do to take care of our } \\
\text { child's condition. }\end{array}$ & -1 & $\mathbf{0}$ & +1 & -1 & $\mathbf{0}$ & +1 & -1 & 0 & +1 & -1 & 0 & +1 & -1 & $\mathbf{0}$ & +1 \\
\hline Tradução & $\begin{array}{l}\text { 28. Geralmente nos sentimos } \\
\text { inseguros em relação ao que fazer } \\
\text { para cuidar da condição de nosso } \\
\text { filho. }\end{array}$ & & & & & & & & & & & & & & & \\
\hline \multicolumn{17}{|l|}{ Sugestões } \\
\hline Frase original & $\begin{array}{l}\text { 29. Our child's condition Will be } \\
\text { harder to take care of in the } \\
\text { future. }\end{array}$ & \multirow[t]{2}{*}{-1} & \multirow[t]{2}{*}{$\mathbf{0}$} & \multirow[t]{2}{*}{+1} & \multirow[t]{2}{*}{-1} & \multirow[t]{2}{*}{$\mathbf{0}$} & \multirow[t]{2}{*}{+1} & \multirow[t]{2}{*}{-1} & \multirow[t]{2}{*}{0} & \multirow[t]{2}{*}{+1} & \multirow[t]{2}{*}{-1} & \multirow[t]{2}{*}{$\mathbf{0}$} & \multirow[t]{2}{*}{+1} & \multirow[t]{2}{*}{-1} & \multirow[t]{2}{*}{$\mathbf{0}$} & \multirow[t]{2}{*}{+1} \\
\hline Tradução & $\begin{array}{l}\text { 29. No futuro, será mais difícil de } \\
\text { cuidar da condição do nosso filho. }\end{array}$ & & & & & & & & & & & & & & & \\
\hline \multicolumn{17}{|l|}{ Sugestões } \\
\hline Frase original & $\begin{array}{l}\text { 30. We think about our child's } \\
\text { condition all the time. }\end{array}$ & \multirow[t]{2}{*}{-1} & \multirow[t]{2}{*}{$\mathbf{0}$} & \multirow[t]{2}{*}{+1} & \multirow[t]{2}{*}{-1} & \multirow[t]{2}{*}{$\mathbf{0}$} & \multirow[t]{2}{*}{+1} & \multirow[t]{2}{*}{-1} & \multirow[t]{2}{*}{0} & \multirow[t]{2}{*}{+1} & \multirow[t]{2}{*}{-1} & \multirow[t]{2}{*}{$\mathbf{0}$} & \multirow[t]{2}{*}{+1} & \multirow[t]{2}{*}{-1} & \multirow[t]{2}{*}{0} & \multirow[t]{2}{*}{+1} \\
\hline Tradução & $\begin{array}{l}\text { 30. Nós pensamos sobre a condição } \\
\text { do nosso filho o tempo todo. }\end{array}$ & & & & & & & & & & & & & & & \\
\hline \multicolumn{17}{|l|}{ Sugestões } \\
\hline Frase original & $\begin{array}{l}\text { 31. It seems as if our child's } \\
\text { condition controls our family life. }\end{array}$ & -1 & 0 & +1 & -1 & 0 & +1 & -1 & 0 & +1 & -1 & 0 & +1 & -1 & 0 & +1 \\
\hline Tradução & $\begin{array}{l}\text { 31. Parece que a condição de nosso } \\
\text { filho controla a vida da nossa família. }\end{array}$ & & & & & & & & & & & & & & & \\
\hline Sugestões & & & & & & & & & & & & & & & & \\
\hline Frase original & $\begin{array}{l}\text { 32. Many conditions are more } \\
\text { serious than our child's. }\end{array}$ & -1 & 0 & +1 & -1 & $\mathbf{0}$ & +1 & -1 & 0 & +1 & -1 & 0 & +1 & -1 & 0 & +1 \\
\hline Tradução & $\begin{array}{l}\text { 32. Outras crianças têm condições } \\
\text { piores que a do nosso filho. }\end{array}$ & & & & & & & & & & & & & & & \\
\hline Sugestões & & & & & & & & & & & & & & & & \\
\hline Frase original & 33. It is hard to get anyone else & & & & & & & & & & & & & & & \\
\hline
\end{tabular}




\begin{tabular}{|c|c|c|c|c|c|c|c|c|c|c|c|c|c|c|c|c|}
\hline Tradução & $\begin{array}{l}\text { to help us with our child's } \\
\text { condition. } \\
\text { 33. É difícil conseguir ajuda de outras } \\
\text { pessoas para cuidar da condição do } \\
\text { nosso filho. }\end{array}$ & -1 & 0 & +1 & -1 & 0 & +1 & -1 & 0 & +1 & -1 & 0 & +1 & -1 & 0 & +1 \\
\hline \multicolumn{17}{|l|}{ Sugestões } \\
\hline Frase original & $\begin{array}{l}\text { 34. We have not been able to } \\
\text { develop a routine for taking care } \\
\text { of our child's condition. }\end{array}$ & -1 & 0 & +1 & -1 & 0 & +1 & -1 & 0 & +1 & -1 & 0 & +1 & -1 & $\mathbf{0}$ & +1 \\
\hline Tradução & $\begin{array}{l}\text { 34. Nós não estamos conseguindo } \\
\text { criar uma rotina para cuidar da } \\
\text { condição do nosso filho. }\end{array}$ & & & & & & & & & & & & & & & \\
\hline \multicolumn{17}{|l|}{ Sugestões } \\
\hline Frase original & $\begin{array}{l}\text { 35. It takes a lot of organization } \\
\text { to manage our child's condition. }\end{array}$ & -1 & 0 & +1 & -1 & 0 & +1 & -1 & 0 & +1 & -1 & 0 & +1 & -1 & 0 & +1 \\
\hline Tradução & $\begin{array}{l}\text { 35. É necessário muita organização } \\
\text { para lidar com a condição de nosso } \\
\text { filho. }\end{array}$ & & & & & & & & & & & & & & & \\
\hline Frase original & $\begin{array}{l}\text { 36. We are sometimes undecided } \\
\text { about how to balance the } \\
\text { condition and family life. }\end{array}$ & -1 & 0 & +1 & -1 & 0 & +1 & -1 & 0 & +1 & -1 & 0 & +1 & -1 & $\mathbf{0}$ & +1 \\
\hline Tradução & $\begin{array}{l}\text { 36. Às vezes somos indecisos de } \\
\text { como equilibrar a vida da família com } \\
\text { a condição de nosso filho. }\end{array}$ & & & & & & & & & & & & & & & \\
\hline
\end{tabular}




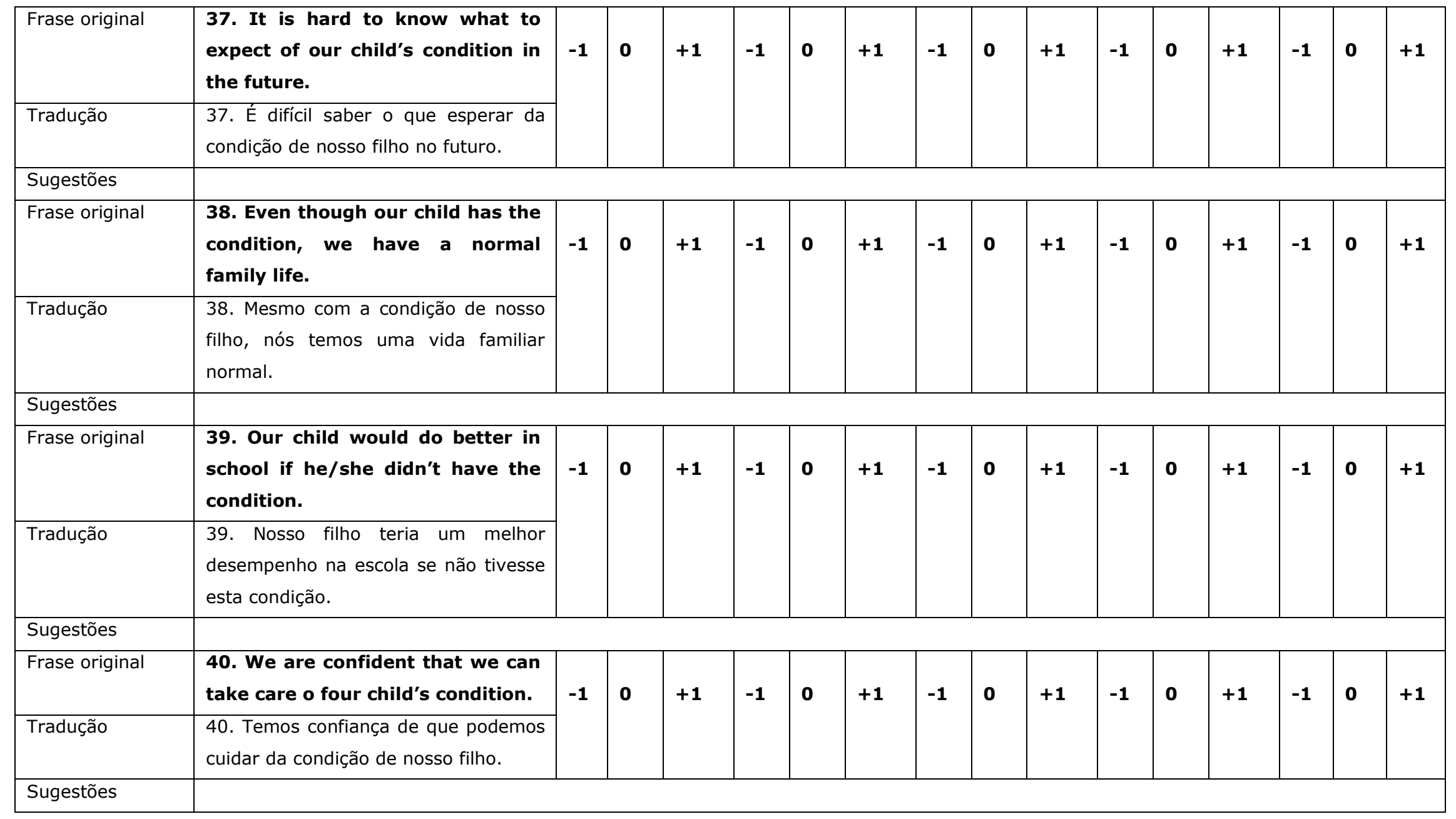




\begin{tabular}{|c|c|c|c|c|c|c|c|c|c|c|c|c|c|c|c|c|}
\hline Frase original & $\begin{array}{l}\text { 41. We have goals in mind to help } \\
\text { us manage our child's condition. }\end{array}$ & \multirow[t]{2}{*}{-1} & \multirow[t]{2}{*}{0} & \multirow[t]{2}{*}{+1} & \multirow[t]{2}{*}{-1} & \multirow[t]{2}{*}{0} & \multirow[t]{2}{*}{+1} & \multirow[t]{2}{*}{-1} & \multirow[t]{2}{*}{0} & \multirow[t]{2}{*}{+1} & \multirow[t]{2}{*}{-1} & \multirow[t]{2}{*}{0} & \multirow[t]{2}{*}{+1} & \multirow[t]{2}{*}{-1} & \multirow[t]{2}{*}{0} & \multirow[t]{2}{*}{+1} \\
\hline Tradução & $\begin{array}{l}\text { 41. Nós temos objetivos que nos } \\
\text { ajudam a cuidar da condição do nosso } \\
\text { filho. }\end{array}$ & & & & & & & & & & & & & & & \\
\hline Frase original & $\begin{array}{l}\text { 42. It is difficult to fit care of our } \\
\text { child's condition into our usual } \\
\text { family routine. }\end{array}$ & \multirow[t]{2}{*}{-1} & \multirow[t]{2}{*}{0} & \multirow[t]{2}{*}{+1} & \multirow[t]{2}{*}{-1} & \multirow[t]{2}{*}{0} & \multirow[t]{2}{*}{+1} & \multirow[t]{2}{*}{-1} & \multirow[t]{2}{*}{0} & \multirow[t]{2}{*}{+1} & \multirow[t]{2}{*}{-1} & \multirow[t]{2}{*}{0} & \multirow[t]{2}{*}{+1} & \multirow[t]{2}{*}{-1} & \multirow[t]{2}{*}{0} & \multirow[t]{2}{*}{+1} \\
\hline Tradução & $\begin{array}{l}\text { 42. É difícil adequar a atividade de } \\
\text { cuidar da condição de nosso filho na } \\
\text { nossa rotina familiar. }\end{array}$ & & & & & & & & & & & & & & & \\
\hline \multicolumn{17}{|l|}{ Sugestões } \\
\hline Frase original & $\begin{array}{l}\text { 43. Dealing with our child's } \\
\text { condition makes family life more } \\
\text { difficult. }\end{array}$ & \multirow[t]{2}{*}{-1} & \multirow[t]{2}{*}{0} & \multirow[t]{2}{*}{+1} & -1 & 0 & +1 & -1 & 0 & +1 & -1 & 0 & +1 & -1 & 0 & +1 \\
\hline Tradução & $\begin{array}{l}\text { 43. Lidar com a condição de nosso } \\
\text { filho torna a vida familiar mais difícil. }\end{array}$ & & & & & & & & & & & & & & & \\
\hline Sugestões & & & & & & & & & & & & & & & & \\
\hline Frase original & $\begin{array}{l}\text { 44. We Know when our child } \\
\text { needs to be a child. }\end{array}$ & -1 & 0 & +1 & -1 & 0 & +1 & -1 & 0 & +1 & -1 & 0 & +1 & -1 & 0 & +1 \\
\hline Tradução & $\begin{array}{l}\text { 44. Nós sabemos quando nosso filho } \\
\text { precisa ser criança. }\end{array}$ & & & & & & & & & & & & & & & \\
\hline Sugestões & & & & & & & & & & & & & & & & \\
\hline Frase original & $\begin{array}{l}\text { 45. A condition like the one our } \\
\text { child has makes it very difficult to } \\
\text { live a normal life. }\end{array}$ & -1 & 0 & +1 & -1 & 0 & +1 & -1 & 0 & +1 & -1 & 0 & +1 & -1 & 0 & +1 \\
\hline Tradução & $\begin{array}{l}\text { 45. É difícil manter uma vida normal } \\
\text { com a condição que nosso filho tem. }\end{array}$ & & & & & & & & & & & & & & & \\
\hline Sugestões & & & & & & & & & & & & & & & & \\
\hline
\end{tabular}

This ends Section 1. 
Section 2 covers aspects of family management when there are adult partner in a household.

The term "partner" refers to a spouse or partner living in the same household.

If you currently have a partner, please proceed to next page. If you do not have a partner, please stop here.

Isto encerra a seção 1.

A Seção 2 aborda aspectos do manejo familiar quando existem parceiros adultos na mesma casa. O termo "parceiros" se refere ao cônjuge ou companheiro que vive na mesma casa.

Se você atualmente mora com um parceiro, por favor continue com o questionário na próxima página. Caso contrário, por favor pare por aqui.

\section{Section 2}

The questions in the next section relate to you and your partner. For each statement in this section, rate your response to the statement on a scale of 1 to 5, with 1 indicating "Strongly disagree" and 5 indicating "Strongly agree". Again, please respond to each statement in this questionnaire based on how feel, not on how think your partner or others might respond.

\section{Seção 2}

As questões nesta próxima seção referem-se a você e seu parceiro. Para cada afirmação deste questionário, pedimos que você dê uma nota de 1 a 5 , sendo que 1 significa "discordo totalmente" e 5 indica "concordo totalmente". Novamente, por favor responda a estas questões com base no que você pensa, não em como você pensa que seu parceiro ou os outros poderiam responder. 


\begin{tabular}{|c|c|c|c|c|c|c|c|c|c|c|c|c|c|c|c|c|}
\hline \multicolumn{2}{|c|}{ Mutualidade dos pais } & \multicolumn{3}{|c|}{$\begin{array}{l}\text { Equivalência } \\
\text { Conceitual }\end{array}$} & \multicolumn{3}{|c|}{$\begin{array}{l}\text { Equivalência } \\
\text { De itens }\end{array}$} & \multicolumn{3}{|c|}{$\begin{array}{l}\text { Equivalência } \\
\text { Semântica/ } \\
\text { idiomática }\end{array}$} & \multicolumn{3}{|c|}{$\begin{array}{l}\text { Equivalência } \\
\text { Operacional }\end{array}$} & \multicolumn{3}{|c|}{$\begin{array}{l}\text { Validade de } \\
\text { Conteúdo }\end{array}$} \\
\hline Frase original & $\begin{array}{l}\text { 46. We are closer family because } \\
\text { of how we deal with our child's } \\
\text { condition. }\end{array}$ & \multirow[t]{2}{*}{-1} & \multirow[t]{2}{*}{0} & \multirow[t]{2}{*}{+1} & \multirow[t]{2}{*}{-1} & \multirow[t]{2}{*}{0} & \multirow[t]{2}{*}{+1} & \multirow[t]{2}{*}{$|-1|$} & \multirow[t]{2}{*}{0} & \multirow[t]{2}{*}{+1} & \multirow[t]{2}{*}{-1} & \multirow[t]{2}{*}{0} & \multirow[t]{2}{*}{+1} & \multirow[t]{2}{*}{-1} & \multirow[t]{2}{*}{0} & \multirow[t]{2}{*}{+1} \\
\hline Tradução & $\begin{array}{l}\text { 46. Nossa família é mais unida pela } \\
\text { maneira lidamos com a condição de } \\
\text { nosso filho. }\end{array}$ & & & & & & & & & & & & & & & \\
\hline \multicolumn{17}{|l|}{ Sugestões } \\
\hline Frase original & $\begin{array}{l}\text { 47. My partner and I have } \\
\text { different ideas about how serious } \\
\text { our child's condition is. }\end{array}$ & \multirow[t]{2}{*}{-1} & \multirow[t]{2}{*}{0} & \multirow[t]{2}{*}{+1} & \multirow[t]{2}{*}{-1} & \multirow[t]{2}{*}{0} & \multirow[t]{2}{*}{+1} & \multirow[t]{2}{*}{-1} & \multirow[t]{2}{*}{0} & \multirow[t]{2}{*}{+1} & \multirow[t]{2}{*}{-1} & \multirow[t]{2}{*}{0} & \multirow[t]{2}{*}{+1} & \multirow[t]{2}{*}{-1} & \multirow[t]{2}{*}{0} & +1 \\
\hline Tradução & $\begin{array}{l}\text { 47. Meu companheiro(a) e eu temos } \\
\text { idéias diferentes sobre a gravidade da } \\
\text { condição de nosso filho. }\end{array}$ & & & & & & & & & & & & & & & \\
\hline Sugestões & & & & & & & & & & & & & & & & \\
\hline Frase original & $\begin{array}{l}\text { 48. I am pleased with how my } \\
\text { partner and I work together to } \\
\text { manage our child's condition. }\end{array}$ & -1 & 0 & +1 & -1 & 0 & +1 & $\mid-1$ & 0 & +1 & $|-1|$ & 0 & +1 & -1 & 0 & +1 \\
\hline Tradução & $\begin{array}{l}\text { 48. Estou satisfeito com a maneira } \\
\text { como eu e meu companheiro(a) } \\
\text { cuidamos juntos da condição de nosso } \\
\text { filho. }\end{array}$ & & & & & & & & & & & & & & & \\
\hline Sugestões & & & & & & & & & & & & & & & & \\
\hline
\end{tabular}




\begin{tabular}{|c|c|c|c|c|c|c|c|c|c|c|c|c|c|c|c|c|}
\hline Frase original & $\begin{array}{l}\text { 49. My partner and I argue about } \\
\text { how to manage our child's } \\
\text { condition. }\end{array}$ & \multirow[t]{2}{*}{-1} & \multirow[t]{2}{*}{0} & \multirow[t]{2}{*}{+1} & \multirow[t]{2}{*}{-1} & \multirow[t]{2}{*}{0} & \multirow[t]{2}{*}{+1} & \multirow[t]{2}{*}{-1} & \multirow[t]{2}{*}{0} & \multirow[t]{2}{*}{+1} & \multirow[t]{2}{*}{-1} & \multirow[t]{2}{*}{0} & \multirow[t]{2}{*}{+1} & \multirow[t]{2}{*}{-1} & \multirow[t]{2}{*}{0} & \multirow[t]{2}{*}{+1} \\
\hline Tradução & $\begin{array}{l}\text { 49. Eu e meu companheiro(a) } \\
\text { discutimos sobre como lidar com a } \\
\text { condição nosso filho. }\end{array}$ & & & & & & & & & & & & & & & \\
\hline \multicolumn{17}{|l|}{ Sugestões } \\
\hline Frase original & $\begin{array}{l}\text { 50. My partner and I consult with } \\
\text { each other before we make a } \\
\text { decision about our child's care. }\end{array}$ & -1 & 0 & +1 & -1 & 0 & +1 & -1 & 0 & +1 & -1 & 0 & +1 & -1 & 0 & +1 \\
\hline Tradução & $\begin{array}{l}\text { 50. Eu e meu companheiro(a) sempre } \\
\text { conversamos antes de tomar qualquer } \\
\text { decisão sobre os cuidados com o } \\
\text { nosso filho. }\end{array}$ & & & & & & & & & & & & & & & \\
\hline \multicolumn{17}{|l|}{ Sugestões } \\
\hline Frase original & $\begin{array}{l}\text { 51. My partner and I have similar } \\
\text { ideas about how we should be } \\
\text { raising our child. }\end{array}$ & -1 & 0 & +1 & -1 & 0 & +1 & -1 & 0 & +1 & -1 & 0 & +1 & -1 & $\mathbf{0}$ & +1 \\
\hline Tradução & $\begin{array}{l}\text { 51. Eu e meu companheiro(a) temos } \\
\text { idéias semelhantes sobre como } \\
\text { devemos criar nosso filho. }\end{array}$ & & & & & & & & & & & & & & & \\
\hline
\end{tabular}




\begin{tabular}{|c|c|c|c|c|c|c|c|c|c|c|c|c|c|c|c|c|}
\hline Frase original & $\begin{array}{l}\text { 52. I am unhappy about the way } \\
\text { my partner and I share the } \\
\text { management of our child's } \\
\text { condition. }\end{array}$ & \multirow[t]{2}{*}{-1} & \multirow[t]{2}{*}{0} & \multirow[t]{2}{*}{+1} & \multirow[t]{2}{*}{-1} & \multirow[t]{2}{*}{$\mathbf{0}$} & \multirow[t]{2}{*}{+1} & \multirow[t]{2}{*}{-1} & \multirow[t]{2}{*}{0} & \multirow[t]{2}{*}{+1} & \multirow[t]{2}{*}{-1} & \multirow[t]{2}{*}{0} & \multirow[t]{2}{*}{+1} & \multirow[t]{2}{*}{-1} & \multirow[t]{2}{*}{0} & \multirow[t]{2}{*}{+1} \\
\hline Tradução & $\begin{array}{l}\text { 52. Estou insatisfeito(a) com a forma } \\
\text { como eu e meu companheiro(a) } \\
\text { compartilhamos os cuidados com a } \\
\text { condição de nosso filho. }\end{array}$ & & & & & & & & & & & & & & & \\
\hline \multicolumn{17}{|l|}{ Sugestões } \\
\hline Frase original & $\begin{array}{l}\text { 53. My partner and I support each } \\
\text { other in taking care of our child's } \\
\text { condition. }\end{array}$ & \multirow[t]{2}{*}{-1} & \multirow[t]{2}{*}{0} & \multirow[t]{2}{*}{+1} & \multirow[t]{2}{*}{-1} & \multirow[t]{2}{*}{0} & \multirow[t]{2}{*}{+1} & \multirow[t]{2}{*}{-1} & \multirow[t]{2}{*}{0} & \multirow[t]{2}{*}{+1} & \multirow[t]{2}{*}{-1} & \multirow[t]{2}{*}{$\mathbf{0}$} & \multirow[t]{2}{*}{+1} & \multirow[t]{2}{*}{-1} & \multirow[t]{2}{*}{0} & \multirow[t]{2}{*}{+1} \\
\hline Tradução & $\begin{array}{l}\text { 53. Eu e meu companheiro(a) } \\
\text { ajudamos um ao outro nos cuidados } \\
\text { com a condição do nosso filho. }\end{array}$ & & & & & & & & & & & & & & & \\
\hline
\end{tabular}

\section{Muito Obrigada!}

Carolliny Rossi de Faria Ichikawa

Regina Szylit Bousso 


\section{APÊNDICE C - TERMO DE CONSENTIMENTO LIVRE E ESCLARECIDO DE PARTICIPAÇÃO NA PESQUISA}

Prezado Senhor(a):

Solicito sua colaboração e participação na pesquisa intitulada TRADUÇÃO, ADAPTAÇÃO TRANSCULTURAL E VALIDAÇÃO DO FAMILY MANAGEMENT MEASURE PARA FAMÍLIAS DE CRIANÇAS PORTADORAS DE DOENÇAS CRÔNICAS, que faz parte de minha dissertação de Mestrado, pela Escola de Enfermagem da Universidade de São Paulo.

Pelo consentimento a seguir, fica claro, que para o sujeito da pesquisa, os objetivos e o método da coleta de dados, estão explicados na carta recebida junto deste termo, de forma clara e objetiva; e também, é permitido o acesso ao referido o projeto.

Coloco-me à disposição para qualquer dúvida.

Carolliny Rossi de Faria Ichikawa

Pesquisadora

Contato:

Rua Otávio Palhares, 242,

Jardim Santos Dumont, Londrina - PR

(43) -33570956

(43) -96135575

caroll@usp.br 


\title{
Título do Projeto:
}

\section{TRADUÇÃO, ADAPTAÇÃO TRANSCULTURAL E VALIDAÇÃO DO FAMILY MANAGEMENT MEASURE PARA FAMÍLIAS DE CRIANÇAS PORTADORAS DE DOENÇAS CRÔNICAS}

\author{
Pesquisadora: Carolliny Rossi de Faria Ichikawa \\ Orientadora: Regina Szylit Bousso
}

Eu, fui esclarecido(a), de forma clara e objetiva, livre de qualquer constrangimento ou coerção que a pesquisa "Tradução, Adaptação Transcultural e Validação do Family Management Measure para famílias de crianças portadoras de doenças crônicas", de autoria de Carolliny Rossi de Faria Ichikawa, tem como objetivo traduzir, adaptar e validar o Family Management Measure para famílias de crianças portadoras de doenças crônicas, no intuito de torná-la acessível e utilizada no Brasil, visto que não há nenhuma escala previamente validada para esta população.

Todos os dados coletados, depois de organizados e analisados, poderão ser divulgados e publicados, ficando a autora comprometida com a apresentação do relatório de pesquisa para as instituições, onde será realizado o estudo.

A participação voluntária é enfatizada, e é garantido o esclarecimento de qualquer dúvida, em qualquer momento.

É importante destacar a liberdade, enquanto população da pesquisa, de participar ou não do estudo e/ou deixar de participar em qualquer momento, sem qualquer prejuízo ou constrangimento e sem sofrer nenhum tipo de represália.

Fica assegurada a garantia do anonimato e o caráter privativo das informações exclusivamente para o estudo.

Londrina, de de 2010. 
APÊNDICE D - DADOS DE IDENTIFICAÇÃO SOCIO-DEMOGRÁFICA

Qual o seu parentesco com a criança?

Qual a última série que cursou com aprovação?

Tem outros filhos? ( ) sim ( ) não

Quantos?

Qual a Idade?

A renda mensal de sua família é:

( ) suficiente ( ) insuficiente ( ) sobra dinheiro no final do mês

E antes da doença sua renda era:

( ) suficiente ( ) insuficiente ( ) sobra dinheiro no final do mês

Sexo da criança:

Idade da criança:

Diagnóstico da criança: 


\section{APÊNDICE E - VERSÃO PORTUGUÊS 2 - VERSÃO FINAL DO FaMM}

\section{INSTRUMENTO DE MEDIDA DE MANEJO FAMILIAR}

Este questionário avalia como a sua família convive com uma criança com doença crônica.

Instruções

Para cada afirmação deste questionário, pedimos que você dê uma nota de 1 a 5 , sendo que 1 significa "discordo totalmente" e 5 indica "concordo totalmente". Por favor responda a estas questões com base no que você pensa, não em como você pensa que os outros poderiam responder. Se (NOME DA CRIANÇA) possui mais de uma doença crônica, a palavra "doença" se refere a todos os diagnósticos juntos. Além disso, várias questões utilizam a palavra "família". Ela se refere às pessoas que vivem na mesma casa que você, e que você considera como sendo da família.

SEÇÃO 1 - a ser preenchida por qualquer família independente do casal morar junto

Por favor marque um " $x$ " no quadrado equivalente à sua resposta para cada questão.

\begin{tabular}{|c|c|c|c|c|c|}
\hline & $\begin{array}{c}\text { Discordo } \\
\text { totalmente }\end{array}$ & & & & $\begin{array}{l}\text { Concordo } \\
\text { totalmente }\end{array}$ \\
\hline & 1 & 2 & 3 & 4 & 5 \\
\hline \multicolumn{6}{|l|}{$\begin{array}{l}\text { 1. O dia a dia de (nome da } \\
\text { criança) é parecido com o de } \\
\text { outras crianças na mesma idade } \\
\text { dele. }\end{array}$} \\
\hline \multicolumn{6}{|l|}{$\begin{array}{l}\text { 2. A doença do (nome da criança) } \\
\text { interfere no relacionamento da } \\
\text { família. }\end{array}$} \\
\hline \multicolumn{6}{|l|}{$\begin{array}{l}\text { 3. A doença do (nome da criança) } \\
\text { requer visitas freqüentes ao } \\
\text { médico. }\end{array}$} \\
\hline \multicolumn{6}{|l|}{$\begin{array}{l}\text { 4. Esperamos que (nome da } \\
\text { criança) no futuro seja capaz de } \\
\text { cuidar de sua doença }\end{array}$} \\
\hline \multicolumn{6}{|l|}{$\begin{array}{l}\text { 5. (nome da criança) aproveita } \\
\text { menos a vida por causa da sua } \\
\text { doença. }\end{array}$} \\
\hline $\begin{array}{l}\text { 6. Cuidar da doença de (nome da } \\
\text { criança) é frequentemente muito } \\
\text { difícil. }\end{array}$ & & & & & \\
\hline
\end{tabular}




\begin{tabular}{|c|c|c|c|c|c|}
\hline & $\begin{array}{c}\text { Discordo } \\
\text { totalmente }\end{array}$ & 2 & 3 & 4 & $\begin{array}{c}\text { Concordo } \\
\text { totalmente } \\
5\end{array}$ \\
\hline $\begin{array}{l}\text { 7. A doença de (nome da criança) } \\
\text { é como uma montanha-russa, } \\
\text { cheia de altos e baixos. }\end{array}$ & & & & & \\
\hline $\begin{array}{l}\text { 8. A doença de (nome da criança) } \\
\text { é a coisa mais importante em } \\
\text { nossa família. }\end{array}$ & & & & & \\
\hline $\begin{array}{l}\text { 9. É muito difícil para nós cuidar } \\
\text { da doença de (nome da criança). }\end{array}$ & & & & & \\
\hline $\begin{array}{l}\text { 10. (nome da criança) participa } \\
\text { de atividades que deseja apesar } \\
\text { da sua doença. }\end{array}$ & & & & & \\
\hline $\begin{array}{l}\text { 11. Nos preocupamos com o } \\
\text { futuro do (nome da criança) por } \\
\text { causa da sua doença. }\end{array}$ & & & & & \\
\hline $\begin{array}{l}\text { 12. Lidar com a doença do (nome } \\
\text { da criança) não exige muito } \\
\text { tempo. }\end{array}$ & & & & & \\
\hline $\begin{array}{l}\text { 13. Temos algumas idéias } \\
\text { definidas acerca de como ajudar } \\
\text { (nome da criança) a conviver com } \\
\text { a doença. }\end{array}$ & & & & & \\
\hline $\begin{array}{l}\text { 14. Apesar da sua doença, } \\
\text { esperamos que, no futuro, (nome } \\
\text { da criança) possa viver em sua } \\
\text { própria casa. }\end{array}$ & & & & & \\
\hline $\begin{array}{l}15 . \quad \text { Nós temos condição } \\
\text { financeira suficiente para pagar } \\
\text { as despesas da doença do (nome } \\
\text { da criança). }\end{array}$ & & & & & \\
\hline $\begin{array}{l}\text { 16. (nome da criança) é diferente } \\
\text { de outras crianças da mesma } \\
\text { idade por causa de sua doença. }\end{array}$ & & & & & \\
\hline $\begin{array}{l}\text { 17. } \vec{E} \text { difícil saber quando a } \\
\text { doença de (nome da criança) } \\
\text { deve vir em primeiro lugar na } \\
\text { família. }\end{array}$ & & & & & \\
\hline $\begin{array}{l}\text { 18. Nós esperamos ter um futuro } \\
\text { feliz com (nome da criança). }\end{array}$ & & & & & \\
\hline $\begin{array}{l}\text { 19. Quando alguma coisa } \\
\text { inesperada acontece em relação } \\
\text { à doença de (nome da criança), } \\
\text { nós geralmente sabemos como } \\
\text { lidar. }\end{array}$ & & & & & \\
\hline
\end{tabular}




\begin{tabular}{|c|c|c|c|c|c|}
\hline & $\begin{array}{c}\text { Discordo } \\
\text { totalmente } \\
1\end{array}$ & 2 & 3 & 4 & \begin{tabular}{|r|}
$\begin{array}{c}\text { Concordo } \\
\text { totalmente }\end{array}$ \\
5
\end{tabular} \\
\hline $\begin{array}{l}20 . \text { As amizades do (nome da } \\
\text { criança) são diferentes por causa } \\
\text { da sua doença. }\end{array}$ & & & & & \\
\hline $\begin{array}{l}\text { 21. No futuro, nós esperamos } \\
\text { dedicar menos tempo aos } \\
\text { cuidados com a doença de (nome } \\
\text { da criança). }\end{array}$ & & & & & \\
\hline $\begin{array}{l}\text { 22. Uma doença como a que } \\
\text { (nome da criança) tem torna a } \\
\text { vida familiar muito difícil. }\end{array}$ & & & & & \\
\hline $\begin{array}{l}\text { 23. As atividades de (nome da } \\
\text { criança) raramente interferem nas } \\
\text { outras atividades da família. }\end{array}$ & & & & & \\
\hline $\begin{array}{l}\text { 24. A doença de } \\
\text { criança) requer da da } \\
\text { internações hospitalares. }\end{array}$ & & & & & \\
\hline $\begin{array}{l}25 . \quad \text { Sentimos que estamos } \\
\text { fazendo um bom trabalho no } \\
\text { cuidado com o (nome da criança). }\end{array}$ & & & & & \\
\hline $\begin{array}{l}\text { 26. Pessoas com a doença como } \\
\text { a de (nome da criança) tem uma } \\
\text { expectativa de vida normal. }\end{array}$ & & & & & \\
\hline $\begin{array}{l}\text { 27. Geralmente é difícil saber se } \\
\text { precisamos ser mais protetores } \\
\text { com (nome da criança). }\end{array}$ & & & & & \\
\hline $\begin{array}{l}\text { 28. Geralmente nos sentimos } \\
\text { inseguros em relação ao que } \\
\text { fazer para cuidar da doença de } \\
\text { (nome da criança). }\end{array}$ & & & & & \\
\hline $\begin{array}{l}\text { 29. No futuro, será mais difícil de } \\
\text { cuidar da doença do (nome da } \\
\text { criança). }\end{array}$ & & & & & \\
\hline $\begin{array}{l}\text { 30. Nós pensamos sobre a } \\
\text { doença do (nome da criança) o } \\
\text { tempo todo. }\end{array}$ & & & & & \\
\hline $\begin{array}{l}\text { 31. Parece que a doença de } \\
\text { (nome da criança) controla a vida } \\
\text { da nossa família. }\end{array}$ & & & & & \\
\hline $\begin{array}{l}\text { 32. Muitas doenças são mais } \\
\text { sérias do que a do (nome da } \\
\text { criança). }\end{array}$ & & & & & \\
\hline $\begin{array}{l}\text { 33. E difícil conseguir outras } \\
\text { pessoas para nos ajudar com a } \\
\text { doença do (nome da criança). }\end{array}$ & & & & & \\
\hline $\begin{array}{l}\text { 34. Nós não conseguimos criar } \\
\text { uma rotina para cuidar da doença } \\
\text { do (nome da criança). }\end{array}$ & & & & & \\
\hline
\end{tabular}




\begin{tabular}{|c|c|c|c|c|c|}
\hline & $\begin{array}{c}\begin{array}{c}\text { Discordo } \\
\text { totalmente }\end{array} \\
1\end{array}$ & ? & 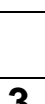 & 4 & \begin{tabular}{|r|}
$\begin{array}{c}\text { Concordo } \\
\text { totalmente }\end{array}$ \\
5
\end{tabular} \\
\hline $\begin{array}{l}35 . \quad \text { É necessário muita } \\
\text { organização para lidar com a } \\
\text { doença de (nome da criança). }\end{array}$ & & & & & \\
\hline $\begin{array}{l}\text { 36. Às vezes ficamos indecisos } \\
\text { sobre como equilibrar a vida da } \\
\text { família com a doença do (nome } \\
\text { da criança). }\end{array}$ & & & & & \\
\hline $\begin{array}{l}\text { 37. É difícil saber o que esperar } \\
\text { da doença de (nome da criança) } \\
\text { no futuro. }\end{array}$ & & & & & \\
\hline $\begin{array}{l}\text { 38. Mesmo com a doença de } \\
\text { (nome da criança), nós temos } \\
\text { uma vida familiar normal. }\end{array}$ & & & & & \\
\hline $\begin{array}{l}\text { 39. (nome da criança) poderia se } \\
\text { sair melhor na escola se não } \\
\text { tivesse esta doença. }\end{array}$ & & & & & \\
\hline $\begin{array}{l}\text { 40. Temos confiança de que } \\
\text { podemos cuidar da doença de } \\
\text { (nome da criança). }\end{array}$ & & & & & \\
\hline $\begin{array}{l}\text { 41. Nós temos objetivos que nos } \\
\text { ajudam a lidar com a doença do } \\
\text { (nome da criança). }\end{array}$ & & & & & \\
\hline $\begin{array}{l}\text { 42. É difícil adequar as atividades } \\
\text { do cuidado do (nome da criança) } \\
\text { à nossa rotina familiar. }\end{array}$ & & & & & \\
\hline $\begin{array}{l}\text { 43. Lidar com a doença de (nome } \\
\text { da criança) torna a vida familiar } \\
\text { mais difícil. }\end{array}$ & & & & & \\
\hline $\begin{array}{l}\text { 44. Nós sabemos quando (nome } \\
\text { da criança) precisa agir como } \\
\text { criança. }\end{array}$ & & & & & \\
\hline $\begin{array}{l}\text { 45. E muito difícil manter uma } \\
\text { vida normal com a doença que } \\
\text { (nome da criança) tem. }\end{array}$ & & & & & \\
\hline
\end{tabular}

Isto encerra a seção 1.

A Seção 2 aborda aspectos do manejo familiar quando existem parceiros adultos na mesma casa. O termo "parceiros" se refere ao cônjuge ou companheiro que vive na mesma casa.

Se você atualmente mora com um parceiro, por favor continue com o questionário na próxima página. Caso contrário, por favor pare por aqui. 


\section{SEÇÃO 2}

As questões nesta próxima seção referem-se a você e seu parceiro. Para cada afirmação deste questionário, pedimos que você dê uma nota de 1 a 5 , sendo que 1 significa "discordo totalmente" e 5 indica "concordo totalmente". Novamente, por favor responda a estas questões com base no que você pensa, não em como você pensa que seu parceiro ou os outros poderiam responder.

\begin{tabular}{|l|c|c|c|c|c|}
\hline & $\begin{array}{l}\text { Discordo } \\
\text { totalmente }\end{array}$ & & & & $\begin{array}{c}\text { Concordo } \\
\text { totalmente }\end{array}$ \\
\hline $\begin{array}{l}\text { 46. Nossa família é mais unida } \\
\text { pela maneira como lidamos com a } \\
\text { doença de (nome da criança). }\end{array}$ & & & & & \\
\hline $\begin{array}{l}\text { 47. Meu companheiro(a) eu } \\
\text { temos idéias diferentes sobre a } \\
\text { gravidade da doença de (nome da } \\
\text { criança). }\end{array}$ & & & & & \\
\hline $\begin{array}{l}\text { 48. Estou satisfeito com a maneira } \\
\text { como eu meu companheiro(a) } \\
\text { cuidamos juntos da doença de } \\
\text { (nome da criança). }\end{array}$ & & & & & \\
\hline $\begin{array}{l}\text { 49. Eu e meu companheiro(a) } \\
\text { discutimos sobre como lidar com a } \\
\text { doença do (nome da criança). }\end{array}$ & & & & \\
\hline $\begin{array}{l}50 . \text { Eu meu companheiro(a) } \\
\text { sempre conversamos antes de } \\
\text { tomar qualquer decisão sobre os } \\
\text { cuidados com (nome da criança). }\end{array}$ & & & & \\
\hline $\begin{array}{l}51 . \text { Eu eu companheiro(a) } \\
\text { temos idéias parecidas sobre } \\
\text { como deveríamos criar o (nome } \\
\text { da criança). }\end{array}$ & & & & \\
\hline $\begin{array}{l}52 . \text { Estou insatisfeito(a) com a } \\
\text { forma como eu e meu } \\
\text { companheiro(a) compartilhamos }\end{array}$ & & & & \\
os cuidados com a doença do & & & & \\
(nome da criança). & & & & \\
\hline $\begin{array}{l}53 \text { Eu e meu companheiro(a) } \\
\text { apoiamos um ao outro nos } \\
\text { cuidados com a doença do (nome } \\
\text { da criança). }\end{array}$ & & & & \\
\hline
\end{tabular}




\section{ANEXO A - VERSÃO ORIGINAL DO FAMM}

\section{FAMILY MANAGEMENT MEASURE}

This questionnaire is about how your family manages caring for a child with a chronic condition.

\section{INSTRUCTIONS}

For each statement in this questionnaire, you are asked to rate your response to the statement on a scale of 1 to 5 , with 1 indicating "Strongly disagree" and 5 indicating "Strongly agree". Please respond to each statement in this questionnaire based on what you think, not on how you think others might respond. If your child has more than one chronic condition the word "condition" refers to all of their diagnoses together. Also, many of these questions use the word "family". This refers to those people living in your household that you think of as family.

Section 1: to be completed by everyone

Please check the boxes with your answers.

\begin{tabular}{|c|c|c|c|c|c|}
\hline & $\begin{array}{c}\text { Strongly } \\
\text { Disagree } \\
1\end{array}$ & 2 & 3 & 4 & $\begin{array}{c}\text { Strongly } \\
\text { Agree } \\
5\end{array}$ \\
\hline $\begin{array}{l}\text { 1. Our child's everyday life is similar to } \\
\text { that of other children his/her age. }\end{array}$ & $\square$ & $\square$ & $\square$ & $\square$ & $\square$ \\
\hline $\begin{array}{l}\text { 2. Our child's condition gets in the way of } \\
\text { family relationships. }\end{array}$ & $\square$ & $\square$ & $\square$ & $\square$ & $\square$ \\
\hline $\begin{array}{l}\text { 3. Our child's condition requires frequent } \\
\text { visits to the clinic. }\end{array}$ & $\square$ & $\square$ & $\square$ & $\square$ & $\square$ \\
\hline $\begin{array}{l}\text { 4. In the future we expect our child to take } \\
\text { care of the condition. }\end{array}$ & $\square$ & $\square$ & $\square$ & $\square$ & $\square$ \\
\hline $\begin{array}{l}\text { 5. Our child enjoys life less because of the } \\
\text { condition. }\end{array}$ & $\square$ & $\square$ & $\square$ & $\square$ & $\square$ \\
\hline $\begin{array}{l}\text { 6. Taking care of our child's condition is } \\
\text { often overwhelming. }\end{array}$ & $\square$ & $\square$ & $\square$ & $\square$ & $\square$ \\
\hline $\begin{array}{l}\text { 7. Our child's condition is like a roller } \\
\text { coaster with lots of ups and downs. }\end{array}$ & $\square$ & $\square$ & $\square$ & $\square$ & $\square$ \\
\hline $\begin{array}{l}\text { 8. Our child's condition is the most } \\
\text { important thing in our family. }\end{array}$ & $\square$ & $\square$ & $\square$ & $\square$ & $\square$ \\
\hline
\end{tabular}




\begin{tabular}{|c|c|c|c|c|c|}
\hline & $\begin{array}{c}\text { Strongly } \\
\text { Disagree } \\
1\end{array}$ & 2 & 3 & 4 & $\begin{array}{c}\text { Strongly } \\
\text { Agree } \\
5\end{array}$ \\
\hline $\begin{array}{l}\text { 9. It is very hard for us to take care of our } \\
\text { child's condition. }\end{array}$ & $\square$ & $\square$ & $\square$ & $\square$ & $\square$ \\
\hline $\begin{array}{l}\text { 10. Our child takes part in activities he/she } \\
\text { wishes to despite the condition. }\end{array}$ & $\square$ & $\square$ & $\square$ & $\square$ & $\square$ \\
\hline $\begin{array}{l}\text { 11. Because of the condition, we worry } \\
\text { about our child's future. }\end{array}$ & $\square$ & $\square$ & $\square$ & $\square$ & $\square$ \\
\hline $\begin{array}{l}\text { 12. Our child's condition doesn't take a } \\
\text { great deal of time to manage. }\end{array}$ & $\square$ & $\square$ & $\square$ & $\square$ & $\square$ \\
\hline $\begin{array}{l}\text { 13. We have some definite ideas about } \\
\text { how to help our child live with the } \\
\text { condition. }\end{array}$ & $\square$ & $\square$ & $\square$ & $\square$ & $\square$ \\
\hline $\begin{array}{l}\text { 14. Despite the condition, we expect our } \\
\text { child to live away from home in the } \\
\text { future. }\end{array}$ & $\square$ & $\square$ & $\square$ & $\square$ & $\square$ \\
\hline $\begin{array}{l}\text { 15. We have enough money to manage our } \\
\text { child's condition. }\end{array}$ & $\square$ & $\square$ & $\square$ & $\square$ & $\square$ \\
\hline $\begin{array}{l}\text { 16. Our child is different from other } \\
\text { children his/her age because of the } \\
\text { condition. }\end{array}$ & $\square$ & $\square$ & $\square$ & $\square$ & $\square$ \\
\hline $\begin{array}{l}\text { 17. It is difficult to know when our child's } \\
\text { condition must come first in the family. }\end{array}$ & $\square$ & $\square$ & $\square$ & $\square$ & $\square$ \\
\hline $\begin{array}{l}\text { 18. We are looking forward to a happy } \\
\text { future with our child. }\end{array}$ & $\square$ & $\square$ & $\square$ & $\square$ & $\square$ \\
\hline $\begin{array}{l}\text { 19. When something unexpected happens } \\
\text { with our child's condition, we usually } \\
\text { know how to handle it. }\end{array}$ & $\square$ & $\square$ & $\square$ & $\square$ & $\square$ \\
\hline $\begin{array}{l}\text { 20. Our child's friendships are different } \\
\text { because of the condition. }\end{array}$ & $\square$ & $\square$ & $\square$ & $\square$ & $\square$ \\
\hline $\begin{array}{l}\text { 21. We expect to be devoting less time to } \\
\text { our child's condition in the future. }\end{array}$ & $\square$ & $\square$ & $\square$ & $\square$ & $\square$ \\
\hline $\begin{array}{l}\text { 22. A condition like the one our child has } \\
\text { makes family life very difficult. }\end{array}$ & $\square$ & $\square$ & $\square$ & $\square$ & $\square$ \\
\hline $\begin{array}{l}\text { 23. Our child's activity rarely interferes } \\
\text { with other family activities. }\end{array}$ & $\square$ & $\square$ & $\square$ & $\square$ & $\square$ \\
\hline $\begin{array}{l}\text { 24. Our child's condition requires frequent } \\
\text { hospital stays. }\end{array}$ & $\square$ & $\square$ & $\square$ & $\square$ & $\square$ \\
\hline
\end{tabular}




\begin{tabular}{|l|c|c|c|c|c|}
\hline & $\begin{array}{c}\text { Strongly } \\
\text { Disagree } \\
1\end{array}$ & 2 & 3 & 4 & 5 \\
\hline $\begin{array}{l}\text { 25. We feel we are doing a good job taking } \\
\text { care of our child's condition. }\end{array}$ & $\square$ & $\square$ & $\square$ & $\square$ & $\square$ \\
\hline $\begin{array}{l}\text { 26. People with our child's condition have } \\
\text { a normal length of life. }\end{array}$ & $\square$ & $\square$ & $\square$ & $\square$ & $\square$ \\
\hline $\begin{array}{l}\text { 27. It's often difficult to know if we need } \\
\text { to be more protective of our child. }\end{array}$ & $\square$ & $\square$ & $\square$ & $\square$ & $\square$ \\
\hline $\begin{array}{l}\text { 28. We often feel unsure about what to do } \\
\text { to take care of our child's condition. }\end{array}$ & $\square$ & $\square$ & $\square$ & $\square$ & $\square$ \\
\hline $\begin{array}{l}\text { 29. Our child's condition will be harder to } \\
\text { take care of in the future. }\end{array}$ & $\square$ & $\square$ & $\square$ & $\square$ & $\square$ \\
\hline $\begin{array}{l}\text { 30. We think about our child's condition } \\
\text { all the time. }\end{array}$ & $\square$ & $\square$ & $\square$ & $\square$ & $\square$ \\
\hline $\begin{array}{l}\text { 31. It seems as if our child's condition } \\
\text { controls our family life. }\end{array}$ & $\square$ & $\square$ & $\square$ & $\square$ & $\square$ \\
\hline $\begin{array}{l}\text { 32. Many conditions are more serious than } \\
\text { our child's. }\end{array}$ & $\square$ & $\square$ & $\square$ & $\square$ & $\square$ \\
\hline $\begin{array}{l}\text { 33. It is hard to get anyone else to help us } \\
\text { with our child's condition. }\end{array}$ & $\square$ & $\square$ & $\square$ & $\square$ & $\square$ \\
\hline $\begin{array}{l}\text { 34. We have not been able to develop a } \\
\text { routine for taking care of our child's } \\
\text { condition. }\end{array}$ & $\square$ & $\square$ & $\square$ & $\square$ & $\square$ \\
\hline $\begin{array}{l}\text { 35. It takes a lot of organization to manage } \\
\text { our child's condition. }\end{array}$ & $\square$ & $\square$ & $\square$ & $\square$ & $\square$ \\
\hline $\begin{array}{l}\text { 36. We are sometimes undecided about } \\
\text { how to balance the condition and } \\
\text { family life. }\end{array}$ & $\square$ & $\square$ & $\square$ & $\square$ & $\square$ \\
\hline $\begin{array}{l}\text { 37. It is hard to know what to expect of our } \\
\text { child's condition in the future. }\end{array}$ & $\square$ & $\square$ & $\square$ & $\square$ & $\square$ \\
\hline $\begin{array}{l}\text { 38. Even though our child has the } \\
\text { condition, we have a normal family } \\
\text { life. }\end{array}$ & $\square$ & $\square$ & $\square$ & $\square$ & $\square$ \\
\hline $\begin{array}{l}\text { 39. Our child would do better in school if } \\
\text { he/she didn't have the condition. }\end{array}$ & $\square$ & $\square$ & $\square$ & $\square$ & $\square$ \\
\hline $\begin{array}{l}\text { 40. We are confident that we can take care } \\
\text { of our child's condition. }\end{array}$ & $\square$ & $\square$ & $\square$ & $\square$ & $\square$ \\
\hline
\end{tabular}




\begin{tabular}{|c|c|c|c|c|c|}
\hline & $\begin{array}{c}\text { Strongly } \\
\text { Disagree } \\
1\end{array}$ & 2 & 3 & 4 & $\begin{array}{c}\text { Strongly } \\
\text { Agree } \\
5\end{array}$ \\
\hline $\begin{array}{l}\text { 41. We have goals in mind to help us } \\
\text { manage our child's condition. }\end{array}$ & $\square$ & $\square$ & $\square$ & $\square$ & $\square$ \\
\hline $\begin{array}{l}\text { 42. It is difficult to fit care of our child's } \\
\text { condition into our usual family routine. }\end{array}$ & $\square$ & $\square$ & $\square$ & $\square$ & $\square$ \\
\hline $\begin{array}{l}\text { 43. Dealing with our child's condition } \\
\text { makes family life more difficult. }\end{array}$ & $\square$ & $\square$ & $\square$ & $\square$ & $\square$ \\
\hline $\begin{array}{l}\text { 44. We know when our child needs to be a } \\
\text { child. }\end{array}$ & $\square$ & $\square$ & $\square$ & $\square$ & $\square$ \\
\hline $\begin{array}{l}\text { 45. A condition like the one our child has } \\
\text { makes it hard to live a normal life. }\end{array}$ & $\square$ & $\square$ & $\square$ & $\square$ & $\square$ \\
\hline
\end{tabular}

This ends Section 1.

Section $\mathbf{2}$ covers aspects of family management when there are adult partners in a household. The term "partner" refers to a spouse or partner living in the same household.

If you currently have a partner, please proceed to the next page. If you do not have a partner, please stop here. 


\section{Section 2}

The questions in the next section relate to you and your partner. For each statement in this section, rate your response to the statement on a scale of 1 to 5 , with 1 indicating "Strongly disagree" and 5 indicating "Strongly agree". Again, please respond to each statement in this questionnaire based on how YOU feel, not on how you think your partner or others might respond.

\begin{tabular}{|l|c|c|c|c|c|}
\hline & $\begin{array}{c}\text { Strongly } \\
\text { Disagree }\end{array}$ & & & & $\begin{array}{c}\text { Strongly } \\
\text { Agree }\end{array}$ \\
& 1 & 2 & 3 & 4 & 5 \\
\hline $\begin{array}{l}\text { 46. We are a closer family because of how } \\
\text { we deal with our child's condition. }\end{array}$ & $\square$ & $\square$ & $\square$ & $\square$ & $\square$ \\
$\begin{array}{l}\text { 47. My partner and I have different ideas } \\
\text { about how serious our child's condition } \\
\text { is. }\end{array}$ & $\square$ & $\square$ & $\square$ & $\square$ & $\square$ \\
\hline $\begin{array}{l}\text { 48. I am pleased with how my partner and I } \\
\text { work together to manage our child's } \\
\text { condition. }\end{array}$ & $\square$ & $\square$ & $\square$ & $\square$ & $\square$ \\
$\begin{array}{l}\text { 49. My partner and I argue about how to } \\
\text { manage our child's condition. }\end{array}$ & $\square$ & $\square$ & $\square$ & $\square$ & $\square$ \\
$\begin{array}{l}\text { 50. My partner and I consult with each } \\
\text { other before we make a decision about } \\
\text { our child's care. }\end{array}$ & $\square$ & $\square$ & $\square$ & $\square$ & $\square$ \\
$\begin{array}{l}\text { 51. My partner and I have similar ideas } \\
\text { about how we should be raising our } \\
\text { child. }\end{array}$ & $\square$ & $\square$ & $\square$ & $\square$ & $\square$ \\
$\begin{array}{l}\text { 52. I am unhappy about the way my partner } \\
\text { and I share the management of our } \\
\text { child's condition. }\end{array}$ & $\square$ & $\square$ & $\square$ & $\square$ & $\square$ \\
$\begin{array}{l}\text { 53. My partner and I support each other in } \\
\text { taking care of our child's condition. }\end{array}$ & $\square$ & $\square$ & $\square$ & $\square$ & $\square$ \\
\hline
\end{tabular}




\section{ANEXO B - CÓPIA DA AUTORIZAÇÃO PARA TRADUÇÃO, ADAPTAÇÃO TRANSCULTURAL E VALIDAÇÃO DO FAMILY MANAGEMENT MEASURE ${ }^{2}$}

Copyright and Permissions

FaMM is a copyrighted instrument. It is made available through this website for use in research and clinical practice. There is no charge for using the FaMM. FaMM can be used in its entirety or selected scales can be used. If you do use the FaMM in your research and clinical practice, we ask that you send us a copy of any publications reporting your work. We will add them to the reference list on this website. Since the FaMM is a new measure, we would appreciate receiving your feedback on how it performs with other samples. We will continue to update this website with new information on the FaMM (http://nursing.unc.edu/research/famm/).

\footnotetext{
${ }^{2}$ Disponível em: <www.nursing.unc.edu/research/famm/> Acesso em 16 set 2011.
} 


\section{ANEXO C - TRADUÇÃO 1}

\section{INSTRUMENTO DE MEDIDA DE MANEJO FAMILIAR}

Este questionário é sobre como a sua família maneja o cuidado de uma criança com doença crônica.

Instruções

Para cada afirmação deste questionário, pedimos que você dê uma nota de 1 a 5 , sendo que 1 significa "discordo bastante" e 5 indica "concordo bastante". Por favor responda a estas questões com base no que você pensa, não em como você pensa que os outros poderiam responder. Se seu filho possui mais de uma doença crônica, a palavra "doença" se refere a todos os diagnósticos juntos. Além disso, várias questões utilizam a palavra "família". Ela se refere às pessoas que vivem na mesma casa que você, e que você considera como sendo da família.

SEÇÃO 1 - a ser preenchida por todos

Por favor marque um " $x$ " no quadrado equivalente à sua resposta para cada questão.

\begin{tabular}{|l|c|c|c|c|c|}
\cline { 2 - 5 } \multicolumn{1}{c|}{} & $\begin{array}{c}\text { Discordo } \\
\text { totalmente }\end{array}$ & & & & $\begin{array}{c}\text { concordo } \\
\text { totalmente }\end{array}$ \\
\cline { 2 - 6 } \multicolumn{1}{c|}{} & $\mathbf{1}$ & $\mathbf{2}$ & $\mathbf{3}$ & $\mathbf{4}$ & $\mathbf{5}$ \\
\hline $\begin{array}{l}\text { 1. O dia a dia de nosso filho é } \\
\text { parecido com o de outras } \\
\text { crianças na mesma idade dele. }\end{array}$ & & & & & \\
\hline $\begin{array}{l}\text { 2. A doença de nosso filho } \\
\text { atrapalha os } \\
\text { relacionamentos familiares }\end{array}$ & & & & & \\
\hline $\begin{array}{l}\text { 3. A doença de nosso filho } \\
\text { requer visitas freqüentes ao } \\
\text { hospital ou consultório. }\end{array}$ & & & & & \\
\hline $\begin{array}{l}\text { 4. No futuro, esperamos que } \\
\text { nosso filho seja capaz de cuidar } \\
\text { de sua doença }\end{array}$ & & & & & \\
\hline $\begin{array}{l}\text { 5. Nosso filho aproveita menos a } \\
\text { vida por causa da sua doença. }\end{array}$ & & & & & \\
\hline $\begin{array}{l}\text { 6. Cuidar da doença de nosso } \\
\text { filho é freqüentemente muito } \\
\text { pesado. }\end{array}$ & & & & & \\
\hline $\begin{array}{l}\text { 7. A doença de nosso filho é } \\
\text { como uma montanha-russa, } \\
\text { cheia de altos e baixos. }\end{array}$ & & & & & \\
\hline
\end{tabular}




\begin{tabular}{|c|c|c|c|c|c|}
\hline & \begin{tabular}{|c|}
$\begin{array}{c}\text { Discordo } \\
\text { totalmente }\end{array}$ \\
1
\end{tabular} & 2 & 3 & 4 & $\begin{array}{c}\begin{array}{c}\text { Concordo } \\
\text { totalmente }\end{array} \\
5\end{array}$ \\
\hline $\begin{array}{l}\text { 8. A doença de nosso filho é a } \\
\text { coisa mais importante em nossa } \\
\text { família. }\end{array}$ & & & & & \\
\hline $\begin{array}{l}\text { 9. Para nós é muito difícil cuidar } \\
\text { da doença de nosso filhos. }\end{array}$ & & & & & \\
\hline $\begin{array}{l}10 . \text { Nosso filho participa de } \\
\text { atividades que ele/ela tem } \\
\text { vontade, independente de sua } \\
\text { doenca. }\end{array}$ & & & & & \\
\hline $\begin{array}{l}\text { 11. Por causa da doença, nós } \\
\text { nos preocupamos com o futuro } \\
\text { dele. }\end{array}$ & & & & & \\
\hline $\begin{array}{l}\text { 12. A doença do nosso filho não } \\
\text { requer muito tempo para cuidar. }\end{array}$ & & & & & \\
\hline $\begin{array}{l}\text { 13. Temos algumas ideias bem } \\
\text { definidas acerca de como ajudar } \\
\text { nosso filho a conviver com a } \\
\text { doença. }\end{array}$ & & & & & \\
\hline $\begin{array}{l}\text { 14. Apesar da doença, } \\
\text { esperamos que nosso filho more } \\
\text { fora de casa no futuro. }\end{array}$ & & & & & \\
\hline $\begin{array}{l}\text { 15. Temos dinheiro suficiente } \\
\text { para bancar as despesas } \\
\text { decorrentes da doença dele. }\end{array}$ & & & & & \\
\hline $\begin{array}{l}\text { 16. Nosso filho é diferente de } \\
\text { outras crianças da mesma idade } \\
\text { por causa de sua doença. }\end{array}$ & & & & & \\
\hline $\begin{array}{l}\text { 17. É difícil saber quando a } \\
\text { doença de nosso filho deve ser } \\
\text { prioridade na família. }\end{array}$ & & & & & \\
\hline $\begin{array}{l}\text { 18. Estamos na expectativa de } \\
\text { termos um futuro feliz com nosso } \\
\text { filho. }\end{array}$ & & & & & \\
\hline $\begin{array}{l}\text { 19. Quando algo inesperado } \\
\text { acontece com nosso filho devido } \\
\text { à doença, geralmente sabemos } \\
\text { como lidar com isso. }\end{array}$ & & & & & \\
\hline $\begin{array}{l}\text { 20. As amizades de nosso filho } \\
\text { são diferentes por conta da } \\
\text { doença. }\end{array}$ & & & & & \\
\hline $\begin{array}{l}21 . \text { Esperamos poder gastar } \\
\text { menos tempo nos cuidados com } \\
\text { a doença de nosso filho no } \\
\text { futuro. }\end{array}$ & & & & & \\
\hline
\end{tabular}




\begin{tabular}{|c|c|c|c|c|c|}
\hline & $\begin{array}{c}\text { Discordo } \\
\text { totalmente }\end{array}$ & 0 & 2 & 1 & $\begin{array}{c}\begin{array}{c}\text { Concordo } \\
\text { totalmente }\end{array} \\
5\end{array}$ \\
\hline $\begin{array}{l}\text { 22. Uma doença como a de } \\
\text { nosso filho torna a vida familiar } \\
\text { muito difícil. }\end{array}$ & & 2 & 3 & 4 & \\
\hline $\begin{array}{l}\text { 23. As atividades de nosso filho } \\
\text { raramente interferem com outras } \\
\text { atividades da família. }\end{array}$ & & & & & \\
\hline $\begin{array}{l}\text { 24. A doença de nosso filho } \\
\text { requer constantes internações } \\
\text { hospitalares. }\end{array}$ & & & & & \\
\hline $\begin{array}{l}\text { 25. Sentimos que estamos } \\
\text { fazendo um bom trabalho } \\
\text { cuidando da doença de nosso } \\
\text { filho. }\end{array}$ & & & & & \\
\hline $\begin{array}{l}\text { 26. Pessoas com a doença como } \\
\text { a dele tem uma expectativa de } \\
\text { vida normal. }\end{array}$ & & & & & \\
\hline $\begin{array}{l}\text { 27. Geralmente é difícil saber se } \\
\text { precisamos ser mais protetores } \\
\text { de nosso filho. }\end{array}$ & & & & & \\
\hline $\begin{array}{l}\text { 28. Geralmente nos sentimos } \\
\text { inseguros em relação ao que } \\
\text { fazer para cuidar da doença de } \\
\text { nosso filho. }\end{array}$ & & & & & \\
\hline $\begin{array}{l}\text { 29. A doença de nosso filho será } \\
\text { mais difícil de cuidar no futuro. }\end{array}$ & & & & & \\
\hline $\begin{array}{l}\text { 30. Nós pensamos sobre a } \\
\text { doença de nosso filho o tempo } \\
\text { todo. }\end{array}$ & & & & & \\
\hline $\begin{array}{l}\text { 31. Parece que a doença de } \\
\text { nosso filho controla a vida da } \\
\text { nossa família. }\end{array}$ & & & & & \\
\hline $\begin{array}{l}\text { 32. Muitas doenças são piores } \\
\text { do que a que nosso filho tem. }\end{array}$ & & & & & \\
\hline $\begin{array}{l}\text { 33. É difícil conseguir qualquer } \\
\text { outra pessoa que nos ajude com } \\
\text { nosso filho. }\end{array}$ & & & & & \\
\hline $\begin{array}{l}\text { 34. Não estamos conseguindo } \\
\text { nos organizar para estabelecer } \\
\text { uma rotina para cuidar da } \\
\text { doença de nosso filho. }\end{array}$ & & & & & \\
\hline $\begin{array}{l}\text { 35. Precisa de muita organização } \\
\text { para lidar com a doença de } \\
\text { nosso filho. }\end{array}$ & & & & & \\
\hline
\end{tabular}




\begin{tabular}{|c|c|c|c|c|c|}
\hline & \multirow{2}{*}{$\begin{array}{c}\begin{array}{c}\text { Discordo } \\
\text { totalmente }\end{array} \\
1 \\
\end{array}$} & \multirow[b]{2}{*}{2} & \multirow[b]{2}{*}{3} & \multirow[b]{2}{*}{4} & \multirow{2}{*}{$\begin{array}{c}\begin{array}{c}\text { Concordo } \\
\text { totalmente }\end{array} \\
5 \\
\end{array}$} \\
\hline & & & & & \\
\hline $\begin{array}{l}\text { 36. Às vezes somos indecisos } \\
\text { sobre como equilibrar a doença } \\
\text { dele e a vida familiar. }\end{array}$ & & & & & \\
\hline $\begin{array}{l}\text { 37. É difícil saber o que esperar } \\
\text { da doença de nosso filho no } \\
\text { futuro. }\end{array}$ & & & & & \\
\hline $\begin{array}{l}\text { 38. Apesar de nosso filho ter a } \\
\text { doença, nós temos uma vida } \\
\text { familiar normal. }\end{array}$ & & & & & \\
\hline $\begin{array}{l}\text { 39. Nosso filho teria um melhor } \\
\text { desempenho na escola se não } \\
\text { tivesse a doença. }\end{array}$ & & & & & \\
\hline $\begin{array}{l}\text { 40. Temos confiança de que } \\
\text { podemos cuidar da doença de } \\
\text { nosso filho. }\end{array}$ & & & & & \\
\hline $\begin{array}{l}\text { 41. Nós mantemos alguns alvos } \\
\text { em mente para nos ajudar a } \\
\text { manejar a doença de nosso filho. }\end{array}$ & & & & & \\
\hline $\begin{array}{l}42 . \text { É difícil incluir o cuidado com } \\
\text { a doença de nosso filho na nossa } \\
\text { rotina familiar. }\end{array}$ & & & & & \\
\hline $\begin{array}{l}\text { 43. Lidar com a doença de nosso } \\
\text { filho torna a vida familiar mais } \\
\text { difícil. }\end{array}$ & & & & & \\
\hline $\begin{array}{l}\text { 44. Nós sabemos quando nosso } \\
\text { filho precisa ser como uma } \\
\text { criança. }\end{array}$ & & & & & \\
\hline $\begin{array}{l}\text { 45. Uma doença como a que } \\
\text { nosso filho tem faz com que seja } \\
\text { muito difícil levar uma vida } \\
\text { normal. }\end{array}$ & & & & & \\
\hline
\end{tabular}

Isto encerra a seção 1.

A Seção 2 aborda aspectos do manejo familiar quando existem parceiros adultos na mesma casa. O termo "parceiros" se refere ao cônjuge ou companheiro que vive na mesma casa.

Se você atualmente mora com um parceiro, por favor continue com o questionário na próxima página. Caso contrário, por favor pare por aqui. 


\section{SEÇÃO 2}

As questões nesta próxima seção referem-se a você e seu parceiro. Para cada afirmação deste questionário, pedimos que você dê uma nota de 1 a 5 , sendo que 1 significa "discordo bastante" e 5 indica "concordo bastante". Novamente, por favor responda a estas questões com base no que você pensa, não em como você pensa que seu parceiro ou os outros poderiam responder.

\begin{tabular}{|c|c|c|c|c|c|}
\hline & $\begin{array}{c}\text { Discordo } \\
\text { totalmente }\end{array}$ & & & & $\begin{array}{l}\text { Concordo } \\
\text { totalmente }\end{array}$ \\
\hline & & 2 & 3 & 4 & \\
\hline \multicolumn{6}{|l|}{$\begin{array}{l}\text { 46. Nós somos uma família mais } \\
\text { unida devido à forma como } \\
\text { lidamos com a doença de nosso } \\
\text { filho. }\end{array}$} \\
\hline \multicolumn{6}{|l|}{$\begin{array}{l}\text { 47. Meu parceiro e eu temos } \\
\text { ideias diferentes acerca da } \\
\text { gravidade da doença de nosso } \\
\text { filho. }\end{array}$} \\
\hline \multicolumn{6}{|l|}{$\begin{array}{l}\text { 48. Estou satisfeito com a forma } \\
\text { como meu parceiro e eu } \\
\text { trabalhamos juntos para manejar } \\
\text { a doença de nosso filho. }\end{array}$} \\
\hline \multicolumn{6}{|l|}{$\begin{array}{l}\text { 49. Meu parceiro e e eu } \\
\text { discutimos/brigamos acerca da } \\
\text { forma como manejar a doença de } \\
\text { nosso filho. }\end{array}$} \\
\hline \multicolumn{6}{|l|}{$\begin{array}{l}\text { 50. Meu parceiro e eu nos } \\
\text { consultamos antes de tomarmos } \\
\text { uma decisão acerca do cuidado } \\
\text { com nosso filho. }\end{array}$} \\
\hline \multicolumn{6}{|l|}{$\begin{array}{l}\text { 51. Meu parceiro e eu temos } \\
\text { ideias semelhantes acerca de } \\
\text { como criar nosso filho. }\end{array}$} \\
\hline \multicolumn{6}{|l|}{$\begin{array}{l}\text { 52. Estou infeliz com a forma } \\
\text { como meu parceiro e eu } \\
\text { compartilhamos o manejo da } \\
\text { doença de nosso filho. }\end{array}$} \\
\hline $\begin{array}{l}\text { 53. Meu parceiro e eu nos } \\
\text { apoiamos e nos ajudamos no } \\
\text { cuidado da doença de nosso filho. }\end{array}$ & & & & & \\
\hline
\end{tabular}




\section{ANEXO D - TRADUÇÃO 2}

\section{PESQUISA DE GESTÃO FAMILIAR}

Este questionário avalia como sua família convive com uma criança com condições críticas.

Instruções

Para cada questão, você deve assinalar sua resposta na escala de 1 a 5 , onde 1 significa "discordo totalmente" e 5 significa "concordo totalmente". Por favor, responda cada pergunta de acordo com o que você pensa, e não como você imagina que outras pessoas responderiam. Se seu filho(a) tem mais do que uma condição crítica, o termo "condição" crítica representa todas elas juntas. O termo "família", contido em muitas questões, refere-se a todos que vivem em sua casa, como uma família.

Parte 1: para ser respondida por todos na família

\begin{tabular}{|c|c|c|c|c|c|c|}
\hline & & $\begin{array}{c}\text { Discordo } \\
\text { totalmente } \\
1\end{array}$ & 2 & 3 & 4 & $\begin{array}{c}\text { Concordo totalmente } \\
5\end{array}$ \\
\hline 1. & $\begin{array}{l}\text { O dia-a-dia do nosso filho(a) é } \\
\text { similar ao de crianças da } \\
\text { mesma idade }\end{array}$ & $\square$ & $\square$ & $\square$ & $\square$ & $\square$ \\
\hline 2. & $\begin{array}{l}\text { A condição do nosso filho(a) } \\
\text { interfere no relacionamento da } \\
\text { família }\end{array}$ & $\square$ & $\square$ & $\square$ & $\square$ & $\square$ \\
\hline 3. & $\begin{array}{l}\text { A condição do nosso filho(a) } \\
\text { requer visitas freqüentes ao } \\
\text { médico }\end{array}$ & $\square$ & $\square$ & $\square$ & $\square$ & $\square$ \\
\hline 4. & $\begin{array}{l}\text { Esperamos que, futuramente, } \\
\text { nosso filho(a) cuide de sua } \\
\text { condição }\end{array}$ & $\square$ & $\square$ & $\square$ & $\square$ & $\square$ \\
\hline 5. & $\begin{array}{l}\text { Nosso filho(a) não aproveita } \\
\text { muito a vida por causa de sua } \\
\text { condição }\end{array}$ & $\square$ & $\square$ & $\square$ & $\square$ & $\square$ \\
\hline 6. & $\begin{array}{l}\text { Cuidar da condição do nosso } \\
\text { filho(a) é frequentemente } \\
\text { insuportável }\end{array}$ & $\square$ & $\square$ & $\square$ & $\square$ & $\square$ \\
\hline 7. & $\begin{array}{l}\text { A condição do nosso filho(a) é } \\
\text { como uma montanha-russa, } \\
\text { com muitos altos e baixos }\end{array}$ & $\square$ & $\square$ & $\square$ & $\square$ & $\square$ \\
\hline 8. & $\begin{array}{l}\text { A condição do nosso filho(a) é } \\
\text { a coisa mais importante na } \\
\text { nossa família }\end{array}$ & $\square$ & $\square$ & $\square$ & $\square$ & $\square$ \\
\hline 9. & $\begin{array}{l}\text { É muito difícil cuidar da } \\
\text { condição do nosso filho(a) }\end{array}$ & $\square$ & $\square$ & $\square$ & $\square$ & $\square$ \\
\hline
\end{tabular}




\begin{tabular}{|c|l|c|c|c|c|c|}
\hline 10. & $\begin{array}{l}\text { Nosso filho(a) participa de } \\
\text { atividades que deseja apesar } \\
\text { de sua condição }\end{array}$ & $\square$ & $\square$ & $\square$ & $\square$ & $\square$ \\
\hline 11. & $\begin{array}{l}\text { Nos preocupamos com o futuro } \\
\text { do nosso filho(a) por causa da } \\
\text { sua condição }\end{array}$ & $\square$ & $\square$ & $\square$ & $\square$ & $\square$ \\
\hline 12. & $\begin{array}{l}\text { Os cuidados com a condição do } \\
\text { nosso filho(a) não exigem muito } \\
\text { tempo }\end{array}$ & $\square$ & $\square$ & $\square$ & $\square$ & $\square$ \\
\hline 13. & $\begin{array}{l}\text { Nós temos idéias bem definidas } \\
\text { de como cuidar da condição de } \\
\text { nosso filho(a) }\end{array}$ & $\square$ & $\square$ & $\square$ & $\square$ & $\square$ \\
\hline 14. & $\begin{array}{l}\text { Apesar de sua condição, } \\
\text { esperamos que, no futuro, } \\
\text { nosso filho(a) possa viver em } \\
\text { sua própria casa }\end{array}$ & $\square$ & $\square$ & $\square$ & $\square$ & $\square$ \\
\hline 15. & $\begin{array}{l}\text { Nós temos condição financeira } \\
\text { suficiente para tratar da } \\
\text { condição do nosso filho(a) }\end{array}$ & $\square$ & $\square$ & $\square$ & $\square$ & $\square$ \\
\hline 16. & $\begin{array}{l}\text { Nosso filho(a) é diferente de } \\
\text { outras crianças da sua idade } \\
\text { por causa da sua condição }\end{array}$ & $\square$ & $\square$ & $\square$ & $\square$ & $\square$ \\
\hline 17. & $\begin{array}{l}\text { E difícil saber quando a } \\
\text { condição do nosso filho(a) deve } \\
\text { vir em primeiro lugar na família }\end{array}$ & $\square$ & $\square$ & $\square$ & $\square$ & $\square$ \\
\hline 18. & $\begin{array}{l}\text { Nós vemos um futuro feliz com } \\
\text { nosso filho(a) }\end{array}$ & $\square$ & $\square$ & $\square$ & $\square$ & $\square$ \\
\hline 19. & $\begin{array}{l}\text { Quando ocorre algo inesperado } \\
\text { com a condição do nosso } \\
\text { filho(a), normalmente sabemos } \\
\text { como lidar }\end{array}$ & $\square$ & $\square$ & $\square$ & $\square$ & $\square$ \\
\hline 20. & $\begin{array}{l}\text { As amizades do nosso filho(a) } \\
\text { são diferentes por causa da sua } \\
\text { condição }\end{array}$ & $\square$ & $\square$ & $\square$ & $\square$ & $\square$ \\
\hline 21. & $\begin{array}{l}\text { No futuro, esperamos dedicar } \\
\text { menos tempo para cuidar da } \\
\text { condição do nosso filho(a) }\end{array}$ & $\square$ & $\square$ & $\square$ & $\square$ \\
\hline 22. & $\begin{array}{l}\text { Uma condição crítica como a } \\
\text { do nosso filho(a) torna a vida } \\
\text { familiar muito difícil }\end{array}$ & $\square$ & $\square$ & $\square$ & $\square$ & $\square$ \\
\hline 23. & $\begin{array}{l}\text { As atividades do nosso filho(a) } \\
\text { raramente interferem nas } \\
\text { atividades da família }\end{array}$ & $\square$ & $\square$ & $\square$ & $\square$ & $\square$ \\
\hline 24. & $\begin{array}{l}\text { A condição do nosso filho(a) } \\
\text { exige permanências freqüentes } \\
\text { no hospital }\end{array}$ \\
\hline 25. & $\begin{array}{l}\text { Nós percebemos que que } \\
\text { estamos cuidando muito bem } \\
\text { da condição crítica do nosso } \\
\text { filho(a) }\end{array}$ & $\square$ & $\square$ & $\square$ & $\square$ \\
\hline
\end{tabular}




\begin{tabular}{|c|l|c|c|c|c|c|}
\hline 26. & $\begin{array}{l}\text { Pessoas com a condição do } \\
\text { nosso filho(a) tem uma } \\
\text { expectativa de vida igual aos } \\
\text { outros }\end{array}$ & $\square$ & $\square$ & $\square$ & $\square$ & $\square$ \\
\hline 27. & $\begin{array}{l}\text { É sempre difícil de saber se } \\
\text { precisamos ser mais protetores } \\
\text { com nosso filho(a) }\end{array}$ & $\square$ & $\square$ & $\square$ & $\square$ & $\square$ \\
\hline 28. & $\begin{array}{l}\text { Nos sentimos sempre } \\
\text { inseguros em o que fazer para } \\
\text { cuidar da condição do nosso } \\
\text { filho(a) }\end{array}$ & $\square$ & $\square$ & $\square$ & $\square$ & $\square$ \\
\hline 29. & $\begin{array}{l}\text { No futuro, será mais difícil de } \\
\text { cuidar da condição do nosso } \\
\text { filho(a) }\end{array}$ & $\square$ & $\square$ & $\square$ & $\square$ & $\square$ \\
\hline 30. & $\begin{array}{l}\text { Nós pensamos na condição do } \\
\text { nosso filho(a) o tempo todo }\end{array}$ & $\square$ & $\square$ & $\square$ & $\square$ & $\square$ \\
\hline 31. & $\begin{array}{l}\text { Sentimos que a condição do } \\
\text { nosso filho(a) controla a vida da } \\
\text { nosso família }\end{array}$ & $\square$ & $\square$ & $\square$ & $\square$ & $\square$ \\
\hline 32. & $\begin{array}{l}\text { Muitas outras condições críticas } \\
\text { são mais sérias do que a do } \\
\text { nosso filho(a) }\end{array}$ & $\square$ & $\square$ & $\square$ & $\square$ & $\square$ \\
\hline 33. & $\begin{array}{l}\text { É difícil conseguir ajuda de } \\
\text { outras pessoas para cuidar da } \\
\text { condição do nosso filho(a) }\end{array}$ & $\square$ & $\square$ & $\square$ & $\square$ & $\square$ \\
\hline 34. & $\begin{array}{l}\text { Nós não estamos conseguindo } \\
\text { criar uma rotina para cuidar da } \\
\text { condição do nosso filho(a) }\end{array}$ & $\square$ & $\square$ & $\square$ & $\square$ & $\square$ \\
\hline 35. & $\begin{array}{l}\text { É necessário muita organização } \\
\text { para cuidar da condição do } \\
\text { nosso filho(a) }\end{array}$ & $\square$ & $\square$ & $\square$ & $\square$ & $\square$ \\
\hline 36. & $\begin{array}{l}\text { Ás vezes, não temos certeza de } \\
\text { como equilibrar a vida da } \\
\text { família com a condição do } \\
\text { nosso filho(a) }\end{array}$ & $\square$ & $\square$ & $\square$ \\
\hline 37. & $\begin{array}{l}\text { É dif́́il saber como será a } \\
\text { condição crítica do nosso } \\
\text { filho(a) no futuro }\end{array}$ \\
\hline 38. & $\begin{array}{l}\text { Mesmo com a condição do } \\
\text { nosso filho(a), nós temos uma } \\
\text { vida familiar normal }\end{array}$ & $\square$ & $\square$ & $\square$ & $\square$ & $\square$ \\
\hline 39. & $\begin{array}{l}\text { Nosso filho(a) teria melhor } \\
\text { desempenho na escola se não } \\
\text { tivesse esta condição }\end{array}$ \\
\hline 40. & $\begin{array}{l}\text { Estamos confiantes que } \\
\text { podemos cuidar da condição do } \\
\text { nosso filho(a) }\end{array}$ & $\square$ & $\square$ & $\square$ \\
\hline 41. & $\begin{array}{l}\text { Nós temos objetivos claros que } \\
\text { nos ajudam a cuidar da } \\
\text { condição do nosso filho(a) }\end{array}$ & $\square$ & $\square$ & $\square$ \\
\hline
\end{tabular}




\begin{tabular}{|r|l|c|c|c|c|c|}
\hline 42. & $\begin{array}{l}\text { É difícil adequar a atividade de } \\
\text { fuidar da condição do nosso } \\
\text { filho(a) dentro da rotina da } \\
\text { família }\end{array}$ & $\square$ & $\square$ & $\square$ & $\square$ & $\square$ \\
\hline 43. & $\begin{array}{l}\text { Lidar com a condição do nosso } \\
\text { filho(a) torna mais difícil a vida } \\
\text { da família }\end{array}$ & $\square$ & $\square$ & $\square$ & $\square$ & $\square$ \\
\hline 44. & $\begin{array}{l}\text { Nós sabemos quando nosso } \\
\text { filho(a) precisa ser criança }\end{array}$ & $\square$ & $\square$ & $\square$ & $\square$ & $\square$ \\
\hline 45. & $\begin{array}{l}\text { É difícil manter uma vida } \\
\text { normal com a condição que o } \\
\text { nosso filho(a) tem }\end{array}$ & $\square$ & $\square$ & $\square$ & $\square$ & $\square$ \\
\hline
\end{tabular}

\section{Parte 2:}

As questões abaixo referem-se a você e seu companheiro(a). Para cada questão, você deve assinalar sua resposta na escala de 1 a 5 , onde 1 significa "discordo totalmente" e 5 significa "concordo totalmente". De novo, responda cada pergunta de acordo com o que você sente, e não como você imagina que seu cônjuge ou outras pessoas responderiam.

\begin{tabular}{|c|c|c|c|c|c|c|}
\hline & & $\begin{array}{c}\text { Discordo } \\
\text { totalmente } \\
1\end{array}$ & 2 & 3 & 4 & $\begin{array}{c}\text { Concordo } \\
\text { totalment } \\
\text { e } \\
5\end{array}$ \\
\hline $\begin{array}{l}46 \\
.\end{array}$ & $\begin{array}{l}\text { Nossa família é mais unida por } \\
\text { causa da maneira como lidamos } \\
\text { com a condição do nosso filho(a) }\end{array}$ & $\square$ & $\square$ & $\square$ & $\square$ & $\square$ \\
\hline 47 & $\begin{array}{l}\text { Eu e meu companheiro(a) temos } \\
\text { idéias diferentes de quão séria é a } \\
\text { condição do nosso filho(a) }\end{array}$ & $\square$ & $\square$ & $\square$ & $\square$ & $\square$ \\
\hline 48 & $\begin{array}{l}\text { A maneira como eu e meu } \\
\text { companheiro(a) cuidamos juntos da } \\
\text { condição do nosso filho(a) me deixa } \\
\text { satisfeito(a) }\end{array}$ & $\square$ & $\square$ & $\square$ & $\square$ & $\square$ \\
\hline 49 & $\begin{array}{l}\text { Eu e meu companheiro(a) } \\
\text { discutimos bastante sobre como } \\
\text { cuidar da condição do nosso filho(a) }\end{array}$ & $\square$ & $\square$ & $\square$ & $\square$ & $\square$ \\
\hline $\begin{array}{l}50 \\
\text {. }\end{array}$ & $\begin{array}{l}\text { Eu e meu companheiro(a) sempre } \\
\text { conversamos antes de tomar } \\
\text { qualquer decisão sobre os cuidados } \\
\text { com a condição do nosso filho(a) }\end{array}$ & $\square$ & $\square$ & $\square$ & $\square$ & $\square$ \\
\hline 51 & $\begin{array}{l}\text { Eu e meu companheiro(a) temos } \\
\text { idéias similares de como } \\
\text { deveríamos educar nosso filho(a) }\end{array}$ & $\square$ & $\square$ & $\square$ & $\square$ & $\square$ \\
\hline 52 & $\begin{array}{l}\text { Estou insatisfeito(a) de como eu e } \\
\text { meu companheiro(a) } \\
\text { compartilhamos os cuidados com a } \\
\text { condição do nosso filho(a) }\end{array}$ & $\square$ & $\square$ & $\square$ & $\square$ & $\square$ \\
\hline 53 & $\begin{array}{l}\text { Eu e meu companheiro(a) ajudamos } \\
\text { um ao outro nos cuidados com a } \\
\text { condição do nosso filho(a) }\end{array}$ & $\square$ & $\square$ & $\square$ & $\square$ & $\square$ \\
\hline
\end{tabular}




\section{ANEXO E - RETROTRADUÇÃO 1}

\section{INSTRUMENT FOR MEASURING FAMILY MANAGEMENT}

This Questionnaire assesses how your family lives with a child with a chronic disease.

\section{Instructions}

For each statement in this questionnaire, we ask that you give it a rating of 1 to 5 , where 1 means "strongly disagree" and 5 indicates "strongly agree". Please answer these questions based on what you think, not how you think others might respond. If (CHILD'S NAME) possesses more than one chronic disease, the word "disease" refers to all diagnosis together. In addition, several questions use the word "family". It refers to people living in the same house as you and who you consider as family.

SECTION 1 - To be filled in by any family regardless if the couple lives together.

Please mark an " $X$ " in the square corresponding to your response to each question.

\begin{tabular}{|c|c|c|c|c|c|}
\hline & $\begin{array}{c}\text { STRONGLY } \\
\text { DISAGREE } \\
\mathbf{1}\end{array}$ & 2 & 3 & 4 & $\begin{array}{c}\text { STRONGLY } \\
\text { AGREE } \\
5\end{array}$ \\
\hline $\begin{array}{l}\text { 1. Day to day life of (child's name) } \\
\text { is similar to that of other children } \\
\text { with the same age. }\end{array}$ & & & & & \\
\hline $\begin{array}{l}\text { 2. The disease of (child's name) } \\
\text { interferes } \\
\text { relationships. }\end{array}$ & & & & & \\
\hline $\begin{array}{l}\text { 3. The disease of (child's name) } \\
\text { requires frequent visits to the } \\
\text { doctor. }\end{array}$ & & & & & \\
\hline $\begin{array}{l}\text { 4. We hope that (child's name) in } \\
\text { the future will be able to care for } \\
\text { his/her disease. }\end{array}$ & & & & & \\
\hline $\begin{array}{l}\text { 5. (Child's name) enjoys life less } \\
\text { because of the disease. }\end{array}$ & & & & & \\
\hline $\begin{array}{l}\text { 6. Taking care of the disease of } \\
\text { (child's name) is often very } \\
\text { difficult. }\end{array}$ & & & & & \\
\hline $\begin{array}{l}\text { 7. The disease of (child's name) } \\
\text { is like a roller coaster, full of ups } \\
\text { and downs. }\end{array}$ & & & & & \\
\hline
\end{tabular}




\begin{tabular}{|c|c|c|c|c|c|}
\hline & $\begin{array}{c}\text { STRONGLY } \\
\text { DISAGREE } \\
\mathbf{1}\end{array}$ & 2 & 3 & 4 & $\begin{array}{l}\text { STRONGLY } \\
\text { AGREE } \\
5\end{array}$ \\
\hline $\begin{array}{l}\text { 8. The disease of (child's name) } \\
\text { is the most important thing in our } \\
\text { family. }\end{array}$ & & & & & \\
\hline $\begin{array}{l}\text { 9. It is very difficult for us to take } \\
\text { care of the disease of (child's } \\
\text { name) }\end{array}$ & & & & & \\
\hline $\begin{array}{l}\text { 10. (Child's name) participates in } \\
\text { activities that he/she wishes in } \\
\text { spite of the disease. }\end{array}$ & & & & & \\
\hline $\begin{array}{l}\text { 11. We worry about the future of } \\
\text { (child's name) because of his/her } \\
\text { disease. }\end{array}$ & & & & & \\
\hline $\begin{array}{l}\text { 12. Dealing with the disease of } \\
\text { (child's name) does not require } \\
\text { much time. }\end{array}$ & & & & & \\
\hline $\begin{array}{l}\text { 13. We have some definate ideas } \\
\text { about how to help (child's name) } \\
\text { to live with the disease. }\end{array}$ & & & & & \\
\hline $\begin{array}{l}\text { 14. Despite the disease, we hope } \\
\text { that in the future (child's name) } \\
\text { can live in his/her own home. }\end{array}$ & & & & & \\
\hline $\begin{array}{l}\text { 15. We have sufficient financial } \\
\text { conditions to pay the costs of the } \\
\text { disease of (child's name) }\end{array}$ & & & & & \\
\hline $\begin{array}{l}\text { 16. (Child's name) is different } \\
\text { from other children the same age } \\
\text { because of his/her disease. }\end{array}$ & & & & & \\
\hline $\begin{array}{l}\text { 17. It is difficult to know when the } \\
\text { disease of (child's name) should } \\
\text { come first in the family. }\end{array}$ & & & & & \\
\hline $\begin{array}{l}\text { 18. We hope to have a happy } \\
\text { future with (child's name). }\end{array}$ & & & & & \\
\hline $\begin{array}{l}\text { 19. When something unexpected } \\
\text { happens in relation to the disease } \\
\text { of (child's name) we usually know } \\
\text { how to cope with it. }\end{array}$ & & & & & \\
\hline $\begin{array}{l}20 . \text { The friendships of (child's } \\
\text { name) are different because of } \\
\text { his/her disease. }\end{array}$ & & & & & \\
\hline $\begin{array}{l}\text { 21. In the future we hope to } \\
\text { devote less time to care for the } \\
\text { disease of (child's name) }\end{array}$ & & & & & \\
\hline $\begin{array}{l}\text { 22. A disease like (child's name) } \\
\text { has makes family life very difficult. }\end{array}$ & & & & & \\
\hline
\end{tabular}




\begin{tabular}{|c|c|c|c|c|c|}
\hline & $\begin{array}{c}\text { STRONGLY } \\
\text { DISAGREE } \\
1\end{array}$ & 2 & 3 & 4 & $\begin{array}{c}\text { STRONGLY } \\
\text { AGREE } \\
5\end{array}$ \\
\hline $\begin{array}{l}23 \text {. The activities of (child's name) } \\
\text { rarely interfere with other family } \\
\text { activities. }\end{array}$ & & & & & \\
\hline $\begin{array}{l}\text { 24. The disease of (child's name) } \\
\text { requires frequent hospitalizations. }\end{array}$ & & & & & \\
\hline $\begin{array}{l}\text { 25. We feel we are doing a good } \\
\text { job in caring for (child's name) }\end{array}$ & & & & & \\
\hline $\begin{array}{l}\text { 26. People with a disease such as } \\
\text { (child's name), have a normal life } \\
\text { expectancy. }\end{array}$ & & & & & \\
\hline $\begin{array}{l}\text { 27. Generally it is difficult to know } \\
\text { whether we need to be more } \\
\text { protective of (child's name). }\end{array}$ & & & & & \\
\hline $\begin{array}{l}\text { 28. Generally we feel uncertain } \\
\text { regarding what to do to take care } \\
\text { of the disease of (child's name). }\end{array}$ & & & & & \\
\hline $\begin{array}{l}\text { 29. In the future it will be more } \\
\text { difficult to care for the disease of } \\
\text { (child's name). }\end{array}$ & & & & & \\
\hline $\begin{array}{l}\text { 30. We think about the disease of } \\
\text { (child's name) all the time. }\end{array}$ & & & & & \\
\hline $\begin{array}{l}\text { 31. It seems that the disease of } \\
\text { (child's name) controls the life of } \\
\text { our family. }\end{array}$ & & & & & \\
\hline $\begin{array}{l}\text { 32. Many diseases are more } \\
\text { serious than that of (child's } \\
\text { name). }\end{array}$ & & & & & \\
\hline $\begin{array}{l}\text { 33. It is difficult to get other } \\
\text { people to help us with the disease } \\
\text { of (child's name). }\end{array}$ & & & & & \\
\hline $\begin{array}{l}\text { 34. We cannot create a routine to } \\
\text { care for the disease of (child's } \\
\text { name). }\end{array}$ & & & & & \\
\hline $\begin{array}{l}\text { 35. It takes a lot of organization to } \\
\text { deal with the disease of (child's } \\
\text { name). }\end{array}$ & & & & & \\
\hline $\begin{array}{l}\text { 36. Sometimes we are unsure } \\
\text { how to balance family life with the } \\
\text { disease of (child's name). }\end{array}$ & & & & & \\
\hline $\begin{array}{l}\text { 37. It is hard to know what to } \\
\text { expect from the disease of (child's } \\
\text { name) in the future. }\end{array}$ & & & & & \\
\hline
\end{tabular}




\begin{tabular}{|c|c|c|c|c|c|}
\hline & $\begin{array}{c}\text { STRONGLY } \\
\text { DISAGREE } \\
\mathbf{1}\end{array}$ & 2 & 3 & 4 & $\begin{array}{c}\text { STRONGLY } \\
\text { AGREE } \\
5\end{array}$ \\
\hline $\begin{array}{l}\text { 38. Even with the disease of } \\
\text { (child's name) we have a normal } \\
\text { family life. . }\end{array}$ & & & & & \\
\hline $\begin{array}{l}\text { 39. (Child's name) could do better } \\
\text { in school if he/she did not have } \\
\text { this disease. }\end{array}$ & & & & & \\
\hline $\begin{array}{l}\text { 40. We are confident that we can } \\
\text { take care of the disease of (child's } \\
\text { name) }\end{array}$ & & & & & \\
\hline $\begin{array}{l}\text { 41. We have goals that help us } \\
\text { deal with the disease of (child's } \\
\text { name). }\end{array}$ & & & & & \\
\hline $\begin{array}{l}\text { 42. It is difficult to adjust the } \\
\text { activities of care for (child's name) } \\
\text { É difícil adequar as atividades to } \\
\text { our family routines. }\end{array}$ & & & & & \\
\hline $\begin{array}{l}\text { 43. Dealing with the disease of } \\
\text { (child's name) makes family life } \\
\text { more difficult. }\end{array}$ & & & & & \\
\hline $\begin{array}{l}\text { 44. We know when (child's name) } \\
\text { needs to act like a child. }\end{array}$ & & & & & \\
\hline $\begin{array}{l}\text { 45. It is very difficult to maintain a } \\
\text { normal life with a disease like } \\
\text { (child's name) has. }\end{array}$ & & & & & \\
\hline
\end{tabular}

This ends Section 1.

Section 2 covers the aspects of managing a family, when there are adult partners in the same house. The term "partners" refers to a spouse or partner, who lives in the same house. If you currently live with a partner, please continue with this questionnaire on the next page. Otherwise, please stop here. (And if the companion is not the father of the child) 


\section{SECTION 2}

The questions in this section relate to you and your partner. For each statement of this questionnaire, we ask that you give it a rating from 1 to 5 , where 1 means "Strongly Disagree" and 5 indicates "Strongly Agree". Again, please answer these questions based on what you think, not how you think your partner or others might respond.

\begin{tabular}{|c|c|c|c|c|c|}
\hline & $\begin{array}{c}\text { STRONGLY } \\
\text { DISAGREE } \\
1\end{array}$ & 2 & 3 & 4 & $\begin{array}{c}\text { STRONGLY } \\
\text { AGREE } \\
5\end{array}$ \\
\hline $\begin{array}{l}\text { 46. Our family is more united by } \\
\text { the way we deal with the disease } \\
\text { of (child's name). }\end{array}$ & & & & & \\
\hline $\begin{array}{l}\text { 47. My partner and I have different } \\
\text { ideas about the severity of the } \\
\text { disease of (child's name) }\end{array}$ & & & & & \\
\hline $\begin{array}{l}\text { 48. I am satisfied with the way that } \\
\text { me and my partner together take } \\
\text { care of the disease of (child's } \\
\text { name). }\end{array}$ & & & & & \\
\hline $\begin{array}{l}\text { 49. Me and my partner discuss } \\
\text { how to deal with the disease of } \\
\text { (child's name). }\end{array}$ & & & & & \\
\hline $\begin{array}{l}\text { 50. Me and my partner always talk } \\
\text { before we take any decision about } \\
\text { the care for (child's name). }\end{array}$ & & & & & \\
\hline $\begin{array}{l}\text { 51. Me and my partner have } \\
\text { similar ideas about how to raise } \\
\text { (child's name). }\end{array}$ & & & & & \\
\hline $\begin{array}{l}\text { 52. I am dissatisfied with the way } \\
\text { that me and my partner share the } \\
\text { care for the disease of (child's } \\
\text { name). }\end{array}$ & & & & & \\
\hline $\begin{array}{l}\text { 53. Me and my partner support } \\
\text { each other in caring for the } \\
\text { disease of (child's name). }\end{array}$ & & & & & \\
\hline
\end{tabular}




\section{ANEXO F - RETROTRADUÇÃO 2}

\section{INSTRUMENT FOR MEASURING FAMILY MANAGEMENT}

This questionnaire aims to evaluate how your family co-exists with a chronically ill child.

Instructions:

We ask that you rate each statement of this questionnaire on a scale of 1 to 5 , where 1 means "totally disagree", and 5 means "totally agree". Please answer the questions based on what you think, and not on how you think others might answer. If (CHILD'S NAME) has more than one chronic illness, the word "illness" refers jointly to all the diagnoses. In addition, several questions use the word "family". It refers to the people who live in the same house as you, and that you consider members of your family.

SECTION 1 - to be filled out by any family member, regardless of whether the couple lives together or not.

Please Mark an " $x$ " in the square that corresponds to your answer for each question.

\begin{tabular}{|c|c|c|c|c|c|}
\hline & $\begin{array}{c}\text { TOTALLY } \\
\text { DISAGREE } \\
1\end{array}$ & 2 & 3 & 4 & $\begin{array}{l}\text { TOTALLY } \\
\text { AGREE } \\
5\end{array}$ \\
\hline $\begin{array}{l}\text { 1. The daily routine of (child's } \\
\text { name) is similar to that of other } \\
\text { children in the same age group. }\end{array}$ & & & & & \\
\hline $\begin{array}{l}\text { 2. The illness of (child's name) } \\
\text { interferes in the family } \\
\text { relationship. }\end{array}$ & & & & & \\
\hline $\begin{array}{l}\text { 3. The illness of (child's name) } \\
\text { requires frequent visits to the } \\
\text { doctor. }\end{array}$ & & & & & \\
\hline $\begin{array}{l}\text { 4. We hope that in the future, } \\
\text { (child's name) will be capable of } \\
\text { handling his/her disease. }\end{array}$ & & & & & \\
\hline $\begin{array}{l}\text { 5. (child's name) gets less out of } \\
\text { life because of his/her disease. }\end{array}$ & & & & & \\
\hline $\begin{array}{l}\text { 6. Caring for (child's name) illness } \\
\text { is often very difficult. }\end{array}$ & & & & & \\
\hline
\end{tabular}




\begin{tabular}{|c|c|c|c|c|c|}
\hline & $\begin{array}{l}\text { TOTALLY } \\
\text { DISAGREE }\end{array}$ & 2 & 3 & 4 & $\begin{array}{l}\text { TOTALLY } \\
\text { AGREE } \\
5\end{array}$ \\
\hline $\begin{array}{l}\text { 7. (child's name) disease is like a } \\
\text { roller coaster, full of ups and } \\
\text { downs. }\end{array}$ & & & & & \\
\hline $\begin{array}{l}\text { 8. The illness of (child's name) is } \\
\text { the most important thing in our } \\
\text { family. }\end{array}$ & & & & & \\
\hline $\begin{array}{l}\text { 9. It is very difficult for us to care } \\
\text { for the illness of (child's name). }\end{array}$ & & & & & \\
\hline $\begin{array}{l}\text { 10. (child's name) takes part in } \\
\text { whatever activities he/she wishes } \\
\text { in spite of his/her illness. }\end{array}$ & & & & & \\
\hline $\begin{array}{l}\text { 11. We worry about (child's } \\
\text { name) future because of his/her } \\
\text { illness. }\end{array}$ & & & & & \\
\hline $\begin{array}{l}\text { 12. Dealing with (child's name) } \\
\text { illness does not demand very } \\
\text { much time. }\end{array}$ & & & & & \\
\hline $\begin{array}{l}\text { 13. We have some specific ideas } \\
\text { about how to help (child's name) } \\
\text { and how to live with the illness. }\end{array}$ & & & & & \\
\hline $\begin{array}{l}\text { 14. Despite his/her illness, we } \\
\text { hope that in the future (child's } \\
\text { name) will be able to live in } \\
\text { his/her own home. }\end{array}$ & & & & & \\
\hline $\begin{array}{l}\text { 15. We have sufficient financial } \\
\text { means to pay for the expenses of } \\
\text { (child's name) illness. }\end{array}$ & & & & & \\
\hline $\begin{array}{l}\text { 16. Because of his/her illness, } \\
\text { (child's name) is different from } \\
\text { other children of the same age. }\end{array}$ & & & & & \\
\hline $\begin{array}{l}\text { 17. It's hard to know when the } \\
\text { (child's name) illness should } \\
\text { come in first place in the family. }\end{array}$ & & & & & \\
\hline $\begin{array}{l}\text { 18. We hope to have a happy } \\
\text { future with (child's name). }\end{array}$ & & & & & \\
\hline $\begin{array}{l}\text { 19. When something unexpected } \\
\text { happens in relation to (child's } \\
\text { name) illness, we usually know } \\
\text { how to deal with it. }\end{array}$ & & & & & \\
\hline $\begin{array}{l}\text { 20. (child's name) friendships are } \\
\text { different because of his/her } \\
\text { illness. }\end{array}$ & & & & & \\
\hline $\begin{array}{l}\text { 21. In the future, we hope to } \\
\text { devote less time to caring for } \\
\text { (child's name) illness. }\end{array}$ & & & & & \\
\hline
\end{tabular}




\begin{tabular}{|c|c|c|c|c|c|}
\hline & $\begin{array}{l}\text { TOTALLY } \\
\text { DISAGREE } \\
1\end{array}$ & 2 & 3 & 4 & $\begin{array}{l}\text { TOTALLY } \\
\text { AGREE } \\
5\end{array}$ \\
\hline $\begin{array}{l}\text { 22. An illness like that which } \\
\text { (child's name) has makes family } \\
\text { life very difficult. }\end{array}$ & & & & & \\
\hline $\begin{array}{l}\text { 23. The activities of (child's name) } \\
\text { rarely interfere in other family } \\
\text { activities. }\end{array}$ & & & & & \\
\hline $\begin{array}{lrr}24 . \quad \text { (child's } & \text { name) } & \text { illness } \\
\text { frequently } & & \text { requires } \\
\text { hospitalization. } & & \\
\end{array}$ & & & & & \\
\hline $\begin{array}{l}\text { 25. We feel that we are doing a } \\
\text { good job of caring for (child's } \\
\text { name). }\end{array}$ & & & & & \\
\hline $\begin{array}{l}\text { 26. People with illnesses like that } \\
\text { of (child's name) have } \\
\text { expectations of a normal life. }\end{array}$ & & & & & \\
\hline $\begin{array}{l}\text { 27. It is usually difficult to know if } \\
\text { we need to be more protective of } \\
\text { (child's name). }\end{array}$ & & & & & \\
\hline $\begin{array}{l}\text { 28. We generally feel insecure } \\
\text { regarding what to do to care for } \\
\text { (child's name) illness. }\end{array}$ & & & & & \\
\hline $\begin{array}{l}\text { 29. In the future, it will be more } \\
\text { difficult to handle (child's name) } \\
\text { illness. }\end{array}$ & & & & & \\
\hline $\begin{array}{l}\text { 30. We think about (child's name) } \\
\text { illness all the time. }\end{array}$ & & & & & \\
\hline $\begin{array}{l}\text { 31. It seems like (child's name) } \\
\text { illness controls the life of our } \\
\text { family. }\end{array}$ & & & & & \\
\hline $\begin{array}{l}\text { 32. Many illnesses are more } \\
\text { serious than that of (child's } \\
\text { name). }\end{array}$ & & & & & \\
\hline $\begin{array}{l}\text { 33. It's hard to get other people to } \\
\text { help us with (child's name) illness. }\end{array}$ & & & & & \\
\hline $\begin{array}{l}\text { 34. We can't manage to create a } \\
\text { routine to deal with (child's name) } \\
\text { illness. }\end{array}$ & & & & & \\
\hline $\begin{array}{l}\text { 35. A lot of organization is } \\
\text { needed to deal with (child's } \\
\text { name) illness. }\end{array}$ & & & & & \\
\hline $\begin{array}{l}\text { 36. We're sometimes undecided } \\
\text { about how to balance family life } \\
\text { with (child's name) illness. }\end{array}$ & & & & & \\
\hline
\end{tabular}




\begin{tabular}{|c|c|c|c|c|c|}
\hline & $\begin{array}{c}\text { TOTALLY } \\
\text { DISAGREE } \\
1\end{array}$ & 2 & 3 & 4 & $\begin{array}{l}\text { TOTALLY } \\
\text { AGREE } \\
5\end{array}$ \\
\hline $\begin{array}{l}\text { 37. It's hard to know what to } \\
\text { expect of (child's name) illness in } \\
\text { the future. }\end{array}$ & & & & & \\
\hline $\begin{array}{l}\text { 38. Even with (child's name) } \\
\text { illness, we do have a normal } \\
\text { family life. }\end{array}$ & & & & & \\
\hline $\begin{array}{l}\text { 39. (child's name) could do better } \\
\text { in school if it weren't for this } \\
\text { illness. }\end{array}$ & & & & & \\
\hline $\begin{array}{l}\text { 40. We are confident that we can } \\
\text { deal with (child's name) illness. }\end{array}$ & & & & & \\
\hline $\begin{array}{l}\text { 41. We have objectives that help } \\
\text { us to deal with (child's name) } \\
\text { illness. }\end{array}$ & & & & & \\
\hline $\begin{array}{l}\text { 42. It's hard to fit activities } \\
\text { involving care of (child's name) } \\
\text { into our family routine. }\end{array}$ & & & & & \\
\hline $\begin{array}{l}\text { 43. Dealing with (child's name) } \\
\text { illness makes family life more } \\
\text { difficult. }\end{array}$ & & & & & \\
\hline $\begin{array}{l}\text { 44. We don't know when (child's } \\
\text { name) needs to act like a child. }\end{array}$ & & & & & \\
\hline $\begin{array}{l}\text { 45. It's very difficult to maintain a } \\
\text { normal life with this illness that } \\
\text { (child's name) has. }\end{array}$ & & & & & \\
\hline
\end{tabular}

This closes SECTION 1.

SECTION 2 addresses aspects of family management when there are adult partners in the same house. The term "partners" refers to the spouse or companion who lives in the same house.

If you currently live with a partner, please continue with the questionnaire on the next page. If not, please stop here. 


\section{SECTION 2}

The questions in this next SECTION refer to yourself and your partner. For each statement in this questionnaire, we ask that you give a score from 1 to 5 , where 1 means "totally disagree", and 5 means "totally agree". Again, please answer these questions based on what you think, and not on what you think your partner or others might answer.

\begin{tabular}{|c|c|c|c|c|c|}
\hline & $\begin{array}{c}\text { TOTALLY } \\
\text { DISAGREE } \\
1\end{array}$ & 2 & 3 & 4 & $\begin{array}{l}\text { TOTALLY } \\
\text { AGREE } \\
5\end{array}$ \\
\hline $\begin{array}{l}\text { 46. Our family is more united due } \\
\text { to the way that we deal with } \\
\text { (child's name) illness. }\end{array}$ & & & & & \\
\hline $\begin{array}{l}\text { 47. My partner and I have different } \\
\text { ideas about the seriousness of } \\
\text { (child's name) illness. }\end{array}$ & & & & & \\
\hline $\begin{array}{l}\text { 48. I am pleased with the way that } \\
\text { my partner and I handle (child's } \\
\text { name) illness together. }\end{array}$ & & & & & \\
\hline $\begin{array}{l}\text { 49. My partner and I discuss } \\
\text { means of dealing with (child's } \\
\text { name) illness. }\end{array}$ & & & & & \\
\hline $\begin{array}{l}\text { 50. My partner and I always talk } \\
\text { before making any decision about } \\
\text { caring for (child's name). }\end{array}$ & & & & & \\
\hline $\begin{array}{l}\text { 51. My partner and I have similar } \\
\text { ideas about how we should raise } \\
\text { (child's name). }\end{array}$ & & & & & \\
\hline $\begin{array}{l}\text { 52. I am not pleased about how } \\
\text { my partner and I share dealing } \\
\text { with (child's name) illness. }\end{array}$ & & & & & \\
\hline $\begin{array}{l}\text { 53. My partner and I support one } \\
\text { another in dealing with (child's } \\
\text { name) illness. }\end{array}$ & & & & & \\
\hline
\end{tabular}


ANEXO G - PARECER DO COMITÊ DE ÉTICA E PESQUISA EEUSP

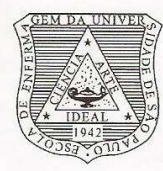

\section{UNIVERSIDADE DE SÃO PAULO \\ ESCOLA DE ENFERMAGEM}

Av. Dr. Enéas de Carvalho Aguiar, 419 - CEP 05403-000

el.: (011) 3061-7548/8858 - Fax: (011) 3061-7548 -

São Paulo - SP - Brasil

São Paulo, 08 de março de 2010.

Ilm. ${ }^{\mathrm{a}} \mathrm{Sr}^{\mathrm{a}}$

Carolliny Rossi de Faria Ichikawa

Ref.: Processo n ${ }^{0} 887 / 2010 /$ CEP-EEUSP

Prezada Senhora,

Em atenção à solicitação referente à análise do projeto "Tradução, adaptação transcultural e validação do Family Management Measure para famílias de crianças portadoras de doenças crônicas", informamos que o mesmo foi considerado aprovado pelo Comitê de Ética em Pesquisa da Escola de Enfermagem da Universidade de São Paulo (CEP/EEUSP).

Analisado sob o aspecto ético-legal, atende às exigências da Resolução $\mathrm{n}^{\circ}$ 196/96 do Conselho Nacional de Saúde.

Esclarecemos que após o término da pesquisa, os resultados obtidos deverão ser encaminhados ao CEP/EEUSP, para serem anexados ao processo.

Atenciosamente,

Mania fat fen ondus

Prof. ${ }^{\text {a }}$ Dr. ${ }^{\text {a }}$ Maria de Fátima Prado Fernandes

Coordenadora do Comitê de Ética em Pesquisa da

Escola de Enfermagem da Universidade de São Paulo 


\section{ANEXO H - PARECER DO COMITÊ DE ÉTICA E PESQUISA UEL}

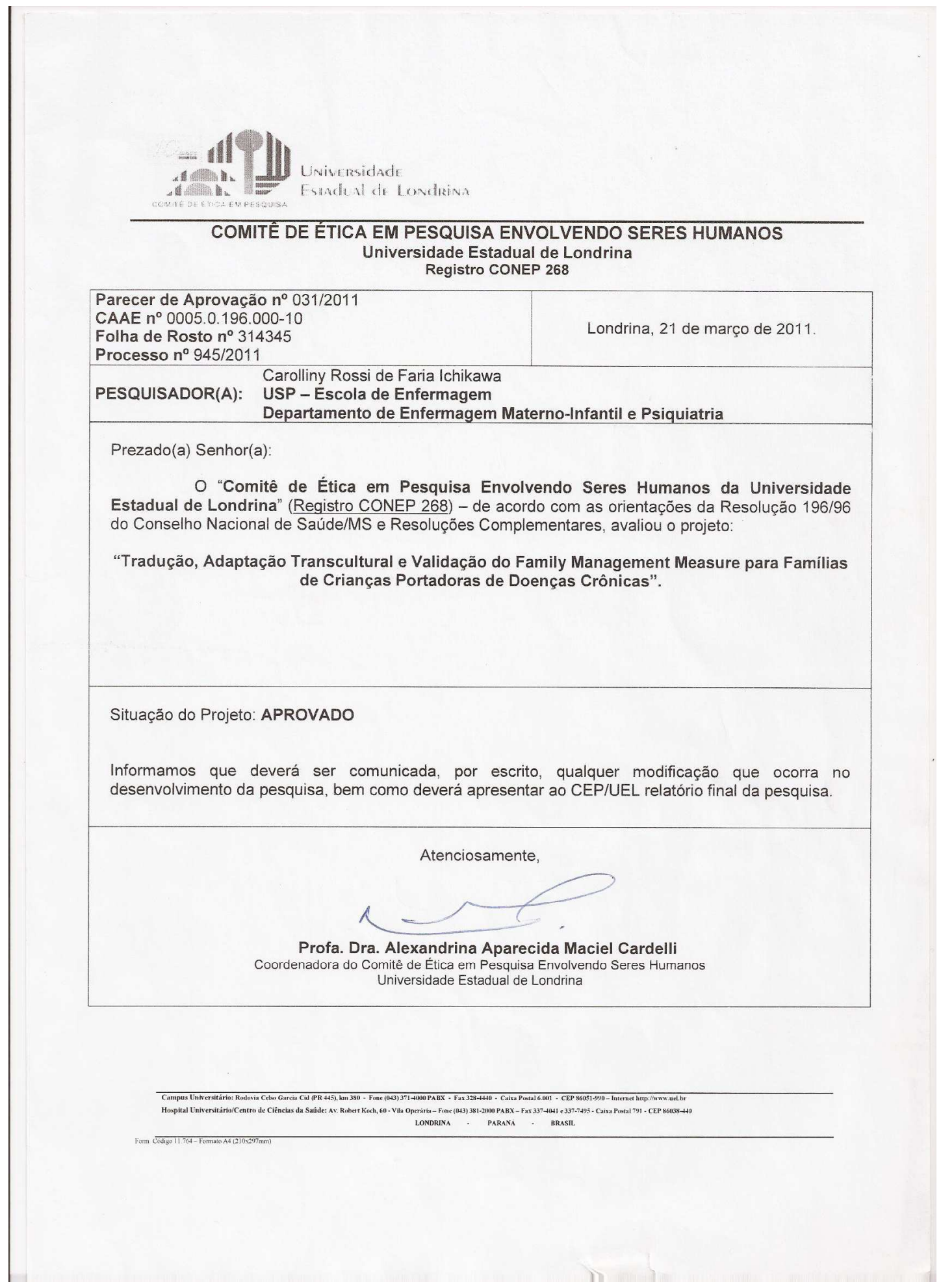

